\title{
Alternative Refrigerant Evaluation for High-Ambient-Temperature Environments: R-22 and R-410A Alternatives for Rooftop Air Conditioners
}

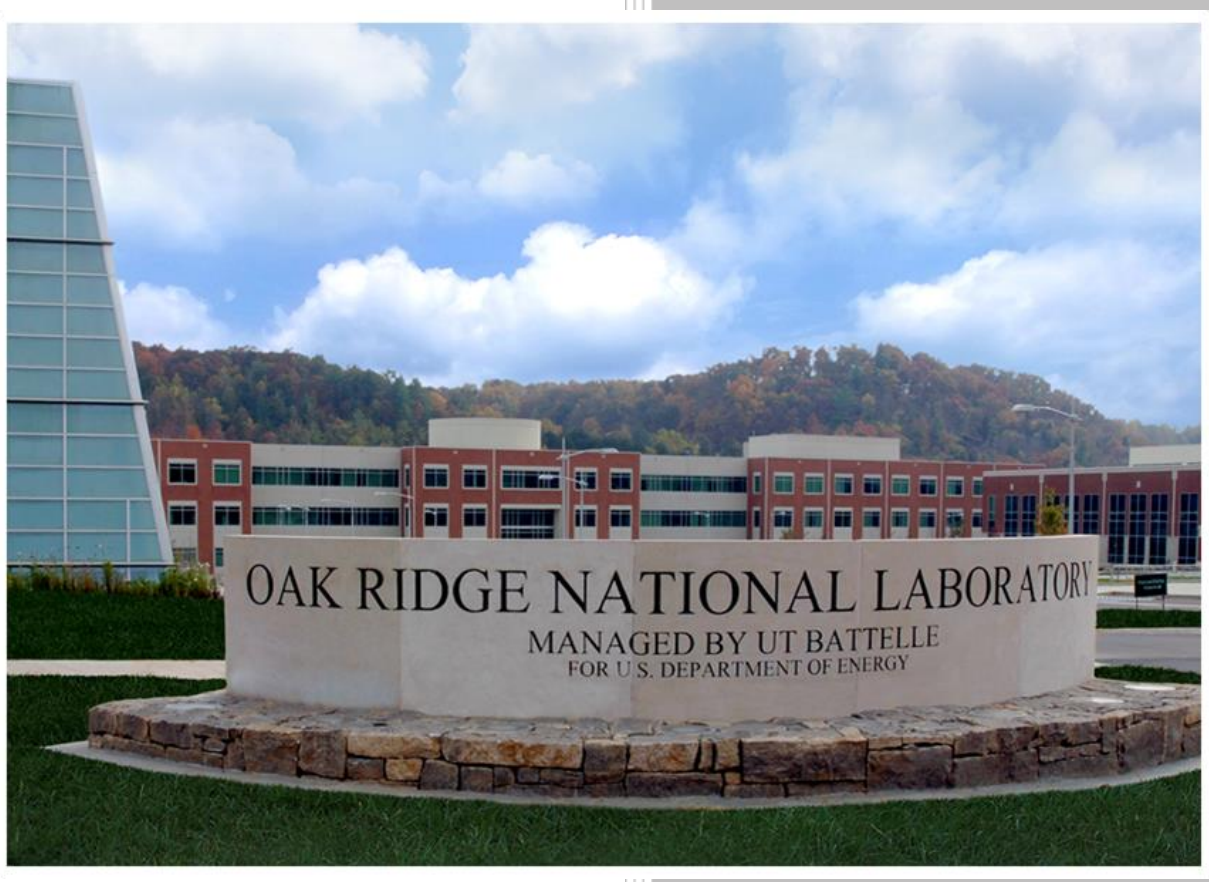

\section{Approved for public release.} Distribution is unlimited
Omar Abdelaziz Som Shrestha Bo Shen Ahmed Elatar Randall Linkous William Goetzler Matthew Guernsey Youssef Bargach

September 2016 


\title{
DOCUMENT AVAILABILITY
}

Reports produced after January 1, 1996, are generally available free via US Department of Energy (DOE) SciTech Connect.

Website http://www.osti.gov/scitech/

Reports produced before January 1, 1996, may be purchased by members of the public from the following source:

\author{
National Technical Information Service \\ 5285 Port Royal Road \\ Springfield, VA 22161 \\ Telephone 703-605-6000 (1-800-553-6847) \\ TDD 703-487-4639 \\ Fax 703-605-6900 \\ E-mail info@ntis.gov \\ Web site http://www.ntis.gov/help/ordermethods.aspx
}

Reports are available to DOE employees, DOE contractors, Energy Technology Data Exchange representatives, and International Nuclear Information System representatives from the following source:

Office of Scientific and Technical Information

PO Box 62

Oak Ridge, TN 37831

Telephone 865-576-8401

Fax 865-576-5728

E-mail reports@osti.gov

Website http://www.osti.gov/contact.html

This report was prepared as an account of work sponsored by an agency of the United States Government. Neither the United States Government nor any agency thereof, nor any of their employees, makes any warranty, express or implied, or assumes any legal liability or responsibility for the accuracy, completeness, or usefulness of any information, apparatus, product, or process disclosed, or represents that its use would not infringe privately owned rights. Reference herein to any specific commercial product, process, or service by trade name, trademark, manufacturer, or otherwise, does not necessarily constitute or imply its endorsement, recommendation, or favoring by the United States Government or any agency thereof. The views and opinions of authors expressed herein do not necessarily state or reflect those of the United States Government or any agency thereof. 
Energy and Transportation Science Division

\section{ALTERNATIVE REFRIGERANT EVALUATION FOR HIGH-AMBIENT- TEMPERATURE ENVIRONMENTS: R-22 AND R-410A ALTERNATIVES FOR ROOFTOP AIR CONDITIONERS}

Omar Abdelaziz, Som Shrestha, Bo Shen, Ahmed Elatar, Randall Linkous, William Goetzler*, Matthew Guernsey*, and Youssef Bargach*

*Navigant Consulting, Inc., Burlington, Massachusetts 01803

Date Published: September 2016

Prepared by

OAK RIDGE NATIONAL LABORATORY

Oak Ridge, TN 37831-6283

managed by

UT-BATTELLE, LLC

for the

US DEPARTMENT OF ENERGY

under contract DE-AC05-00OR22725 



\section{ACKNOWLEDGEMENTS}

We would like to acknowledge the international expert panel members and co-chairs, Dr. Patrick Phelan, Arizona State University and Dr. Suely Machado Carvalho, adviser to the Superintendent at the Instituto de Pesquisas Energéticas e Nucleares, IPEN (CNEN/MCTI) Brazil, for their support and guidance to the evaluation program and review of test results and reports.

We would also like to acknowledge Mr. Antonio Bouza; HVAC\&R Technology Manager at the US Department of Energy Building Technologies Office for his continued support.

The authors would also like to acknowledge the panel of international experts for their role in guiding the research work and providing critical review to the experimental data and published documents:

Dr. Radhey Agarwal (India)

Dr. Fotouh Al-Raqom (Kuwait)

Dr. Karim Amrane (USA)

Dr. Enio Bandarra (Brazil)

Dr. Jitendra M. Bhambure (India)

Dr. Suely Machado Carvalho (co-chair; Brazil)

Mr. Ayman El-Talouny (UNEP)

Mr. Daniel Giguère (Canada)

Dr. Tingxun Li (China)

Dr. Samuel Yana Motta (Peru)

Mr. Maher Moussa (Kingdom of Saudi Arabia)

Mr. Ole Nielsen (UNIDO)

Mr. Tetsuji Okada (Japan)

Dr. Alaa Olama (Egypt)

Dr. Alessandro Giuliano Peru (Italy)

Dr. Patrick Phelan (co-chair; USA) 



\section{TABLE OF CONTENTS}

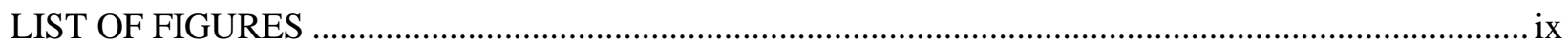

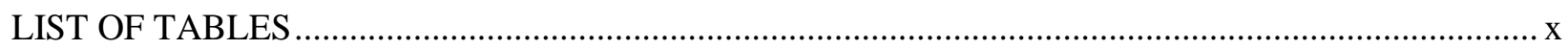

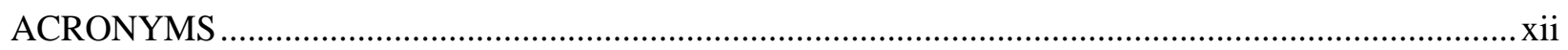

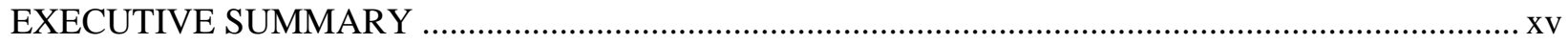

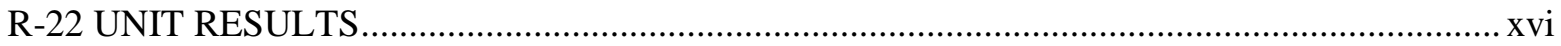

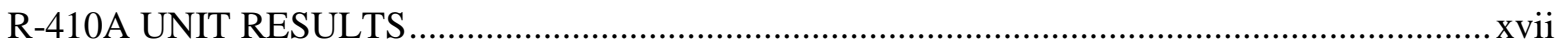

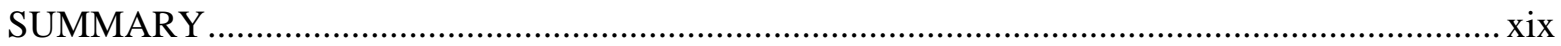

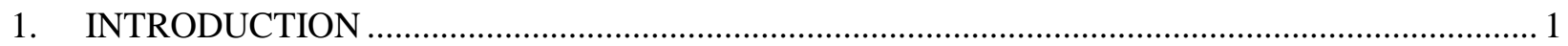

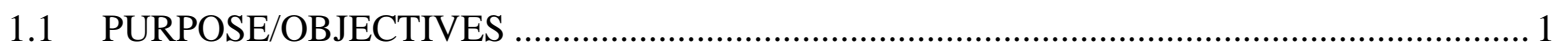

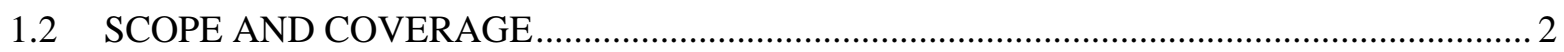

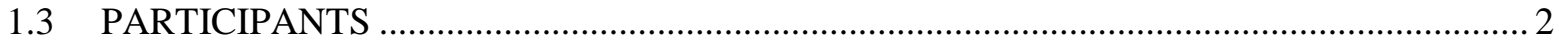

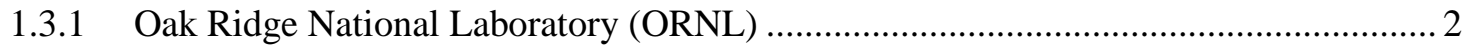

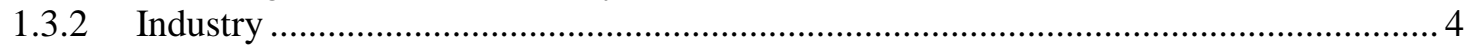

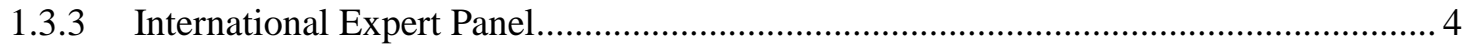

2. SELECTION OF ALTERNATIVES AND TESTING CONDITIONS ......................................... 4

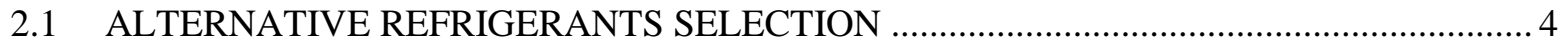

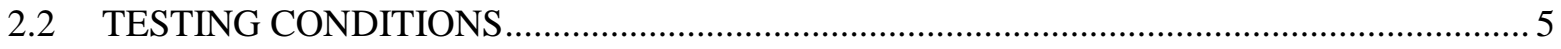

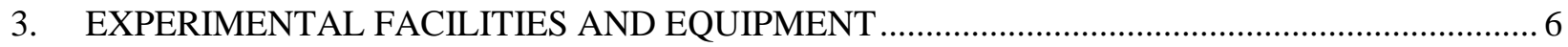

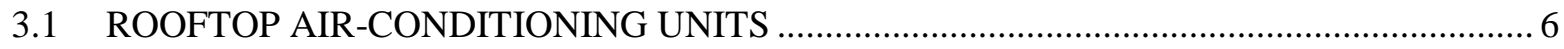

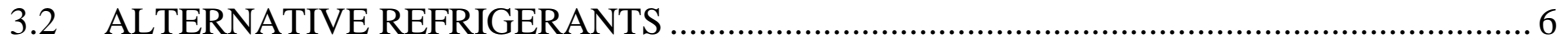

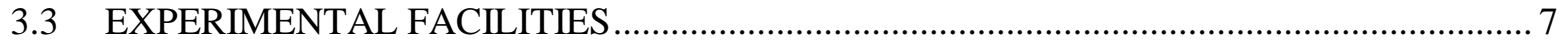

3.4 EXPERIMENTAL SETUP AND INSTRUMENTATION ............................................... 9

3.5 ALTERNATIVE REFRIGERANT EVALUATION EXPERIMENTAL DESIGN ................9

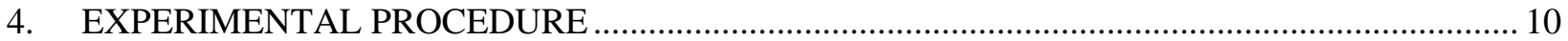

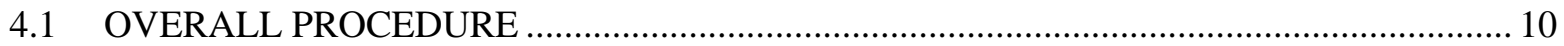

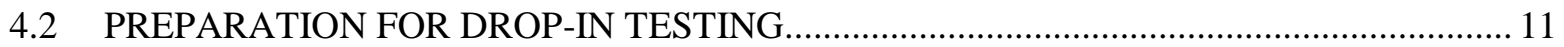

4.3 PROCESS FOR CHANGING REFRIGERANTS AND THE LUBRICANTS ...................... 12

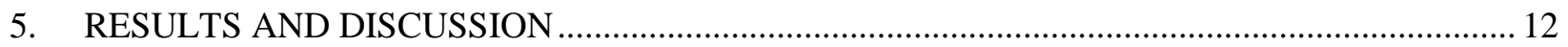

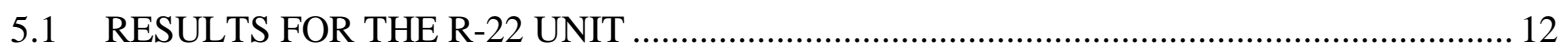

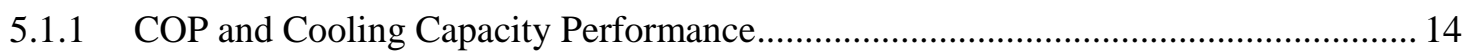

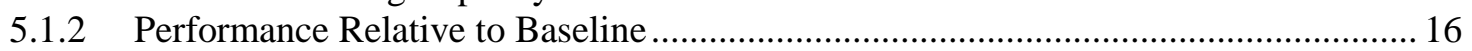

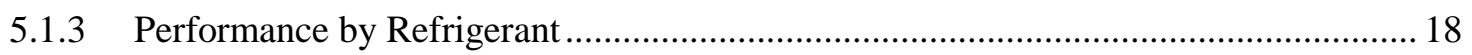

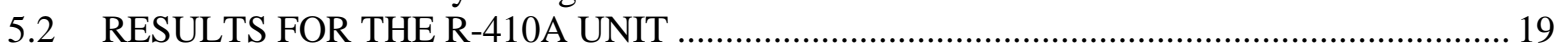

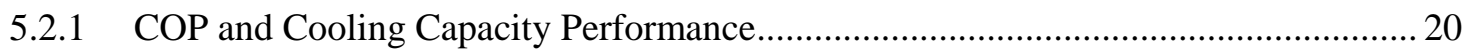

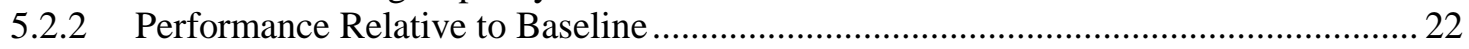

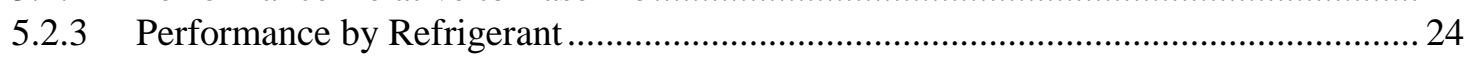

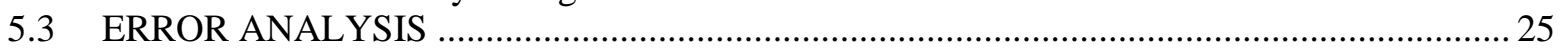

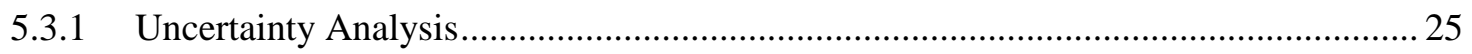

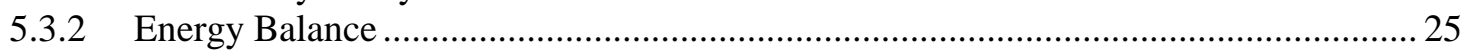

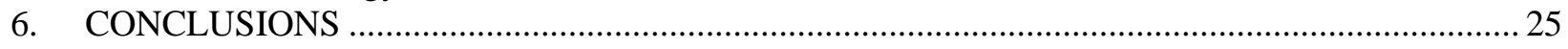

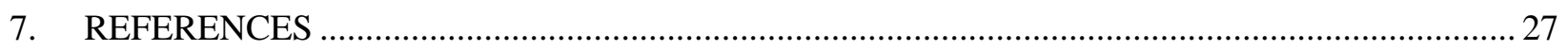

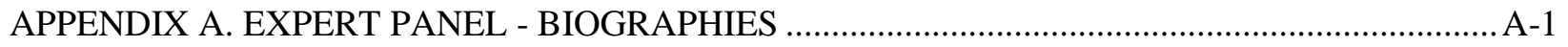

APPENDIX B. OTHER HIGH-AMBIENT-TEMPERATURE TESTING PROGRAMS .................... B-1

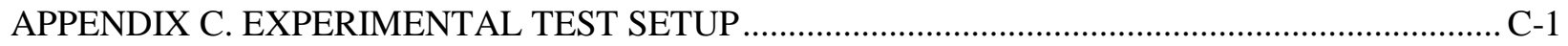

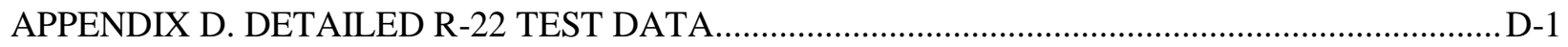

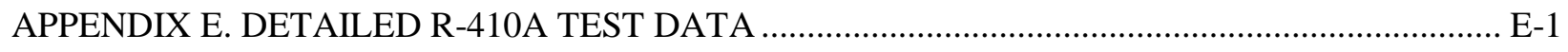

APPENDIX F. DATA REDUCTION METHODOLOGY ….............................................................

APPENDIX G. DISCLOSURES OF INTEREST …....................................................................... 


\section{LIST OF FIGURES}

Figure 1. Baseline equipment designed for high-ambient-temperature conditions................................. 6

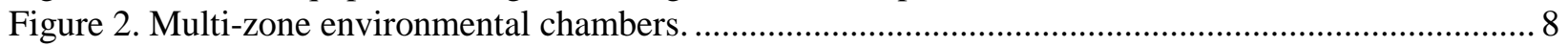

Figure 3. ORNL's large environmental chambers - outdoor chamber............................................. 9

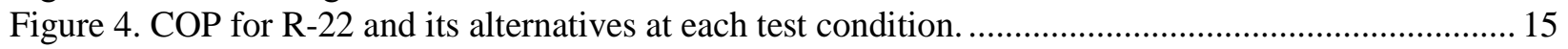

Figure 5. Cooling capacity for R-22 and its alternatives at each test condition..................................... 15

Figure 6. Performance of alternative refrigerants compared with R-22 (mineral oil) at all conditions.

Figure 7. Compressor discharge temperature of the R-22 alternative refrigerants, with differences compared to the baseline.

Figure 8. Performance of alternative refrigerants compared with R-22 (mineral oil) at all conditions.

Figure 9. COP for R-410A and its alternatives at each test condition.

Figure 10. Cooling capacity for R-410A and its alternatives at each test condition.............................2 21

Figure 11. Performance of alternative refrigerants compared with R-410A at each test condition............ 22

Figure 12. Compressor discharge temperature of the R-410A alternative refrigerants, with differences compared to the baseline.

Figure 13. Performance of alternative refrigerants compared with R-22 (mineral oil) at all

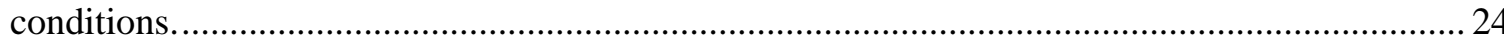

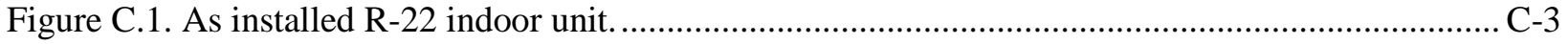

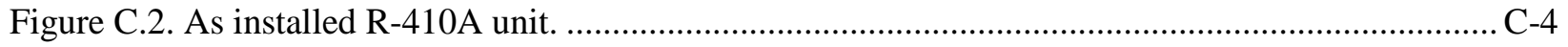

Figure F.1. LabView ${ }^{\circledR}$ display of room temperature and fan flow rate .................................................3

Figure F.2. LabView ${ }^{\circledR}$ display of various monitored parameters.......................................................

Figure F.3. LabView ${ }^{\circledR}$ display of built-in REFPROP calculation...................................................... 


\section{LIST OF TABLES}

Table ES.1. ORNL test plan summary.............................................................................. Xv

Table ES.2. Baseline and lower-GWP alternative refrigerant characteristics for the R-22 unit........ xvi

Table ES.3. ORNL test result for the R-22 unit at AHRI and T3 conditions (performance

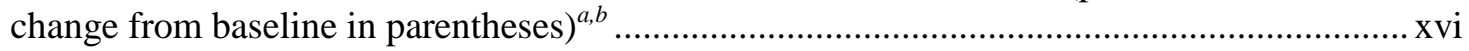

Table ES.4. ORNL test results for the R-22 unit at Hot conditions (performance change from

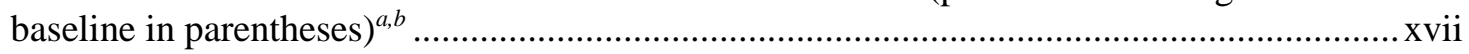

Table ES.5. Baseline and lower-GWP alternative refrigerant characteristics for the R-410A

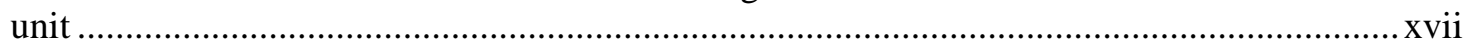

Table ES.6. ORNL test results for the R-410A unit at AHRI and T3 conditions (performance

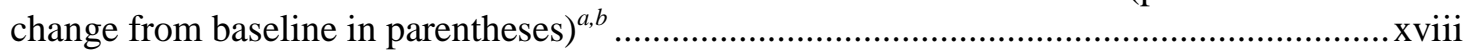

Table ES.7. ORNL test results for the R-410A unit at Hot and Extreme conditions

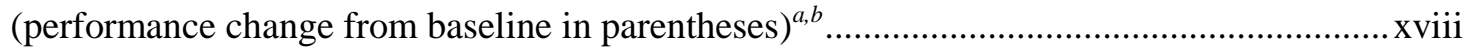

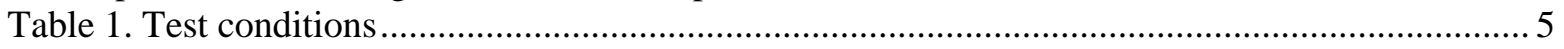

Table 2. Baseline and alternative refrigerant data for the R-22 unit............................................ 7

Table 3. Baseline and alternative refrigerant data for the R-410A unit ........................................ 7

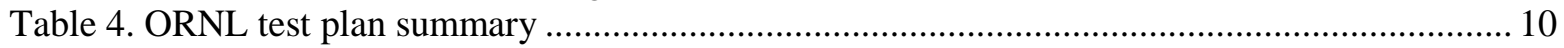

Table 5. Additional tests conducted (not included in original schedule) …..................................... 10

Table 6. Optimized refrigerant charge masses for the R-22 unit .................................................... 13

Table 7. Test results for R-22 and its alternatives at moderate ambient temperatures

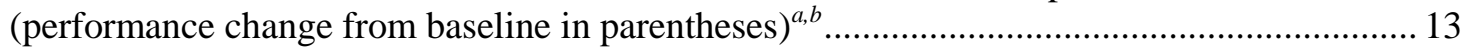

Table 8. Test results for R-22 and its alternatives at high ambient temperatures (performance

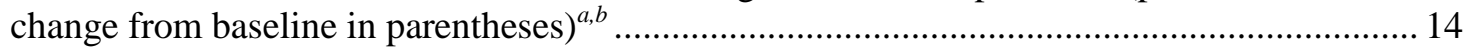

Table 9. Optimized refrigerant charge masses for the R-410A unit ............................................. 19

Table 10. Test results for R-410A and its alternatives at moderate ambient temperatures

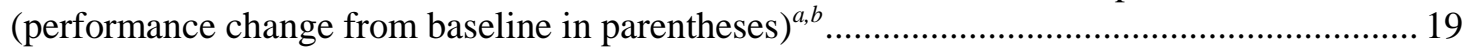

Table 11. Test results for R-410A and its alternatives at high ambient temperatures

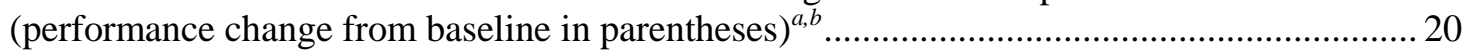

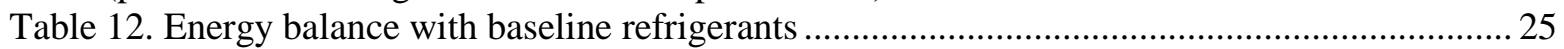

Table B.1. EGYPRA (UNEP, UNIDO, Egypt) high-ambient-temperature testing programs .......... B-3

Table C.1. R-22 unit experimental setup instrumentation .........................................................

Table C.2. R-410A unit experimental setup instrumentation ........................................................ C-6

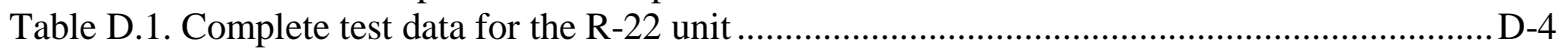

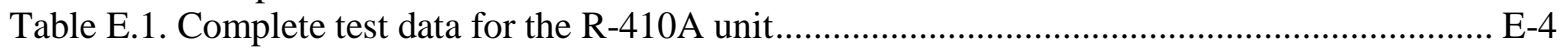

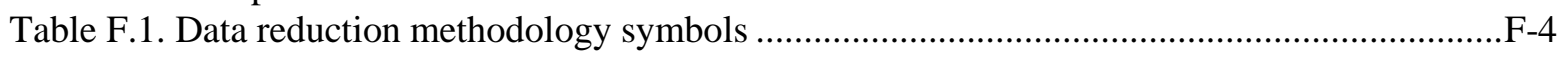

Table F.2. Data reduction methodology subscripts................................................................ 



\section{ACRONYMS}

\begin{tabular}{|c|c|}
\hline $\mathrm{AC}$ & Air conditioner \\
\hline AHRI & Air-Conditioning, Heating, and Refrigeration Institute \\
\hline ASHRAE & American Society of Heating, Refrigerating, and Air-Conditioning Engineers \\
\hline ASME & American Society of Mechanical Engineers \\
\hline BEE & Bureau of Energy Efficiency \\
\hline BIS & Bureau of Indian Standards \\
\hline BTRIC & ORNL’s Building Technologies Research and Integration Center \\
\hline CAP & Compliance Assistance Programme at UNEP's Regional Office for West Asia \\
\hline $\mathrm{CFC}$ & Chlorofluorocarbon \\
\hline CFD & Computational fluid dynamics \\
\hline CFM & Cubic feet per minute \\
\hline $\mathrm{COP}$ & Coefficient of performance \\
\hline DOE & US Department of Energy \\
\hline EER & Energy efficiency ratio \\
\hline EGYPRA & Egyptian Program for Promoting Low-GWP Refrigerants' Alternatives \\
\hline EPA & US Environmental Protection Agency \\
\hline EOS & Egyptian Organization for Standardization and Quality \\
\hline EXV & Electronic Expansion Valve \\
\hline GHG & Green House Gases \\
\hline GWP & Global Warming Potential \\
\hline $\mathrm{HCFC}$ & Hydrochlorofluorocarbon \\
\hline HFC & Hydrofluorocarbon \\
\hline HFO & hydrofluoroolefin (unsaturated HFC) \\
\hline $\mathrm{HP}$ & heat pump \\
\hline HPDM & ORNL's Heat Pump Design Model \\
\hline IIR & International Institute of Refrigeration \\
\hline ISO & International Organization for Standardization \\
\hline ITH & Integration Time Horizon (for GWP calculations) \\
\hline LCCP & Life cycle climate performance \\
\hline $\mathrm{MBH}$ & 1,000 British thermal units per hour \\
\hline MLF & Multilateral Fund for the Implementation of the Montreal Protocol \\
\hline NSCL & National Superconducting Cyclotron Laboratory \\
\hline ODS & Ozone-depleting substance \\
\hline OEM & Original Equipment Manufacturer \\
\hline ORNL & Oak Ridge National Laboratory \\
\hline POE & Polyolester (oil) \\
\hline PRAHA & $\begin{array}{l}\text { Promoting Low-GWP Alternative Refrigerants in the Air-Conditioning Industry for } \\
\text { High Ambient Conditions }\end{array}$ \\
\hline R\&D & research and development \\
\hline RAMA & Refrigeration \& Air-Conditioning Manufacturers Association \\
\hline RTOC & $\begin{array}{l}\text { Refrigeration and Air Conditioning Technical Options Committee of UNEP (also } \\
\text { referred to as the UNEP Technical Options Committee on Refrigeration, Air- } \\
\text { Conditioning, and Heat Pumps) }\end{array}$ \\
\hline TEAP & Technology and Economics Assessment Panel \\
\hline TEWI & Total Equivalent Warming Impact \\
\hline TR & Refrigeration tons \\
\hline TXV & Thermal Expansion Valve \\
\hline UN & United Nations \\
\hline
\end{tabular}


UNEP

UNIDO

VRF
United Nations Environmental Programme

United Nations Industrial Development Organization

Variable refrigerant flow 



\section{EXECUTIVE SUMMARY}

The Oak Ridge National Laboratory (ORNL) High-Ambient-Temperature Evaluation Program for LowGlobal Warming Potential (Low-GWP) Refrigerants aims to develop an understanding of the performance of low-GWP alternative refrigerants relative to hydrochlorofluorocarbon (HCFC) and hydrofluorocarbon (HFC) refrigerants in packaged or Rooftop Unit (RTU) air conditioners under highambient-temperature conditions. This final report describes the parties involved, the alternative refrigerants selection process, the test procedures, and the final results.

ORNL designed a matrix of 52 tests. Table ES.1 shows the refrigerants identified for testing by ORNL with guidance from a panel of international experts (expert panel). ${ }^{*}$ The expert panel is composed of members from various nations, as well as United Nations Environment Programme (UNEP) and United Nations Industrial Development Organization (UNIDO) personnel. Guided by input from the expert panel, ORNL selected the alternative refrigerants based on their GWP, commercial availability and physical properties, also considering whether information about the characteristics of the refrigerants is readily available. ORNL conducted tests on two units designed for high-ambient conditions, including one RTU provided by S.K.M. Air Conditioning LLC (27.2 $\mathrm{kW}_{\text {th }}$ [7.7 Refrigeration tons (TR)]), which is designed to operate with R-22, and one unit provided by Petra $\left(38.7 \mathrm{~kW}_{\text {th }}[11 \mathrm{TR}]\right)$, which was designed to operate with R-410A. ${ }^{\dagger, t}$

Table ES.1. ORNL test plan summary

\begin{tabular}{|l|c|c|c|c|c|c|c|c|c|c|c|c|}
\hline Unit: & $\begin{array}{c}\text { Base - } \\
\text { Mineral } \\
\text { Oil }\end{array}$ & $\begin{array}{c}\text { Base - } \\
\text { POE } \\
\text { Oil }\end{array}$ & $\begin{array}{c}\text { L-20A } \\
(\mathbf{R - 4 4 4 B})\end{array}$ & $\begin{array}{c}\text { ARM- } \\
\mathbf{2 0 b}\end{array}$ & $\begin{array}{c}\text { DR-7 } \\
(\mathbf{R - 4 5 4})\end{array}$ & $\begin{array}{c}\text { ARM- } \\
\text { 20a }\end{array}$ & $\begin{array}{c}\text { DR-55 } \\
(\mathbf{R - 4 5 2 B})\end{array}$ & $\begin{array}{c}\text { L41z } \\
(\mathbf{R}-4473)\end{array}$ & $\begin{array}{c}\text { ARM- } \\
\mathbf{7 1 a}\end{array}$ & R-32 & $\begin{array}{c}\text { Base- } \\
\text { re-run }\end{array}$ & $\begin{array}{c}\text { Total } \\
\text { Tests }\end{array}$ \\
\hline R-22 & $\begin{array}{c}\mathrm{X} \\
\text { (baseline) }\end{array}$ & $\mathrm{X}$ & $\mathrm{X}$ & $\mathrm{X}$ & $\mathrm{X}$ & $\mathrm{X}$ & & & & & $\mathrm{X}$ & $\mathbf{2 8}$ \\
$\mathbf{R - 4 1 0 A}$ & & $\begin{array}{c}\mathrm{X} \\
\text { (baseline) }\end{array}$ & & & & & $\mathrm{X}$ & $\mathrm{X}$ & $\mathrm{X}$ & $\mathrm{X}$ & $\mathrm{X}$ & $\mathbf{2 4}$ \\
\hline
\end{tabular}

Testing was conducted in ORNL's Multi-Zone Environmental Chambers for the R-22 unit, and the ORNL Large Environmental Chambers for the R-410A unit. The test procedure involved drop-in testing. ORNL used the same drop-in test procedure as defined in the Air Conditioning, Heating, and Refrigeration Institute (AHRI) Low GWP Alternative Refrigerants Evaluation Program (AREP), which allows for only minor, if any, modifications to the equipment. ORNL completed testing on each of the R22 alternative refrigerants at three different environmental testing conditions, and completed testing on the R-410A alternatives at four different test conditions. Operation of the R-22 unit was attempted, but not completed, at the fourth and highest-ambient temperature condition due to actuation of the refrigerant high-pressure cut-off at those conditions.

For all refrigerants, including the baseline refrigerants, R-22 and R-410A, efficiency degraded with increased ambient temperature. Further, when evaluating the results, it is important to keep in mind that the test units were not designed specifically for the alternative refrigerants. As a result, the alternative

\footnotetext{
* Additional tests beyond the original test plan were performed; for details, see Section 3.5.

$\dagger$ Drop-in tests are conducted on production units that have undergone limited, if any, modifications such as refrigerant charge optimization, lubricant change, and flow control device changes to run with a different refrigerant. This is contrast with softoptimization or full-optimization, where more substantial changes and/or engineering work is done to optimize performance with a specific refrigerant. For details, see Section 1.2.

$¥$ Capacity specifications are determined at ISO $5051 \mathrm{~T} 1$ conditions (indoor dry-bulb temperature at $27^{\circ} \mathrm{C}\left[80.6^{\circ} \mathrm{F}\right]$ and wet-bulb temperature at $\left.19^{\circ} \mathrm{C}\left[66.2^{\circ} \mathrm{F}\right]\right)$.
} 
refrigerants should not be expected to perform as well as they would if the system designs were fully optimized for them.

Due to the differences in design and in baseline efficiency, it is not possible to directly compare the test results for the R-22 unit and the R-410A unit; thus, their results are not directly comparable and presented separately.

\section{R-22 UNIT RESULTS}

Table ES.2 lists the characteristics of the alternative refrigerants evaluated in the R-22 unit."

Table ES.2. Baseline and lower-GWP alternative refrigerant characteristics for the R-22 unit

\begin{tabular}{|c|c|c|c|c|}
\hline Refrigerant & Manufacturer & $\begin{array}{c}\text { ASHRAE } \\
\text { Safety Class }\end{array}$ & GWP $_{\text {AR4 }}{ }^{a}$ & GWP $_{\text {AR5 }}{ }^{\boldsymbol{a}}$ \\
\hline R-22 (Baseline) & - & A1 & 1,810 & 1,760 \\
\hline L-20A (R-444B) & Honeywell & A2L & 295 & 295 \\
ARM-20b & Arkema & A2L & 251 & 251 \\
DR-7 (R-454A) & Chemours & A2L & 239 & 238 \\
ARM-20a & Arkema & A2L & 139 & 139 \\
\hline
\end{tabular}

${ }^{a}$ Evaluated as weighted average values of the GWP of the refrigerant blend components provided by the refrigerant manufacturers and the reported GWP values of those components in IPCC AR4, 2007 [1] and IPCC AR5, 2013 [2] respectively. GWPs are based on a 100 year integration time horizon (ITH).

Table ES.3 summarizes the test results at AHRI Standard 340/360 ${ }^{\dagger}$ Standard Rating Conditions (AHRI or AHRI Conditions, $35.0^{\circ} \mathrm{C}\left[95^{\circ} \mathrm{F}\right]$ outdoor temperature) and ISO T3 conditions $\left(46.0^{\circ} \mathrm{C}\left[114.8^{\circ} \mathrm{F}\right]\right.$ outdoor temperature). At AHRI Standard Rating Conditions, the results from the R-22 unit showed that all the alternative refrigerants performed within approximately $\pm 6 \%$ of the baseline for coefficient of performance (COP) and about -3 to $+7 \%$ for cooling capacity. At these performance levels, most deficiencies can be overcome with limited engineering optimization, with the potential for performance improvements for all alternative refrigerants. At ISO T3 conditions, performance change was slightly more widespread than at AHRI conditions, with COP ranging from approximately -10 to $-2 \%$ relative to the baseline and cooling capacity within $\pm 10 \%$ of the baseline.

Table ES.3. ORNL test result for the R-22 unit at AHRI and T3 conditions (performance change from baseline in parentheses) ${ }^{a, b}$

\begin{tabular}{|c|c|c|c|c|}
\hline & \multicolumn{2}{|c|}{$\begin{array}{l}\text { AHRI Standard Rating Conditions } \\
\text { Outdoor: } 35.0^{\circ} \mathrm{C}\left(95^{\circ} \mathrm{F}\right) \\
\text { Indoor: } 26.7^{\circ} \mathrm{C}\left(80.0^{\circ} \mathrm{F}\right) \\
\end{array}$} & \multicolumn{2}{|c|}{$\begin{array}{c}\text { ISO T3 } \\
\text { Outdoor: } 46.0^{\circ} \mathrm{C}\left(114.8^{\circ} \mathrm{F}\right) \\
\text { Indoor: } 29.0^{\circ} \mathrm{C}\left(84.2^{\circ} \mathrm{F}\right)\end{array}$} \\
\hline & COP & $\begin{array}{c}\text { Cooling Capacity, } \\
\mathrm{kW}_{\text {th. }}\end{array}$ & COP & $\begin{array}{c}\text { Cooling Capacity, } \\
\mathrm{kW}_{\text {th. }}\end{array}$ \\
\hline R-22 (Baseline) & 3.04 & 25.27 & 2.23 & 21.84 \\
\hline $\mathrm{L}-20 \mathrm{~A}(\mathrm{R}-444 \mathrm{~B})$ & $2.94(-3.3 \%)$ & $25.46(+0.7 \%)$ & $2.10(-5.8 \%)$ & $21.67(-0.8 \%)$ \\
\hline ARM-20b & $2.85(-6.2 \%)$ & $26.29(+4.0 \%)$ & $2.19(-1.7 \%)$ & $24.03(+10 \%)$ \\
\hline DR-7 (R-454A) & $2.86(-6.2 \%)$ & $27.15(+7.4 \%)$ & $2.00(-9.9 \%)$ & $22.76(+4.2 \%)$ \\
\hline ARM-20a & $3.21(+5.5 \%)$ & $24.58(-2.8 \%)$ & $2.18(-2.3 \%)$ & $19.58(-10.4 \%)$ \\
\hline
\end{tabular}

${ }^{a}$ Shading - green: performance improvement; blank: 0-5\% degradation; yellow: 5-10\% degradation; orange: $>10 \%$ degradation

${ }^{b} 5 \%$ losses may be nullified by soft optimization, while $10 \%$ losses may require additional engineering and losses greater than $10 \%$ may require complete redesign of the unit

\footnotetext{
${ }^{*}$ Hydrocarbons were excluded from testing due to potential safety concerns.

${ }^{\dagger}$ http://www.ahrinet.org/App_Content/ahri/files/STANDARDS/AHRI/AHRI_Standard_340-360_2015.pdf
} 
Table ES.4 summarizes the results at Hot conditions $\left(52.0^{\circ} \mathrm{C}\left[125.6^{\circ} \mathrm{F}\right]\right.$ outdoor temperature). Using ARM-20a, the system operated at a COP approximately $1 \%$ higher than the baseline with approximately a $7 \%$ drop in cooling capacity. The other three alternative refrigerants all showed cooling capacities about 1-2\% above the baseline, with COPs ranging from about 5 to $14 \%$ below the baseline.

Table ES.4. ORNL test results for the R-22 unit at Hot conditions (performance change from baseline in parentheses) $)^{a, b}$

\begin{tabular}{|c|c|c|c|c|}
\hline & $\begin{array}{r}\text { Hot } \\
\text { Outdoor: } \\
\text { Indoor: } 2 \\
\end{array}$ & $\begin{array}{l}\text { bient } \\
\left(125.6^{\circ} \mathrm{F}\right) \\
\mathrm{C}\left(84.2^{\circ} \mathrm{F}\right)\end{array}$ & $\begin{array}{r}\mathbf{F} \\
\text { Ou } \\
\text { Ind }\end{array}$ & $\begin{array}{l}\text { mbient } \\
{ }^{\circ} \mathrm{C}\left(131^{\circ} \mathrm{F}\right) \\
\mathrm{C}\left(84.2^{\circ} \mathrm{F}\right)\end{array}$ \\
\hline & COP & $\begin{array}{c}\text { Cooling Capacity, } \\
\mathrm{kW}_{\text {th. }}\end{array}$ & COP & $\begin{array}{c}\text { Cooling Capacity, } \\
\mathrm{kW}_{\text {th. }}\end{array}$ \\
\hline R-22 (Baseline) & 1.84 & 19.82 & \multirow{5}{*}{\multicolumn{2}{|c|}{$\begin{array}{l}\text { Unavailable due to triggering of the unit's } \\
\text { high-pressure cutoff switch, which prevented } \\
\text { operation at these conditions }\end{array}$}} \\
\hline $\mathrm{L}-20 \mathrm{~A}(\mathrm{R}-444 \mathrm{~B})$ & $1.74(-5.3 \%)$ & $20.17(+1.8 \%)$ & & \\
\hline ARM-20b & $1.65(-10.5 \%)$ & $20.05(+1.2 \%)$ & & \\
\hline DR-7 (R-454A) & $1.58(-14 \%)$ & $19.95(+0.6 \%)$ & & \\
\hline ARM-20a & $1.86(+0.8 \%)$ & $18.48(-6.8 \%)$ & & \\
\hline
\end{tabular}

${ }^{a}$ Shading - green: performance improvement; blank: 0-5\% degradation; yellow: 5-10\% degradation; orange: $>10 \%$ degradation

${ }^{b} 5 \%$ losses may be nullified by soft optimization, while $10 \%$ losses may require additional engineering and losses greater than $10 \%$ may require complete redesign of the unit

ORNL's uncertainty analysis shows an air-side capacity uncertainty of $\pm 2.75 \%$ and an air-side COP uncertainty of $\pm 2.75 \%$. Considering these uncertainties and the potential for further performance enhancements, refrigerants with performance values within $5 \%$ of the baseline may be expected to match the performance of R-22 with further engineering optimization. Furthermore, values within $10 \%$ of the baseline indicate an acceptable match that requires additional engineering design to reach parity with R22 performance. For performance losses greater than 10\%, significant redesign of the unit would likely be necessary to match the performance of the baseline. This suggests that, at high ambient temperatures, at least a few alternative refrigerants could be expected to perform at least as well as R-22, if not better, with additional optimization, while others might require additional engineering to overcome COP losses.

Section 5.1 of this report provides detailed results for the R-22 alternatives.

\section{R-410A UNIT RESULTS}

Table ES.5 lists the alternative refrigerants evaluated in the R-410A unit and their characteristics.

Table ES.5. Baseline and lower-GWP alternative refrigerant characteristics for the R-410A unit

\begin{tabular}{|c|c|c|c|c|}
\hline Refrigerant & Manufacturer & $\begin{array}{c}\text { ASHRAE } \\
\text { Safety Class }\end{array}$ & $\mathbf{G W P}_{\text {AR4 }}{ }^{a}$ & $\mathbf{G W P}_{\text {AR5 }}{ }^{\boldsymbol{a}}$ \\
\hline R-410A (Baseline) & - & A1 & 2088 & 1924 \\
\hline DR-55 & Chemours & A2L & 698 & 676 \\
L41z (R-447B) & Honeywell & A2L & 740 & 714 \\
ARM-71a & Arkema & A2L & 460 & 461 \\
R-32 & Daikin & A2L & 675 & 677 \\
\hline
\end{tabular}

${ }^{a}$ Evaluated as weighted average values of the 100-year ITH GWP of the refrigerant blend components provided by the refrigerant manufacturers and the reported GWP values of those components in IPCC AR4, 2007 [1] and IPCC AR5, 2013 [2] respectively. 
Table ES.6 summarizes the test results at AHRI Standard Rating Conditions and ISO T3 conditions. At these conditions, the R-410A alternatives closely matched the baseline performance. All the alternatives exceeded the baseline's COP by approximately $1-4 \%$ except for R-32 at the ISO T3 condition (-1\%). Cooling capacities for three of the alternatives were approximately $0-4 \%$ lower than the baseline. R-32 exceeded the baseline's cooling capacity by $7 \%$ at AHRI and about $4 \%$ at ISO T3 conditions.

Table ES.6. ORNL test results for the R-410A unit at AHRI and T3 conditions (performance change from baseline in parentheses) ${ }^{a, b}$

\begin{tabular}{|c|c|c|c|c|}
\hline & \multicolumn{2}{|c|}{$\begin{array}{l}\text { AHRI Standard Rating Conditions } \\
\text { Outdoor: } 35.0^{\circ} \mathrm{C}\left(95^{\circ} \mathrm{F}\right) \\
\text { Indoor: } 26.7^{\circ} \mathrm{C}\left(80.0^{\circ} \mathrm{F}\right)\end{array}$} & \multicolumn{2}{|c|}{$\begin{array}{c}\text { ISO T3 } \\
\text { Outdoor: } 46.0^{\circ} \mathrm{C}\left(114.8^{\circ} \mathrm{F}\right) \\
\text { Indoor: } 29.0^{\circ} \mathrm{C}\left(84.2^{\circ} \mathrm{F}\right)\end{array}$} \\
\hline & COP & $\begin{array}{c}\text { Cooling Capacity, } \\
\mathrm{kW}_{\text {th. }}\end{array}$ & COP & $\begin{array}{c}\text { Cooling Capacity, } \\
\mathrm{kW}_{\text {th. }}\end{array}$ \\
\hline R-410A (Baseline) & 3.06 & 39.37 & 2.26 & 34.32 \\
\hline DR-55 & $3.15(+3.0 \%)$ & $39.35(-0.1 \%)$ & $2.29(+1.4 \%)$ & $34.04(-0.8 \%)$ \\
\hline L41z (R-447B) & $3.16(+3.4 \%)$ & $37.96(-3.6 \%)$ & $2.33(+3.5 \%)$ & $33.08(-3.6 \%)$ \\
\hline ARM-71a & $3.16(+3.2 \%)$ & $38.49(-2.2 \%)$ & $2.31(+2.2 \%)$ & $33.38(-2.7 \%)$ \\
\hline $\mathrm{R}-32$ & $3.12(+2.0 \%)$ & $42.12(+7.0 \%)$ & $2.23(-1.0 \%)$ & $35.64(+3.9 \%)$ \\
\hline
\end{tabular}

${ }^{a}$ Shading - green: performance improvement; blank: 0-5\% degradation; yellow: 5-10\% degradation; orange: $>10 \%$ degradation

${ }^{b} 5 \%$ losses may be nullified by soft optimization, while $10 \%$ losses may require additional engineering and losses greater than $10 \%$ may require complete redesign of the unit

Table ES.7 summarizes the results at high ambient temperatures (Hot and Extreme). At these conditions, the R-410A alternatives exceeded the baseline performance. All the alternatives exceeded the baseline's COP by about 2-9\%, with the exception of R-32 at Extreme conditions only, which showed a COP approximately $3 \%$ lower than the baseline. Each of the alternative refrigerants exhibited cooling capacities approximately 1 to $8 \%$ better than the baseline.

Table ES.7. ORNL test results for the R-410A unit at Hot and Extreme conditions (performance change from baseline in parentheses) ${ }^{a, b}$

\begin{tabular}{|c|c|c|c|c|}
\hline & \multicolumn{2}{|c|}{$\begin{array}{c}\text { Hot Ambient } \\
\text { Outdoor: } 52^{\circ} \mathrm{C}\left(125.6^{\circ} \mathrm{F}\right) \\
\text { Indoor: } 29.0^{\circ} \mathrm{C}\left(84.2^{\circ} \mathrm{F}\right) \\
\end{array}$} & \multicolumn{2}{|c|}{$\begin{array}{l}\text { Extreme Ambient } \\
\text { Outdoor: } 55^{\circ} \mathrm{C}\left(131^{\circ} \mathrm{F}\right) \\
\text { Indoor: } 29.0^{\circ} \mathrm{C}\left(84.2^{\circ} \mathrm{F}\right)\end{array}$} \\
\hline & COP & $\begin{array}{c}\text { Cooling Capacity, } \\
\text { kW }_{\text {th. }}\end{array}$ & COP & $\begin{array}{c}\text { Cooling Capacity, } \\
\mathrm{kW}_{\text {th. }}\end{array}$ \\
\hline R-410A (Baseline) & 1.85 & 31.01 & 1.74 & 30.37 \\
\hline DR-55 & $1.94(+4.9 \%)$ & $31.93(+3.0 \%)$ & $1.77(+2.1 \%)$ & $30.60(+0.8 \%)$ \\
\hline L41z (R-447B) & $2.01(+8.9 \%)$ & $31.56(+1.8 \%)$ & $1.86(+7.1 \%)$ & $30.61(+0.8 \%)$ \\
\hline ARM-71a & $1.99(+8.1 \%)$ & $31.96(+3.1 \%)$ & $1.86(+7.1 \%)$ & $31.14(+2.6 \%)$ \\
\hline R-32 & $1.91(+3.6 \%)$ & $33.58(+8.3 \%)$ & $1.69(-2.9 \%)$ & $31.42(+3.5 \%)$ \\
\hline
\end{tabular}

${ }^{a}$ Shading - green: performance improvement; blank: 0-5\% degradation; yellow: 5-10\% degradation; orange: $>10 \%$ degradation ${ }^{b} 5 \%$ losses may be nullified by soft optimization, while $10 \%$ losses may require additional engineering and losses greater than $10 \%$ may require complete redesign of the unit

ORNL's uncertainty analysis shows an air-side capacity uncertainty of $\pm 3.5 \%$ and an air-side COP uncertainty of $\pm 3.5 \%$. Considering these uncertainties and the potential for further performance enhancements, refrigerants with performance values within $5 \%$ of the baseline may be expected to match the performance of R-410A with further engineering optimization. Furthermore, values within $10 \%$ of the 
baseline indicate an acceptable match that requires additional engineering design to reach parity with R410A performance. This suggests that, at high ambient temperatures, all of the alternatives to R-410A tested could deliver performance better than the baseline. In most cases, achieving such performance would not require further optimization or redesign; however, further engineering may still be required to ensure safe and reliable operation.

Section 5.2 of this report provides detailed results for all R-410A alternatives.

\section{SUMMARY}

The test results from this evaluation program demonstrate that there are several viable alternatives to both R-22 and R-410A in RTUs at high ambient temperatures. In many cases there was an improvement in the performance of RTUs using the alternatives versus the baseline, both in terms of COP and cooling capacity. In other cases, the performance of the alternatives fell within $10 \%$ of the baseline, which suggests that parity with baseline performance would likely be possible through soft optimization.

The R-410A alternative refrigerants showed very promising results; three of the four alternative refrigerants exhibited COPs at all testing conditions that exceeded those measured with the baseline R410A. At high ambient temperatures (Hot and Extreme conditions), L41z (R-447B) and ARM-71a both exceeded the COP of the baseline by more than $7 \%$, with cooling capacities within $+3 \%$ of the baseline. All the R-410A alternative refrigerants exhibited higher compressor discharge temperatures than the baseline, which may negatively impact compressor reliability. Conversely, the reduction in compressor discharge temperatures exhibited by the R-22 alternatives can improve compressor reliability.

The R-22 alternative refrigerants also showed promising results. Three alternative refrigerants closely matched or exceeded the baseline cooling capacity at all test conditions. Their COP results were mixed; two refrigerants, ARM-20a and L-20A (R-444B), exhibited results within $\sim 6 \%$ of the baseline at all test conditions. At Hot ambient conditions, ARM-20a exhibited a COP that was $0.8 \%$ better than the baseline and L-20A (R-444B) exhibited a cooling capacity $1.8 \%$ better than the baseline.

The efficiency and capacity of the alternative refrigerants would be expected to improve through design modifications that manufacturers would conduct prior to introducing a new product to market. However, given that the scope of this study only covered drop-in testing, no detailed assessment can be made as to the extent of potential improvements through design changes. The limited changes made to the units for this testing likely indicate that these are conservative results that could improve through further optimization. Improved heat transfer circuiting, proper compressor sizing and selection, and other system improvements would likely yield better performance results for all of the alternative refrigerants.

Losses in cooling capacity are typically easier to recover through engineering optimization compared to losses in COP. The primary practical limit to improvements in capacity is the physical size of the unit, but that is not expected to be a significant concern in this case based on the magnitude of the observed cooling capacity losses. Thus, the COP losses and the increase in compressor discharge temperature for the R-410A alternatives are particularly important results of this testing program, in that these variables will be the primary focus of future optimization efforts.

This performance evaluation shows that viable replacements exist for both R-22 and R-410A at highambient temperatures. Multiple alternatives for R-22 performed well, and many R-410A alternatives performed as well as, and often better than, R-410A, making them prime candidate refrigerants. Prior to commercialization, manufacturers' engineering optimization can address performance loss, the increase in compressor discharge temperature that the R-410A alternatives exhibited, and any safety concerns for flammable alternatives. 


\section{INTRODUCTION}

Hydrofluorocarbon (HFC) refrigerants are non-ozone-depleting fluids that are used as working fluids in air conditioning and refrigeration equipment as substitutes for ozone-depleting substances (ODS) which have been or are being phased out under the Montreal Protocol. ${ }^{*}$ However, some of the HFCs have high global warming potential (GWP), which introduces uncertainty about their use in the future due to their impact on the climate. HFCs currently account for only $1 \%$ of greenhouse gas emissions, but their use is growing rapidly by as much as 10 to $15 \%$ per year, primarily due to their use as replacements for ODS and the increasing use of air conditioners globally. [3] Therefore, there is potential for significant reduction in direct greenhouse gas (GHG) emissions through the substitution of high-GWP HFCs with lower-GWP alternatives.

While progress toward widespread application of low-GWP refrigerants continues, only limited information regarding the performance of the most commonly proposed low-GWP refrigerants is available. A particular concern is that low-GWP refrigerants might experience performance degradation at high-ambient-temperature conditions. In order to address this issue, the US Department of Energy (DOE), in cooperation with Oak Ridge National Laboratory (ORNL), established an evaluation program to assess the performance of several candidate low-GWP alternative refrigerants under high-ambienttemperature conditions. The program evaluated the performance of packaged or rooftop air conditioners (RTU) under high-ambient-temperature conditions using low-GWP refrigerants. The objective was to assess whether it is possible to achieve similar or better energy efficiency and cooling capacity with lower-GWP refrigerants compared with current baseline refrigerants R-22 and R-410A in existing production units available in hot climate markets such as the Middle East. This program was guided by a panel of international experts consisting of members of government, academia, and industry from interested countries.

Other evaluation programs aimed at understanding the performance of low-GWP refrigerants at high ambient temperatures are currently under way. The United Nations Environment Programme (UNEP) and the United Nations Industrial Development Organization (UNIDO) are sponsoring two separate programs funded by the Multilateral Fund for the Implementation of the Montreal Protocol (MLF): Promoting LowGWP Alternative Refrigerants in the Air-Conditioning Industry for High-Ambient Conditions (PRAHA), which recently completed testing, and the Egyptian Program for Promoting Low-GWP Refrigerants' Alternatives (EGYPRA), which is targeted for completion in late 2016. [4][5] In addition to those efforts, participants in the Air-Conditioning, Heating, and Refrigeration Institute's (AHRI) Low-GWP Alternative Refrigerants Evaluation Program (Low-GWP AREP) are conducting high-ambient-temperature testing with a variety of heating, ventilation, and air conditioning (HVAC) equipment. [6] Due to the different scopes of each program, the specific results of each are not directly comparable; instead, together they provide a comprehensive picture of the viability of low-GWP refrigerants. For additional details on the other programs, see APPENDIX B.

\subsection{PURPOSE/OBJECTIVES}

The objective of this program was to evaluate the performance and help determine the viability of several lower-GWP refrigerants as replacements for the baseline refrigerants (R-22 and R-410A) in packaged RTUs under high-ambient temperatures.

This is the second phase of a larger effort to evaluate alternative refrigerants in high-ambient conditions. The first phase tested mini-split (ductless) air conditioners and the results are documented in a report

\footnotetext{
${ }^{*}$ UNEP provides additional information on the Montreal Protocol at: http://ozone.unep.org/en/treaties-and-decisions/montrealprotocol-substances-deplete-ozone-layer
} 
titled "Alternative Refrigerant Evaluation for High-Ambient-Temperature Environments: $R-22$ and R410A Alternatives for Mini-Split Air Conditioners" by Omar Abdelaziz et. al. (hereafter "The High Ambient Phase I Study"). The report is available at:

http://energy.gov/sites/prod/files/2015/10/f27/bto_pub59157_101515.pdf.

\subsection{SCOPE AND COVERAGE}

The program experimentally evaluated the performance of rooftop air-conditioning units originally designed to use R-22 (an HCFC with GWP=1,760) or R-410A (a blend of two HFCs with GWP=1,924), both when using the baseline refrigerants and when using low-GWP alternatives. ${ }^{*}$ The primary objective of the evaluation was to determine whether it is possible, using the lower-GWP alternatives, to achieve comparable or better performance than with R-22 and R-410A. Low-GWP alternatives may or may not reduce indirect GHG emissions and overall total equivalent warming impact (TEWI) or life cycle climate performance (LCCP) depending on whether or not system energy efficiency is improved. RTUs were chosen as the equipment to be evaluated because they are a common type of air conditioner used in light commercial applications in most high-ambient-temperature regions and are therefore a natural follow-up research focus after The High Ambient Phase I study in 2015.

ORNL in Oak Ridge, Tennessee, USA, performed the evaluation using a range of fluorinated low-GWP refrigerants, which are tested and compared with two baselines - R-22 and R-410A. There is currently a global effort to transition away from R-22, as agreed under the Montreal Protocol. ${ }^{\dagger}$ Many nations are also transitioning away from R-410A due to its high GWP. The Parties to the Montreal Protocol have recently agreed to manage HFCs under the Montreal Protocol. The pace of the transition away from these HFCs will depend on control schedules under discussion by the Parties. These transitions are at various stages in different regions of the world, so including both refrigerants as baselines can provide a point of reference regardless of where particular countries stand in the transition process.

Testing of the baseline refrigerants was first carried out on the original equipment provided by the manufacturer. ORNL tested the alternative refrigerants as "drop-in" replacements. This is a change from the phase I evaluation of mini split units, as documented in The High Ambient Phase I Report, where the units were soft-optimized for each alternative refrigerant. Drop-in tests allow only minor adjustments to the equipment (as defined by Low-GWP AREP $\$$ ), which differentiates it from soft-optimized testing, which can be modified with standard production line components, and from purpose-built prototype testing where units are custom-designed to work with a specific alternative refrigerant. Drop-in tests are the simplest to conduct, while purpose-built prototypes are the most complex. Therefore, both softoptimized equipment and purpose-built prototypes have the potential to achieve higher efficiency levels than simple drop in-tests like those reported here.

\subsection{PARTICIPANTS}

\subsubsection{Oak Ridge National Laboratory (ORNL)}

ORNL has been involved in the research and development (R\&D) of space-conditioning equipment and appliances for nearly 40 years. ${ }^{\S}$ The Building Technologies Research and Integration Center (BTRIC)

\footnotetext{
* IPCC AR5 GWP values. [2] See Section 3.2 for discussion of refrigerants and GWP values (and sources).

$\dagger$ UNEP provides additional information on the Montreal Protocol at: http://ozone.unep.org/en/treaties-and-decisions/montrealprotocol-substances-deplete-ozone-layer

\$Details on Low-GWP AREP are available via the AHRI website: http://www.ahrinet.org/arep.aspx

$\S$ ORNL's website includes detailed information on their history of work in space conditioning and appliances; available at: http://web.ornl.gov/sci/buildings/
} 
partnerships with industry have resulted in successful introduction of products such as high-efficiency refrigerator-freezers, heat pump water heaters, high-efficiency supermarket refrigeration systems, and hybrid desiccant/vapor compression air-conditioning systems. ${ }^{*}$ Nine of these products have won the prestigious R\&D 100 Award.

The BTRIC User Facility at ORNL is the premier US DOE research facility devoted to the development of technologies that improve the energy efficiency and environmental compatibility of residential and commercial HVAC building equipment. BTRIC's mission is to identify, develop, and deploy energyefficient technologies by forming partnerships between DOE and industry for technology development and analysis, well-characterized laboratory and field experiments, and market outreach. The experimental facilities for building equipment research are ISO14001 certified for environmental compliance.

BTRIC is a leading center for the development of innovative air conditioners, heat pumps, water heaters, and appliances. The public domain ORNL Heat Pump Design Model (HPDM) is one of the most frequently used heat pump models and is currently being used by several original equipment manufacturers (OEMs) in their sizing and selection software tools. ${ }^{\dagger}$ " Furthermore, ORNL plays an active role in the development in the U.S. of integrated heat pumps (air source and ground source) as well as heat-pump water heaters. [7][8]

BTRIC also has decades of experience in the research, design, and development of advanced heat exchangers. Its expertise in this area includes the measurement of heat transfer coefficients for zeotropic refrigerant mixtures and methods for improvement; evaluation of microchannel heat exchangers; and computational fluid dynamics (CFD) modeling to improve the performance of heat exchangers in heating, ventilation, and air-conditioning equipment by reducing maldistribution of air across the heat exchanger and of refrigerant inside the heat exchanger. In addition, ORNL has recently been involved in the application of rotating heat exchangers for refrigeration applications. ${ }^{\S}$

Finally, BTRIC has decades of experience in alternative refrigerant evaluation programs. User facilities and flagship modeling capabilities were used during the CFC-to-HCFC transition, the HCFC-to-HFC transition, and are currently being leveraged as part of the transition from high-GWP HFCs to lower GWP refrigerants. This work has produced numerous publications in this field. In addition to the High Ambient Phase I Report (see section 1.1), other select examples include:

- $\quad$ CFC Phase-out - a strategy development project concerned with containing existing refrigerant and retrofitting or replacing CFC-based chillers with alternative refrigerants [9]

- Global Warming Impacts of Ozone-Safe Refrigerants and Refrigeration, Heating, and AirConditioning Technologies - an analysis of the contributions of various refrigerants in major applications to global warming [10]

- Development of Low Global Warming Potential Refrigerant Solutions for Commercial Refrigeration Systems Using a Life Cycle Climate Performance (LCCP) Design Tool - an LCCP analysis of the performance of typical commercial refrigeration systems with alternative refrigerants and minor system modifications [11]

- Energy and Global Warming Impacts of HFC Refrigerants and Emerging Technologies - a comparative analysis of the global warming impacts of alternative technologies using total equivalent warming impact (TEWI) [12]

\footnotetext{
* For more information on BTRIC, see the website at: http://www.ornl.gov/user-facilities/btric

† For more information on ORNL's HPDM, see their website at: http://web.ornl.gov/ wlj/hpdm/MarkVII.shtml

$\$$ For a list of relevant reports on HPDM, see http://web.ornl.gov/ wlj/hpdm/Related_Reports.html

$\S$ For a list of capabilities, see ORNL's Experimental Capabilities and Apparatus Directory at:

http://web.ornl.gov/sci/buildings/docs/buildings_catalog.pdf
} 


\subsubsection{Industry}

As part of this program, major refrigerant producers such as Arkema, Chemours (formerly DuPont), and Honeywell provided sample prototype refrigerants with a lower GWP compared with existing refrigerants. They supplied ORNL with refrigerants that are being considered as alternatives to R-22 and R-410A. RTU manufacturers SKM and Petra donated equipment for testing, including both RTUs specially designed for the high-ambient-temperature conditions. One unit is designed for R-22 and the other for R-410A.

\subsubsection{International Expert Panel}

A group of HVAC experts was assembled to provide input and guidance to the evaluation program, including design of the program and review of the test results and the final report. For biographies of the panel members, refer to APPENDIX A. The investigators conducting the testing recognized that, given the international implications of the results of the evaluation program, it was essential that this panel consist of individuals from various nations, especially countries with hot climates. Accordingly, a number of governments were contacted to recommend experienced technical personnel who, whether from government, academia, or industry, would act independently, on their own behalf (i.e., not formally representing a government or an industrial entity) in providing guidance for this effort. In addition, representatives from UNEP and UNIDO were also asked to join the panel, given the significant involvement of both these UN organizations in projects aimed at developing solutions for the replacements of HCFC and high-GWP HFC refrigerants in the air-conditioning sector in high ambient temperature countries. The panel met three times via teleconference:

- March 29, 2016 - presentation of test plans and selection of alternative refrigerants

- May 15, 2016 - status update

- August 9,2016 - review of preliminary results

The panel was tasked with providing technical input for this study, including recommending alternative refrigerants to be tested, commenting on appropriate test procedures, assessing results, and reviewing the final report. This panel, aside from two newly-added members, also provided technical input for The High Ambient Phase I Report.

\section{SELECTION OF ALTERNATIVES AND TESTING CONDITIONS}

\subsection{ALTERNATIVE REFRIGERANTS SELECTION}

Guided by input from the expert panel, the investigators decided on a set of criteria (in no particular order) for consideration when selecting alternative refrigerants for testing. The alternative refrigerants shall:

- Have a lower GWP than the refrigerants being replaced. No strict upper limit on the GWP of alternative refrigerants was specified.

- Be relatively close to commercial availability, or already commercially available (as determined by the expert panel).

- Have properties that are a relatively close match to the baseline refrigerant that they are replacing. It is notable that temperature glide is an especially important property, in addition to capacity and coefficient of performance (COP).

- Have readily available information about their characteristics.

- Be able to meet the safety constraints of the ORNL laboratory where the units will be tested. 
In addition, it was decided that this program should not consider flammability as one of the selection criteria. ASHRAE Standard $34^{*}$ defines flammability and toxicity classes. The flammability classes are: 1 , 2, 2L, and 3, where higher numbers indicate higher flammability. Class $2 \mathrm{~L}$ is a subgroup of mildly flammable class 2 refrigerants with a maximum burning velocity of $10 \mathrm{~cm} / \mathrm{sec}$. The toxicity classes are A and B, with A being nontoxic. As discussed in Section 3.2, this evaluation program only tested class A2L refrigerants, but the universe of candidate refrigerants also included refrigerants from classes A1 and A3. There is significant ongoing research and discussion on the safe use of flammable refrigerants, such as in the JRAIA International Symposium on New Refrigerants and Environmental Technology 2014 (Kobe, 2014) and the $4^{\text {th }}$ Symposium on Alternative Refrigerants for High-Ambient Countries (Dubai, 2014). ${ }^{\dagger, t}$

Given the uncertainties in Life Cycle Climate Performance (LCCP) models, the panel could not come to a consensus on whether to use LCCP as a selection criterion, and therefore recommended that LCCP not be used as a selection criterion. While the concept of LCCP is generally accepted as a metric for evaluating alternative refrigerants, there is considerable disagreement about accurate LCCP values, largely due to uncertainties related to assumptions about refrigerant leakage rates and electric emissions factors.

\subsection{TESTING CONDITIONS}

ORNL conducted testing of all refrigerants in the R-410A unit at each of the environmental conditions described in Table 1. They completed testing of all refrigerants in the R-22 unit at only the AHRI Standard Rating Conditions, ISO T3, and Hot conditions because the unit's refrigerant high-pressure cutout controls prevented operation at the Extreme test conditions.

Table 1. Test conditions

\begin{tabular}{|c|c|c|c|c|c|}
\hline \multirow[b]{2}{*}{ Test Condition } & \multirow{2}{*}{$\begin{array}{c}\text { Outdoor }^{a} \\
\text { Dry-Bulb Temp. }\end{array}$} & \multicolumn{4}{|c|}{ Indoor } \\
\hline & & Dry-Bulb Temp. & Wet-Bulb Temp. & Dew Point Temp. ${ }^{b}$ & $\begin{array}{l}\text { Relative } \\
\text { Humidity }{ }^{b}\end{array}$ \\
\hline & ${ }^{\circ} \mathrm{C}\left({ }^{\circ} \mathrm{F}\right)$ & ${ }^{\circ} \mathrm{C}\left({ }^{\circ} \mathrm{F}\right)$ & ${ }^{\circ} \mathrm{C}\left({ }^{\circ} \mathrm{F}\right)$ & ${ }^{\circ} \mathrm{C}\left({ }^{\circ} \mathrm{F}\right)$ & $\%$ \\
\hline $\begin{array}{l}\text { AHRI Standard } \\
\text { Rating Conditions }\end{array}$ & $35.0(95)$ & $26.7(80.0)$ & $19.4(67)$ & $15.8(60.4)$ & 50.9 \\
\hline ISO T3 & $46(114.8)$ & $29(84.2)$ & $19(66.2)$ & $13.7(56.6)$ & 39 \\
\hline Hot & $52(125.6)$ & $29(84.2)$ & $19(66.2)$ & $13.7(56.6)$ & 39 \\
\hline Extreme & $55(131)$ & $29(84.2)$ & $19(66.2)$ & $13.7(56.6)$ & 39 \\
\hline
\end{tabular}

${ }^{a}$ There is no specification for the outdoor relative humidity as it has no impact on the performance.

${ }^{b}$ Dew-point temperature and relative humidity evaluated at $0.973 \mathrm{~atm}(14.3 \mathrm{psi})$

${ }^{c}$ Per AHRI Standard 340/360

\footnotetext{
* ASHRAE Standard 34 information: https://www.ashrae.org/resources--publications/bookstore/standards-15--34

$\dagger$ For details on the JRAIA International Symposium on New Refrigerants and Environmental Technology 2014, refer to: http://www.jraia.or.jp/english/symposium/index.html

$\$$ For details on the $4^{\text {th }}$ Symposium on Alternative Refrigerants for High-Ambient Countries, refer to: http://4thhighambient.com/index.html
} 


\section{EXPERIMENTAL FACILITIES AND EQUIPMENT}

\subsection{ROOFTOP AIR-CONDITIONING UNITS}

ORNL performed drop-in tests for two baseline RTUs:

- R-22 unit: $27.2 \mathrm{~kW}_{\text {th }}(7.7 \mathrm{TR}) \mathrm{R}-22$ system from SKM; PACL Series, model number PACL$51095 \mathrm{Y}(380 / 415 \mathrm{~V}, 3$ Phase, $50 \mathrm{~Hz})$

- R-410A unit: 38.7 kW th $(11$ TR) R-410A system from Petra; PPH Series, model PPH4 115 $(460 \mathrm{~V}, 3$ Phase, $60 \mathrm{~Hz}) ; 3.12 \mathrm{COP}(10.66 \text { energy efficiency ratio [EER] })^{\dagger}$

Figure 1 shows the two units (left: SKM PACL Series; Right: Petra PPH Series).
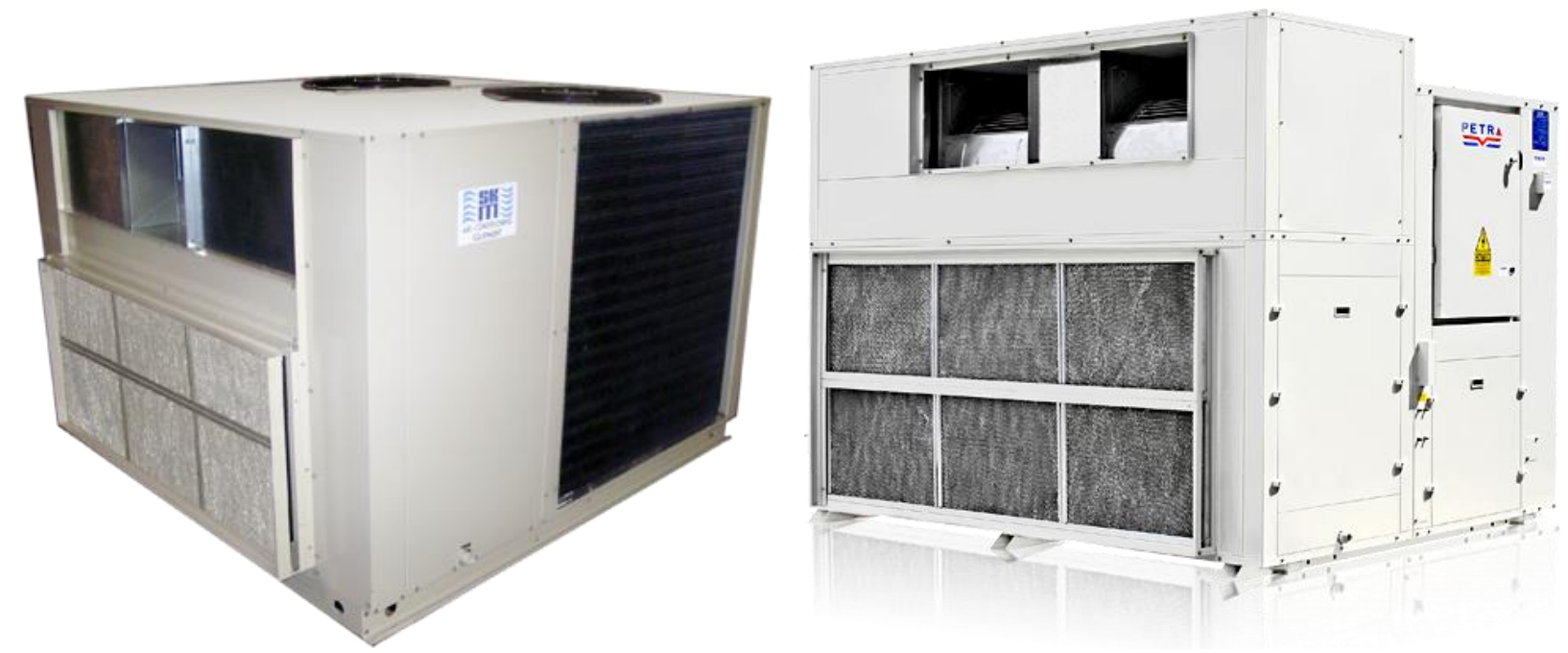

Figure 1. Baseline equipment designed for high-ambient-temperature conditions.

Due to the differences in design and in baseline efficiency, it is not possible to compare the test results for the R-22 unit and the R-410A unit directly. Thus, results in Sections 5.1 and 5.2 for each unit are not directly comparable.

\subsection{ALTERNATIVE REFRIGERANTS}

The panel selected four alternative refrigerants for testing in the R-22 unit and four different alternative refrigerants for testing in the R-410A unit. Table 2 and Table 3 show the details for each of the alternative and baseline refrigerants for the R-22 and R-410A RTUs, respectively. ${ }^{\ddagger}$ All the selected alternatives for both units are ASHRAE safety class A2L (nontoxic, mildly flammable, low burning velocity). The expert panel expressed interest in including hydrocarbons (safety class A3), but ORNL ultimately excluded them from testing due to potential safety concerns that they could not sufficiently mitigate in the tight

\footnotetext{
${ }^{*}$ Capacity specifications are determined at ISO $5051 \mathrm{~T} 1$ conditions (indoor dry-bulb temperature at $27^{\circ} \mathrm{C}\left[80.6^{\circ} \mathrm{F}\right]$ and wet-bulb temperature at $\left.19^{\circ} \mathrm{C}\left[66.2^{\circ} \mathrm{F}\right]\right)$.

${ }^{\dagger}$ EER is an efficiency metric commonly used in the U.S. for cooling performance of air conditioning equipment. COP is given in $\mathrm{W} / \mathrm{W}$, while EER is in Btu/W-h.

$\$$ For thermodynamic cycle calculations for the baseline refrigerants as well as many of the component refrigerants that make up the alternatives, refer to the Low-GWP AREP Participants' Handbook (April 17, 2015) by the Air-Conditioning, Heating and Refrigeration Institute. Available: http://www.ahrinet.org/App Content/ahri/files/RESEARCH/Participants Handbook2015-04$\underline{17 . p d f}$
} 
timeframe of the testing. The GWP values are weighted average values of the GWP of each of the refrigerant blend components, the composition of which was provided by the refrigerant manufacturers, and the reported GWP values of those components in IPCC AR4, 2007 [1] and IPCC AR5, 2013 [2] respectively. See Section 4 for discussion of the charge optimization process.

Table 2. Baseline and alternative refrigerant data for the R-22 unit

\begin{tabular}{|c|c|c|c|c|}
\hline Refrigerant & Manufacturer & $\begin{array}{c}\text { ASHRAE } \\
\text { Safety Class }\end{array}$ & GWP $_{\text {AR4 }}$ & GWP $_{\text {AR5 }}$ \\
\hline R-22 (Baseline) & - & A1 & 1,810 & 1,760 \\
\hline L-20A (R-444B) & Honeywell & A2L & 295 & 295 \\
ARM-20b & Arkema & A2L & 251 & 251 \\
DR-7 (R-454A) & Chemours & A2L & 239 & 238 \\
ARM-20a & Arkema & A2L & 139 & 139 \\
\hline
\end{tabular}

Table 3. Baseline and alternative refrigerant data for the $R-410 A$ unit

\begin{tabular}{|c|c|c|c|c|}
\hline Refrigerant & Manufacturer & $\begin{array}{c}\text { ASHRAE } \\
\text { Safety Class }\end{array}$ & GWP $_{\text {AR4 }}$ & GWP $_{\text {AR5 }}$ \\
\hline R-410A (Baseline) & - & A1 & 2088 & 1924 \\
\hline DR-55 (R-452B) & Chemours & A2L & 698 & 676 \\
L41z (R-447B) & Honeywell & A2L & 740 & 714 \\
ARM-71a & Arkema & A2L & 460 & 461 \\
R-32 & Daikin & A2L & 675 & 677 \\
\hline \multicolumn{4}{|r}{}
\end{tabular}

The panel did recommend re-testing each unit with the unit's intended refrigerant (i.e., the baseline) again upon completion of all the alternatives in order to ensure that each unit's operating conditions remain unchanged.

ORNL tested the R-22 unit with both mineral oil (46cSt), the OEM-specified lubricant for the unit, and with POE oil (3MAF), the lubricant used for all the R-22 alternative refrigerants. The expert panel's consensus recommendation was that R-22 with mineral oil should be the baseline since that is how the unit was designed and shipped by the manufacturer. (See APPENDIX D for results of R-22 with POE oil.) ORNL tested the R-410A unit using the manufacturer-specified POE oil for all refrigerants except R-32, which ORNL tested using a prototype POE oil as recommended by the compressor manufacturer.

\subsection{EXPERIMENTAL FACILITIES}

The ORNL team evaluated both the R-22 Unit and the R-410A unit in parallel. Performance evaluation was carried at the ORNL Multi-Zone Environmental Chambers for the R-22 unit, (Figure 2), and the ORNL Large Environmental Chambers (Figure 3) for the R-410A unit.

- The ORNL Multi-Zone Environmental Chambers are capable of characterizing the performance of multi-zone electric or gas HVAC systems for residential and light commercial use. The "outdoor" chamber is $6.1 \times 4.6 \mathrm{~m}(20 \times 15 \mathrm{ft}$. $)$; the $8.5 \mathrm{~m}(28 \mathrm{ft}$. $)$ square "indoor" chamber can be divided into up to four spaces controlled at different conditions to represent separate zones. Drybulb temperature can be controlled at -23 to $55^{\circ} \mathrm{C}\left(-10\right.$ to $\left.131^{\circ} \mathrm{F}\right)$ and relative humidity at 30 to $90 \%$. Utilities include $480 \mathrm{~V}$, three-phase power at $225 \mathrm{~A}$ with step-down to 240,208 , and $120 \mathrm{~V}$. In this project, the indoor side was split into two chambers, each $8.5 \times 4.25 \mathrm{~m}$ such that two 
systems can be evaluated in parallel. The chambers are equipped with two code testers - one that can supply and measure airflow up to $5,100 \mathrm{~m}^{3} / \mathrm{hr}$. $(3,000 \mathrm{cfm})$ and the other up to $11,900 \mathrm{~m}^{3} / \mathrm{hr}$. $(7,000 \mathrm{cfm})$. The code testers have the required duct mixers and temperature sampling trees.

- The Large Environmental Chambers can characterize the performance of commercial HVAC, supermarket refrigeration, and combined heat and power systems (up to 30 tons). It is accomplished using "outdoor" and "indoor" chambers of the same size at $6.1 \times 6.1 \mathrm{~m}(20 \times 20 \mathrm{ft}$. $)$ with a $4.3 \mathrm{~m}$ (14 ft.) ceiling. Gas and electricity are supplied, with $480 \mathrm{~V}, 3$-phase power at 225 Amps and stepped-down voltage at 240, 208, and $120 \mathrm{~V}$. The chamber can control the dry bulb temperature setpoint from -18 to $65.6^{\circ} \mathrm{C}\left(0\right.$ to $\left.150^{\circ} \mathrm{F}\right)$ and the relative humidity setpoint from 0 to $100 \%$. The chambers are equipped with one code tester that can supply and measure airflow up to $11,900 \mathrm{~m}^{3} / \mathrm{hr}$. (7000 $\left.\mathrm{cfm}\right)$. The code tester has the required duct mixers and temperature sampling trees.

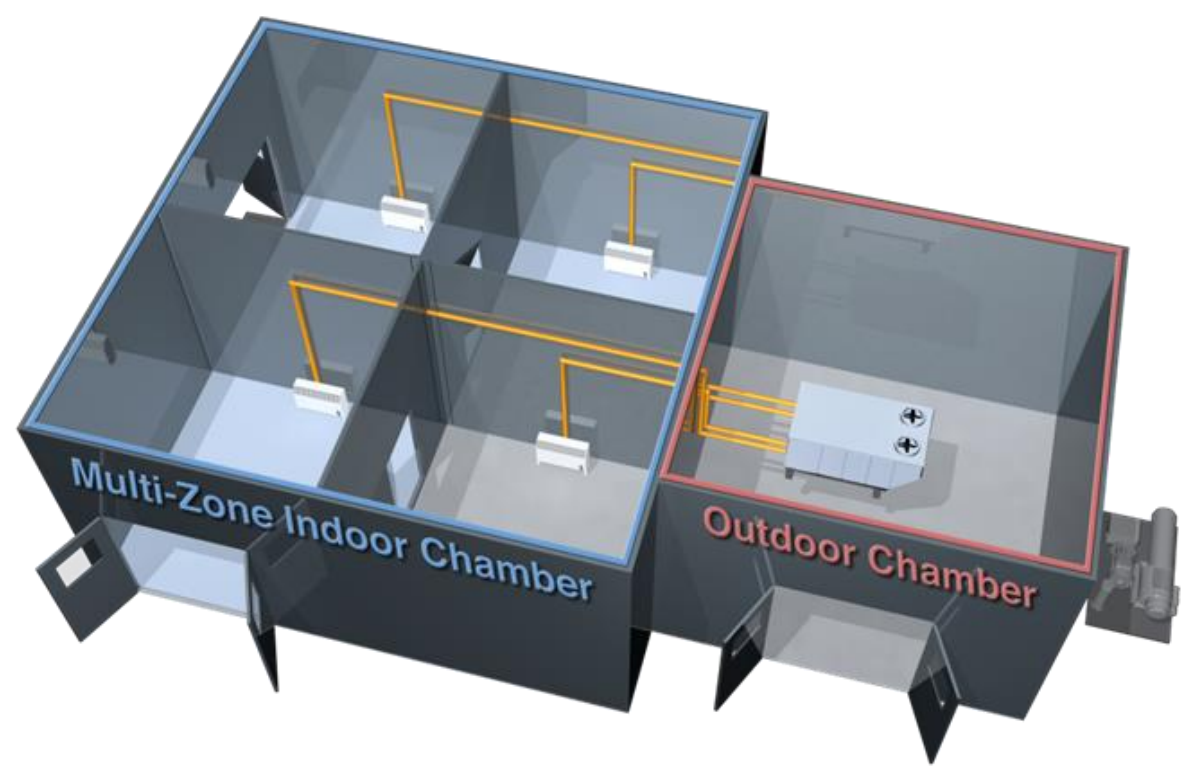

Figure 2. Multi-zone environmental chambers. 


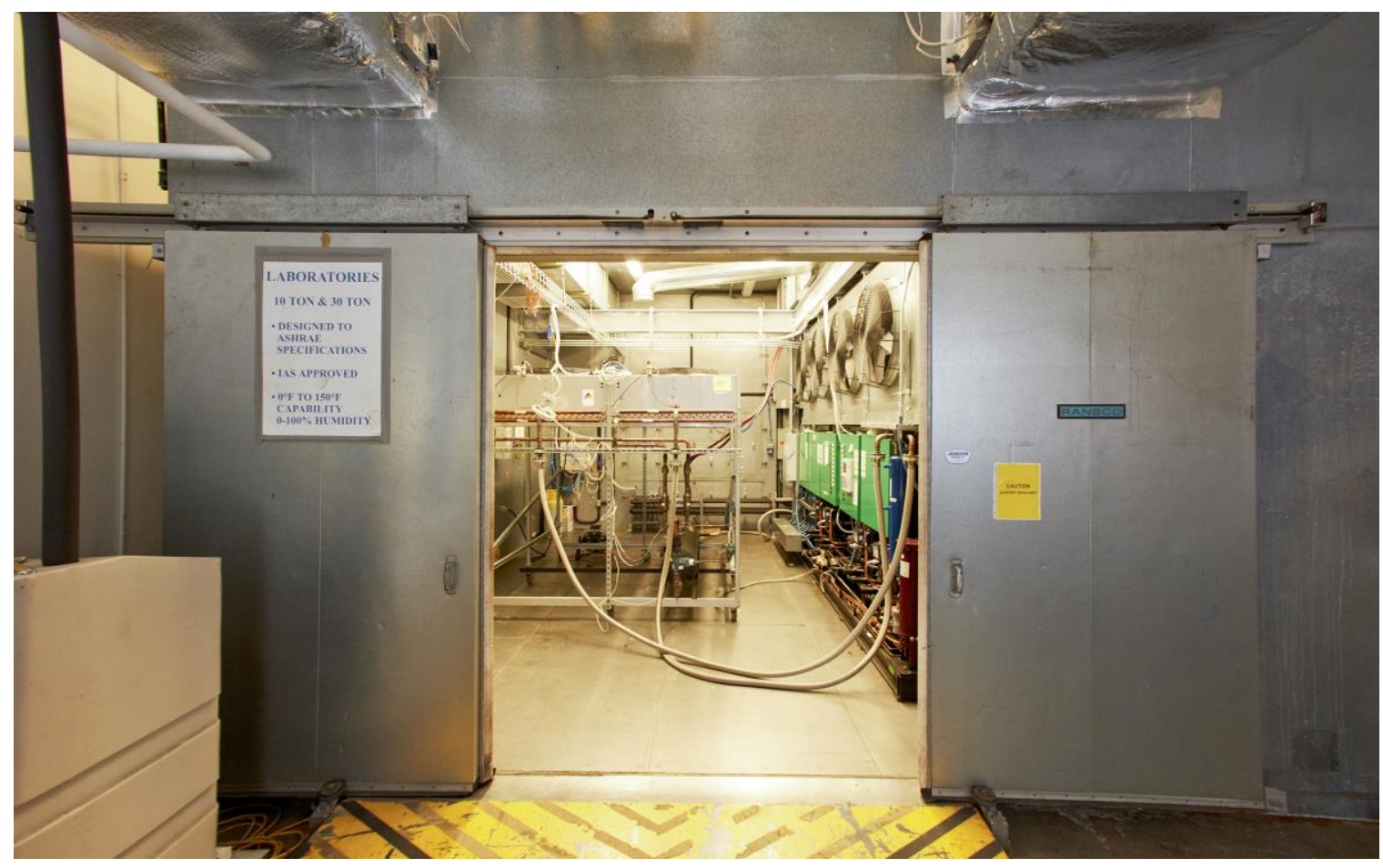

Figure 3. ORNL's large environmental chambers - outdoor chamber.

\subsection{EXPERIMENTAL SETUP AND INSTRUMENTATION}

A comprehensive experimental facility was designed and built to comply with ANSI/AHRI Standard 340/360 and ANSI/ASHRAE Standard 37. The Air Enthalpy method is used to evaluate the performance of the indoor unit, and the Refrigerant Enthalpy Method is used as a secondary means of evaluating the system performance in order to establish energy balance and assess measurement accuracy. For an overview of the experiment test setup, refer to APPENDIX C.

Table C. 1 in APPENDIX C summarizes the instrumentation used for testing. All of the instrumentation provides better accuracy than required by ASHRAE Standard 37 (Table 2b). The data are collected to satisfy Table 3 of the ASHRAE Standard 37 for both the Indoor Air Enthalpy Method column and the Refrigerant Enthalpy Method column. Additional data were recorded to increase the level of understanding of the alternative refrigerants, including compressor shell temperature and additional surface thermocouples on the liquid line and the compressor suction line.

\subsection{ALTERNATIVE REFRIGERANT EVALUATION EXPERIMENTAL DESIGN}

ORNL evaluated the R-22 unit as baseline and with four alternative refrigerants at four different test conditions each, constituting 20 tests. In addition, ORNL tested R-22 with POE oil (as opposed to mineral oil, as used for the baseline tests) both before and after testing of all refrigerants, adding an additional 6 tests. ORNL evaluated the R-410A unit as baseline and with four alternative refrigerants at four different test conditions (see section 2.2 for discussion of test conditions) constituting 20 tests. In addition ORNL retested R-410A after testing all the refrigerants, adding an additional 4 tests. Consequently, the total number of tests was 52 . Table 4 summarizes the test plan. 
Table 4. ORNL test plan summary

\begin{tabular}{|l|c|c|c|c|c|c|c|c|c|c|c|c|}
\hline Unit: & $\begin{array}{c}\text { Base - } \\
\text { Mineral } \\
\text { Oil }\end{array}$ & $\begin{array}{c}\text { Base - } \\
\text { POE Oil }\end{array}$ & $\begin{array}{c}\text { L-20A } \\
(\text { R-444B) }\end{array}$ & $\begin{array}{c}\text { ARM- } \\
\text { 20b }\end{array}$ & $\begin{array}{c}\text { DR-7 } \\
\text { (R-454A) }\end{array}$ & $\begin{array}{c}\text { ARM- } \\
\text { 20a }\end{array}$ & $\begin{array}{c}\text { DR-55 } \\
\text { (R-452B })\end{array}$ & $\begin{array}{c}\text { L41z } \\
(\text { R-447B })\end{array}$ & $\begin{array}{c}\text { ARM- } \\
\text { 71a }\end{array}$ & R-32 & $\begin{array}{c}\text { Base - } \\
\text { re-run }\end{array}$ & $\begin{array}{c}\text { Total } \\
\text { Tests }\end{array}$ \\
\hline R-22 & $\begin{array}{c}\mathrm{X} \\
\text { (baseline) }\end{array}$ & $\mathrm{X}$ & $\mathrm{X}$ & $\mathrm{X}$ & $\mathrm{X}$ & $\mathrm{X}$ & & & & & $\mathrm{X}$ & $\mathbf{2 8}$ \\
R-410A & & $\begin{array}{c}\mathrm{X} \\
\text { (baseline) }\end{array}$ & & & & & $\mathrm{X}$ & $\mathrm{X}$ & $\mathrm{X}$ & $\mathrm{X}$ & $\mathrm{X}$ & $\mathbf{2 4}$ \\
\hline
\end{tabular}

ORNL performed selected additional tests which were not initially planned.

Table 5 shows a summary of the additional tests and the section of the report where their results are presented. Considering the tests in both Table 4 and Table 5 the total number of tests performed by ORNL was 53.

Table 5. Additional tests conducted (not included in original schedule)

\begin{tabular}{|c|c|c|c|c|c|}
\hline Purpose of test & RTU & Refrigerant & $\begin{array}{c}\text { Test } \\
\text { Conditions }\end{array}$ & $\begin{array}{l}\text { Test Series } \\
\text { ID }^{\mathrm{a}}\end{array}$ & $\begin{array}{c}\text { Results } \\
\text { Location }\end{array}$ \\
\hline Increase superheat to $12^{\circ} \mathrm{F}$ & $\mathrm{R}-22$ & $\mathrm{R}-22$ & A, T3, Hot & $\mathrm{T} 1$ & Appendix D \\
\hline $\begin{array}{l}\text { Increase superheat to } 12^{\circ} \mathrm{F} \text { w/smaller } \\
\text { charge }\end{array}$ & $\mathrm{R}-22$ & $\mathrm{R}-444 \mathrm{~B}$ & A, T3, Hot & $\mathrm{T} 2$ & Appendix D \\
\hline Increase superheat to $12^{\circ} \mathrm{F}$ & $\mathrm{R}-22$ & ARM-20b & A & T3 & Appendix D \\
\hline Increase superheat to $12^{\circ} \mathrm{F}$ & $\mathrm{R}-22$ & $\begin{array}{c}\text { DR-7 } \\
\text { (R454A) }\end{array}$ & A & $\mathrm{T} 4$ & Appendix D \\
\hline Increase superheat to $12^{\circ} \mathrm{F}$ & R-22 & ARM-20a & A & T5 & Appendix D \\
\hline $\begin{array}{l}\text { Increase superheat to } 12^{\circ} \mathrm{F} \mathrm{w} / \text { larger } \\
\text { charge }\end{array}$ & $\mathrm{R}-22$ & ARM-20a & $\mathrm{A}$ & T6 & Appendix D \\
\hline
\end{tabular}

${ }^{a}$ Test Series ID is used here to identify the relevant results in Appendix D

\section{EXPERIMENTAL PROCEDURE}

\subsection{OVERALL PROCEDURE}

The following steps were taken to evaluate the equipment and refrigerant combinations.

1. Perform charge adjustment at AHRI Standard Rating Conditions. ${ }^{*}$ See Section 4.2.

2. Run the test matrix (each refrigerant at each test condition) as summarized in Table 4. Collect steady-state data for 30 minutes at each condition. ${ }^{\dagger}$

\footnotetext{
* ORNL performed charge adjustment at AHRI Standard Rating Conditions $\left(35^{\circ} \mathrm{C}\left[95^{\circ} \mathrm{F}\right]\right.$ outdoor and $26.7^{\circ} \mathrm{C}\left[80.0^{\circ} \mathrm{F}\right]$ indoor $)$ because it is the closest of the test conditions in this study to manufacturers' reported rating conditions (ISO T1 conditions $35^{\circ} \mathrm{C}\left[95^{\circ} \mathrm{F}\right]$ outdoor and $27^{\circ} \mathrm{C}\left[80.6^{\circ} \mathrm{F}\right]$ indoor). It is assumed that this is therefore also the condition for which manufacturers do their system design and analysis.

'Steady state is established when the average dry-bulb temperatures at the inlet of the indoor and outdoor heat exchangers are within $0.28^{\circ} \mathrm{C}\left(0.5^{\circ} \mathrm{F}\right)$ of the desired conditions, and the individual readings of each instrument at the inlet and outlet of each heat exchanger are within $0.56^{\circ} \mathrm{C}\left(1.0^{\circ} \mathrm{F}\right)$ of the average values of these quantities. Furthermore, the average wet-bulb temperature at the inlet of the indoor heat exchanger must be within $0.17^{\circ} \mathrm{C}\left(0.3^{\circ} \mathrm{F}\right)$ of the desired conditions with the individual readings within $0.56^{\circ} \mathrm{C}\left(1.0^{\circ} \mathrm{F}\right)$ of the average value, and the airflow rate must be within $1 \%$ of the desired value.
} 
3. To ensure system performance is maintained over the test period, the unit is retested with the baseline refrigerant to verify the system performance stability after finishing all alternative refrigerant tests.

\subsection{PREPARATION FOR DROP-IN TESTING}

ORNL used similar drop-in testing procedures as defined in the Low-GWP AREP. These procedures allow only minor modifications, if any, to the equipment. Minor modifications may include [13]:

- Adjustment of refrigerant charge quantity (by mass, the charge quantity may be different from the baseline refrigerant). It is strongly preferred to perform some type of charge optimization for each candidate refrigerant.

- Adjustment of expansion device (if adjustable).

- Adjustment of compressor speed to modify compressor flow rate, either mass flow or volumetric flow (if baseline equipment is variable-speed capable).

During the course of this program, ORNL replaced the mineral oil (46cSt) in the R-22 unit with compatible POE oil (3MAF) as recommended by the compressor manufacturer. The 3MAF POE oil was used for evaluating R-22 as well as all other alternative refrigerants. Furthermore, ORNL replaced the POE oil used in the R-410A unit with a prototype POE oil as recommended by the compressor manufacturer for the evaluation of R-32 only.

ORNL replaced the thermostatic expansion valves (TXV) on each unit with electronic expansion valves (EXV) with fixed opening control. The EXVs were used to impose the required superheat degree for the different alternative refrigerants as described in the following preparation procedure:

1. Estimate refrigerant charge based on liquid density ratio at $26.7^{\circ} \mathrm{C}\left(80^{\circ} \mathrm{F}\right)$. The initial charge should not be higher than $85 \%$ of the estimated charge

2. Evacuate the system overnight, and charge liquid refrigerant to the system liquid line as much as possible

3. Start the system, and add liquid refrigerant to the system suction line until $85 \%$ of the estimated charge. Always use a charging orifice to flash the liquid refrigerant before it enters the system

4. Add liquid refrigerant in discrete steps, and record 30 minutes data for each step to monitor system performance using the following guidelines:

- $\quad$ Add $3-5 \%$ refrigerant each step

- At each step, TXV (TXV must be adjustable) should be adjusted for proper superheat

- Superheat (dew) setting is based on baseline refrigerant superheat minus $80 \%$ of evaporator full glide divided by 2

$$
\Delta T_{\text {sup, dew }}=\Delta T_{\text {sup,baseline }}-\frac{80 \% \times \text { Evaporator Full Glide }}{2}
$$

where the glide is the difference between the dew point temperature (Tdew) and the bubble point temperature (Tbub), evaluated based on just evaporator inlet pressure (or just outlet pressure) ${ }^{\dagger}$

\footnotetext{
* "Refrigerant Charge Guidelines", Buffalo Research Laboratory, Honeywell, May 25 $5^{\text {th }}, 2016$

†The dew point temperature is a measure of the temperature at which air reaches saturation given constant pressure and number of molecules. The bubble point temperature is a measure of the temperature at which vapor bubbles begin to form in a heated liquid at a given pressure.
} 
- In case of EEV, either a new Pressure-Temp chart should be uploaded to the superheat controller or the opening of the valve must be set manually to match the superheat according to the above equation

- Subcooling (bubble point) is not controlled, and it keeps increasing - Typically at the end of charge optimization, the optimum subcooling should be close to the baseline refrigerant subcooling minus condenser full glide divided by 2

5. The optimum refrigerant charge is at the highest efficiency region and above $95 \%$ of new refrigerant maximum capacity (determined during charge optimization)

\subsection{PROCESS FOR CHANGING REFRIGERANTS AND THE LUBRICANTS}

The following steps were followed to change refrigerants between sets of tests.

1. The refrigerant is reclaimed in empty cylinders.

2. The system is put under vacuum for an extended period of time (minimum of $3 \mathrm{hr}$.) to ensure all the refrigerant is dissolved from the oil; a vacuum gauge is used to ensure system is evacuated to 300 microns.

3. Refrigerant is slowly charged from the liquid port through the refrigerant suction line.

In the case of the R-22 unit, further modifications were required after baseline testing and prior to initiating testing of the alternative refrigerants:

1. Replace mineral oil with POE oil

2. Adjust the refrigerant charge to account for R-22 absorption in POE oil

3. Run tests at all test conditions

4. Evacuate system to 300 microns over the weekend (>24 hrs.) and proceed with the alternative refrigerant evaluation

Also for the case of evaluating R-32 in the R-410A unit, the baseline POE oil had to be replaced with prototype $\mathrm{POE}$ oil based on the compressor manufacturer recommendations:

1. Replace baseline POE oil with prototype POE oil

2. Adjust the refrigerant charge to account for different R-410A miscibility in the prototype POE oil

3. Run tests at all test conditions

4. Evacuate system to 300 microns overnight ( $>24 \mathrm{hrs}$.) and proceed with R-32 evaluation

\section{RESULTS AND DISCUSSION}

\subsection{RESULTS FOR THE R-22 UNIT}

This section describes the air-side performance results for R-22 and its alternatives at all test conditions (AHRI, ISO T3, and Hot, as defined in Table 1). The four alternative refrigerants (as discussed in Section 4.2) are: L-20A (R-444B), ARM-20b, DR-7 (R-454A), and ARM-20a. All the alternatives were tested 
using POE oil as a lubricant. As discussed in Section 4.2.1, the expert panel recommended using R-22 with mineral oil as the baseline; all results in this section reflect this decision.

Table 6 shows the refrigerant charge masses used in the R-22 unit after the optimization process described in Section 5.2. The charges for the alternatives range from 14\% lower (DR-7) to 17\% lower (both ARM20a and ARM-20b) than the baseline charge.

Table 6. Optimized refrigerant charge masses for the R-22 unit

\begin{tabular}{|c|c|c|c|c|}
\hline Refrigerant & Manufacturer & $\begin{array}{c}\text { ASHRAE } \\
\text { Safety Class }\end{array}$ & $\begin{array}{c}\text { Charge Mass } \\
\text { kg (oz.) }\end{array}$ & $\begin{array}{c}\text { Charge Increase } \\
\text { vs. Baseline }\end{array}$ \\
\hline R-22 (Baseline) & - & A1 & $10.170(358)$ & N/A \\
\hline L-20A (R-444B) & Honeywell & A2L & $8.636(304)$ & $-15 \%$ \\
ARM-20b & Arkema & A2L & $8.466(298)$ & $-17 \%$ \\
DR-7 (R-454A) & Chemours & A2L & $8.722(307)$ & $-14 \%$ \\
ARM-20a & Arkema & A2L & $8.438(297)$ & $-17 \%$ \\
\hline
\end{tabular}

Table 7 summarizes the results of testing the baseline refrigerant and alternatives in the R-22 unit at AHRI and T3 conditions. At these conditions, all alternatives exhibited COPs and cooling capacities within approximately $\pm 10 \%$ of the baseline.

Table 7. Test results for $\mathrm{R}-22$ and its alternatives at moderate ambient temperatures (performance change from baseline in parentheses) ${ }^{a, b}$

\begin{tabular}{|r|c|c|c|c|}
\hline & \multicolumn{2}{|c|}{$\begin{array}{c}\text { AHRI Standard Rating Conditions } \\
\text { Outdoor: } 35.0^{\circ} \mathrm{C}\left(95^{\circ} \mathrm{F}\right)\end{array}$} & \multicolumn{2}{c|}{$\begin{array}{c}\text { ISO T3 } \\
\text { Outdoor: } 46.0^{\circ} \mathrm{C}\left(114.8^{\circ} \mathrm{F}\right) \\
\text { Indoor: } 29.0^{\circ} \mathrm{C}\left(84.2^{\circ} \mathrm{F}\right)\end{array}$} \\
& COP & $\begin{array}{c}\text { Cooling Capacity, } \\
\mathrm{kW}_{\text {th. }}\end{array}$ & COP & $\begin{array}{c}\text { Cooling Capacity, }_{\mathrm{kW}_{\text {th. }}} \\
\end{array}$ \\
\hline R-22 (Baseline) & 3.04 & 25.27 & 2.23 & 21.84 \\
\hline L-20A (R-444B) & $2.94(-3.3 \%)$ & $25.46(+0.7 \%)$ & $2.10(-5.8 \%)$ & $21.67(-0.8 \%)$ \\
\hline ARM-20b & $2.85(-6.2 \%)$ & $26.29(+4.0 \%)$ & $2.19(-1.7 \%)$ & $24.03(+10 \%)$ \\
\hline DR-7 (R-454A) & $2.86(-6.2 \%)$ & $27.15(+7.4 \%)$ & $2.00(-9.9 \%)$ & $22.76(+4.2 \%)$ \\
\hline ARM-20a & $3.21(+5.5 \%)$ & $24.58(-2.8 \%)$ & $2.18(-2.3 \%)$ & $19.58(-10.4 \%)$ \\
\hline
\end{tabular}

${ }^{a}$ Shading - green: performance improvement; blank: 0-5\% degradation; yellow: 5-10\% degradation; orange: $>10 \%$ degradation ${ }^{b} 5 \%$ losses may be nullified by system optimization, while $10 \%$ losses may require additional engineering and losses greater than $10 \%$ may require complete redesign of the unit

Table 8 summarizes the results of testing the baseline refrigerant and alternatives in the R-22 unit at high ambient temperatures. The results show a tradeoff between cooling capacity and unit efficiency; refrigerants that maintained roughly the same capacity had COP loss between -5 to $14 \%$ whereas ARM20 a showed similar COP compare with the baseline but at the cost of roughly $7 \%$ reduction in cooling capacity. 
Table 8. Test results for R-22 and its alternatives at high ambient temperatures (performance change from baseline in parentheses) ${ }^{a, b}$

\begin{tabular}{|c|c|c|c|c|}
\hline & $\begin{array}{r}\text { Hot } \\
\text { Outdoor: } \\
\text { Indoor: } 2 \\
\end{array}$ & $\begin{array}{l}\text { lbient } \\
\mathrm{C}\left(125.6^{\circ} \mathrm{F}\right) \\
\mathrm{C}\left(84.2^{\circ} \mathrm{F}\right)\end{array}$ & $\begin{array}{l}\mathbf{I} \\
\text { Ou } \\
\text { Ind }\end{array}$ & $\begin{array}{l}\text { mbient } \\
\mathrm{C}\left(131^{\circ} \mathrm{F}\right) \\
\mathrm{C}\left(84.2^{\circ} \mathrm{F}\right)\end{array}$ \\
\hline & COP & $\begin{array}{c}\text { Cooling Capacity, } \\
\mathrm{kW}_{\text {th. }}\end{array}$ & COP & $\begin{array}{c}\text { Cooling Capacity, } \\
\mathrm{kW}_{\text {th. }}\end{array}$ \\
\hline R-22 (Baseline) & 1.84 & 19.82 & \multirow{5}{*}{\multicolumn{2}{|c|}{$\begin{array}{l}\text { Results unavailable due to triggering of the } \\
\text { unit's high-pressure cutoff switch, which } \\
\text { prevented operation at these conditions }\end{array}$}} \\
\hline $\mathrm{L}-20 \mathrm{~A}(\mathrm{R}-444 \mathrm{~B})$ & $1.74(-5.3 \%)$ & $20.17(+1.8 \%)$ & & \\
\hline ARM-20b & $1.65(-10.5 \%)$ & $20.05(+1.2 \%)$ & & \\
\hline DR-7 (R-454A) & $1.58(-14 \%)$ & $19.95(+0.6 \%)$ & & \\
\hline ARM-20a & $1.86(+0.8 \%)$ & $18.48(-6.8 \%)$ & & \\
\hline
\end{tabular}

${ }^{a}$ Shading - green: performance improvement; blank: 0-5\% degradation; yellow: 5-10\% degradation; orange: $>10 \%$ degradation ${ }^{b} 5 \%$ losses may be nullified by system optimization, while $10 \%$ losses may require additional engineering and losses greater than $10 \%$ may require complete redesign of the unit

Some refrigerant mixtures result in high temperature glide (difference in saturation vapor and saturation liquid temperatures at a given saturation pressure). This results in unfavorable performance, since condensation and evaporation would no longer be constant-temperature processes. Unfortunately, evaporator temperature glide could not be calculated during testing because the evaporator inlet pressure could not be measured due to the long distribution lines between the expansion valve and the evaporator. Exact evaporator inlet and outlet pressures are required in order to accurately calculate the evaporator temperature glide.

Based on the uncertainty analysis described in Section 5.3.1, the air-side capacity has an uncertainty of $\pm 2.75 \%$ and the air-side COP has an uncertainty of $\pm 2.75 \%$ Considering these uncertainties and the potential for performance enhancements through system optimization, refrigerants with performance values within 5\% of the baseline may be expected to match the performance of R-22 with optimization; whereas refrigerants within $10 \%$ of the baseline may require only additional engineering to achieve the same performance as the baseline refrigerant. For performance losses greater than $10 \%$, significant design changes would likely be necessary to match the performance of the baseline.

\subsubsection{COP and Cooling Capacity Performance}

Figure 4 shows the COP for each refrigerant at each test condition. For all refrigerants, including R-22, the efficiency degraded with the increase in ambient temperature. The percentage of efficiency degradation associated with increasing ambient temperature was roughly consistent for both the R-22 baseline and all the alternatives; the COP degraded approximately $40 \%$ to $45 \%$ as the ambient temperature increased from AHRI to Hot conditions. The system COP was highest using ARM-20a at AHRI conditions (about 5.5\% better than the baseline) and Hot conditions (about $0.8 \%$ better than the baseline). At T3 conditions, the baseline R-22 exhibited the highest COP, with both ARM-20a and ARM20b showing COPs within approximately $2 \%$. 


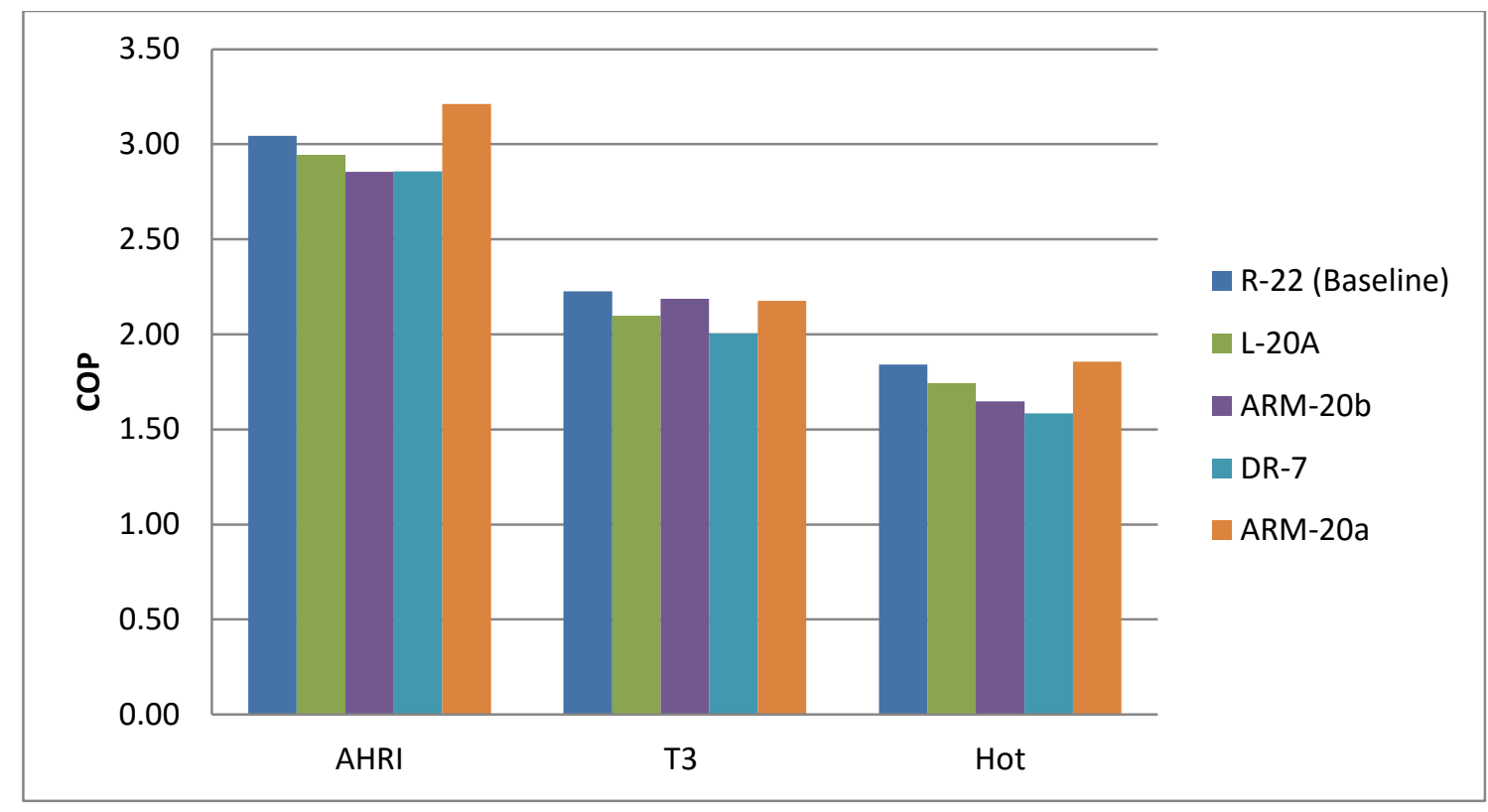

Figure 4. COP for R-22 and its alternatives at each test condition.

Figure 5 shows the cooling capacity for each refrigerant at each test condition. For all tested refrigerants, including R-22, the cooling capacity degraded as the ambient temperature increased. The amount of capacity degradation varied by refrigerant, with R-22 showing the least degradation (39\%) from AHRI to Hot conditions. The other refrigerants exhibited between $41 \%$ (L-20A) to 45\% (DR-7) degradation from AHRI to Hot conditions. Two refrigerants, ARM-20b and DR-7, exhibited cooling capacities that were better than the baseline at all three test conditions. A third refrigerant, L-20A had higher cooling capacity than the baseline at both AHRI and Hot conditions.

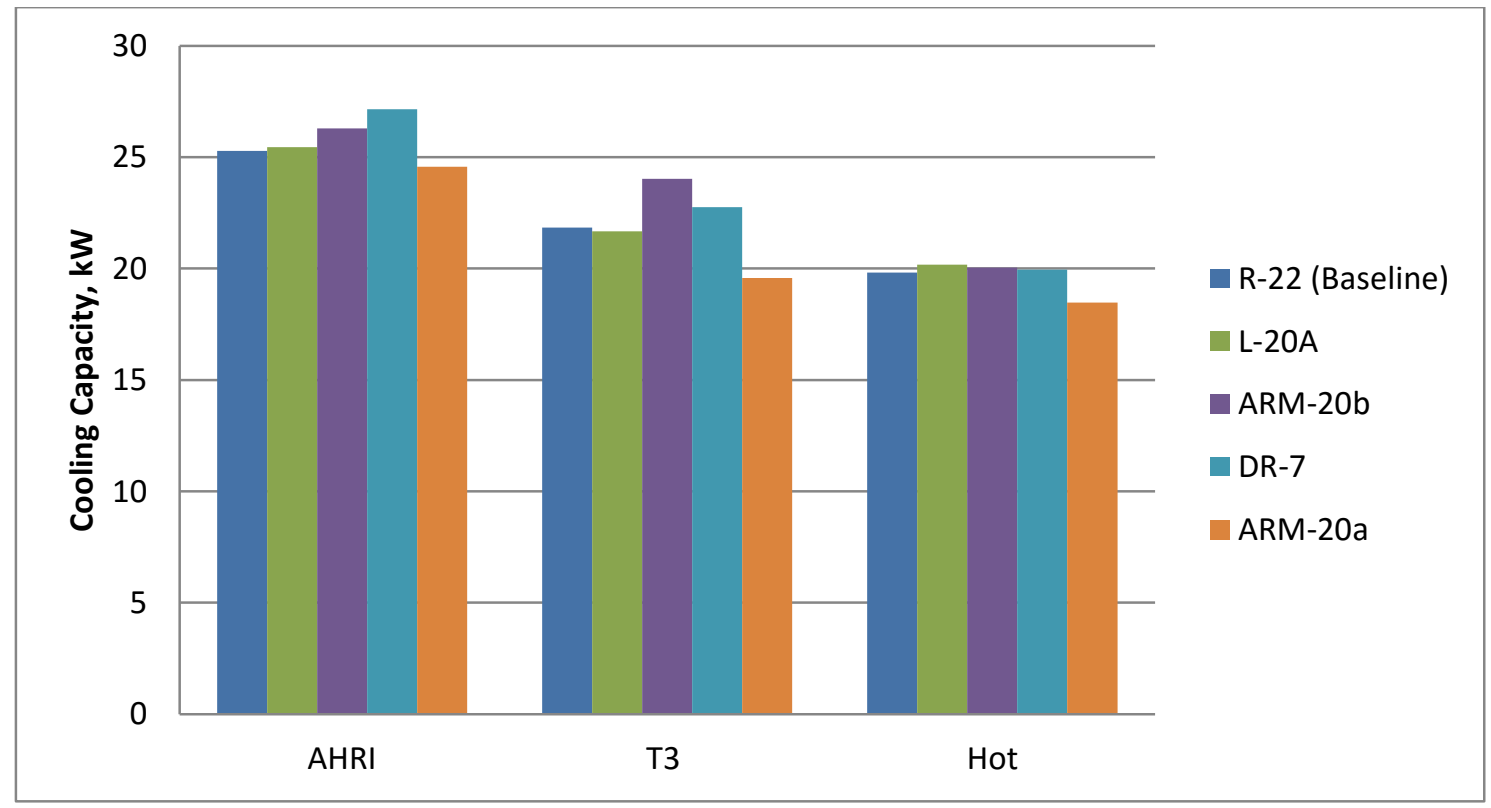

Figure 5. Cooling capacity for R-22 and its alternatives at each test condition. 


\subsubsection{Performance Relative to Baseline}

Another way to visualize the system performance using the alternative refrigerants is to normalize the COP and cooling capacity using the corresponding COP and cooling capacity of the baseline system at the same test conditions. Figure 6 compares the COP and capacity of the alternative refrigerants with the baseline under each of the test conditions.

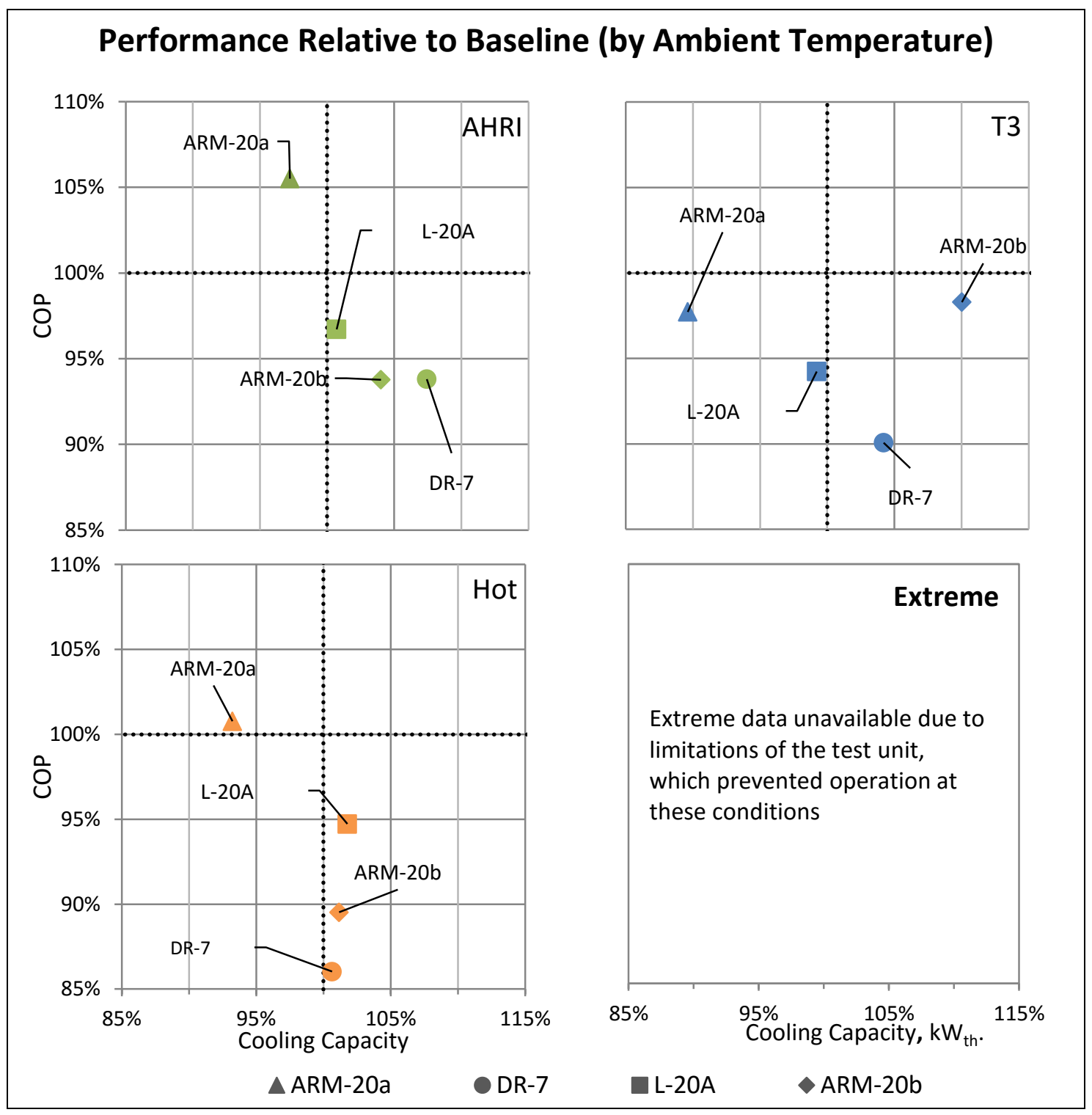

Figure 6. Performance of alternative refrigerants compared with R-22 (mineral oil) at all conditions.

At AHRI conditions, the alternative refrigerants present a tradeoff between either improved COP or improved cooling capacity, but not both. ARM-20a resulted in a COP more than 5\% better than the baseline, but with a $2.8 \%$ lower cooling capacity. The other three alternatives performed with between approximately 3 and $6 \%$ lower COP, but between approximately 1 and $7 \%$ better cooling capacity than the baseline. 
At ISO T3 conditions, ARM-20a and ARM-20b showed COPs within approximately $2 \%$ of the baseline; however, ARM-20b showed a 10\% improvement in cooling capacity while ARM-20a had a 10\% loss in cooling capacity. L-20A closely matched the baseline in cooling capacity, but had an approximately $6 \%$ lower COP. The normalized performance of all refrigerants (relative to the baseline) except ARM-20b decreased from AHRI conditions to ISO T3 conditions for both COP and cooling capacity. The performance of ARM-20b relative to the baseline in both COP and cooling capacity improved approximately $5 \%$ from AHRI conditions.

Test results at the Hot test conditions also exhibited a tradeoff between either improved COP or improved cooling capacity. ARM-20a closely matched the baseline for COP with a decrease in cooling capacity of 6.8\%. L-20A, ARM-20b, and DR-7 all showed slight (1-2\%) improvements in cooling capacity, but showed decreases in COP ranging from $-5.3 \%$ for L-20A to $-14 \%$ for DR-7. The relative performance of ARM-20a and L-20A at Hot conditions relative to the baseline improved compared to the ISO T3 results for both COP and cooling capacity. The relative performance of DR-7 versus the baseline continued to decrease from ISO T3 to Hot conditions. ARM-20b, the only refrigerant to show a relative improvement versus the baseline at ISO T3, also showed a decrease in relative performance at Hot conditions.

As discussed in Section 2.2, above, there are no test data available at Extreme test conditions for the R-22 unit.

Figure 7 shows the difference between the compressor discharge temperatures of each refrigerant compared to the baseline, at each test condition. This result is to be expected from the selected alternative refrigerants because the compressor discharge temperature is largely driven by the thermophysical properties of the alternative refrigerants. In this case the selected R-22 alternative refrigerants have lower heat capacities and therefore run at higher mass flow rates through the compressor compared to the baseline, which results in the same heat input from the compressor dissipating faster than would occur with R-22. The reduction in compressor discharge temperatures exhibited by the R-22 alternatives is beneficial and can improve compressor reliability and longevity.

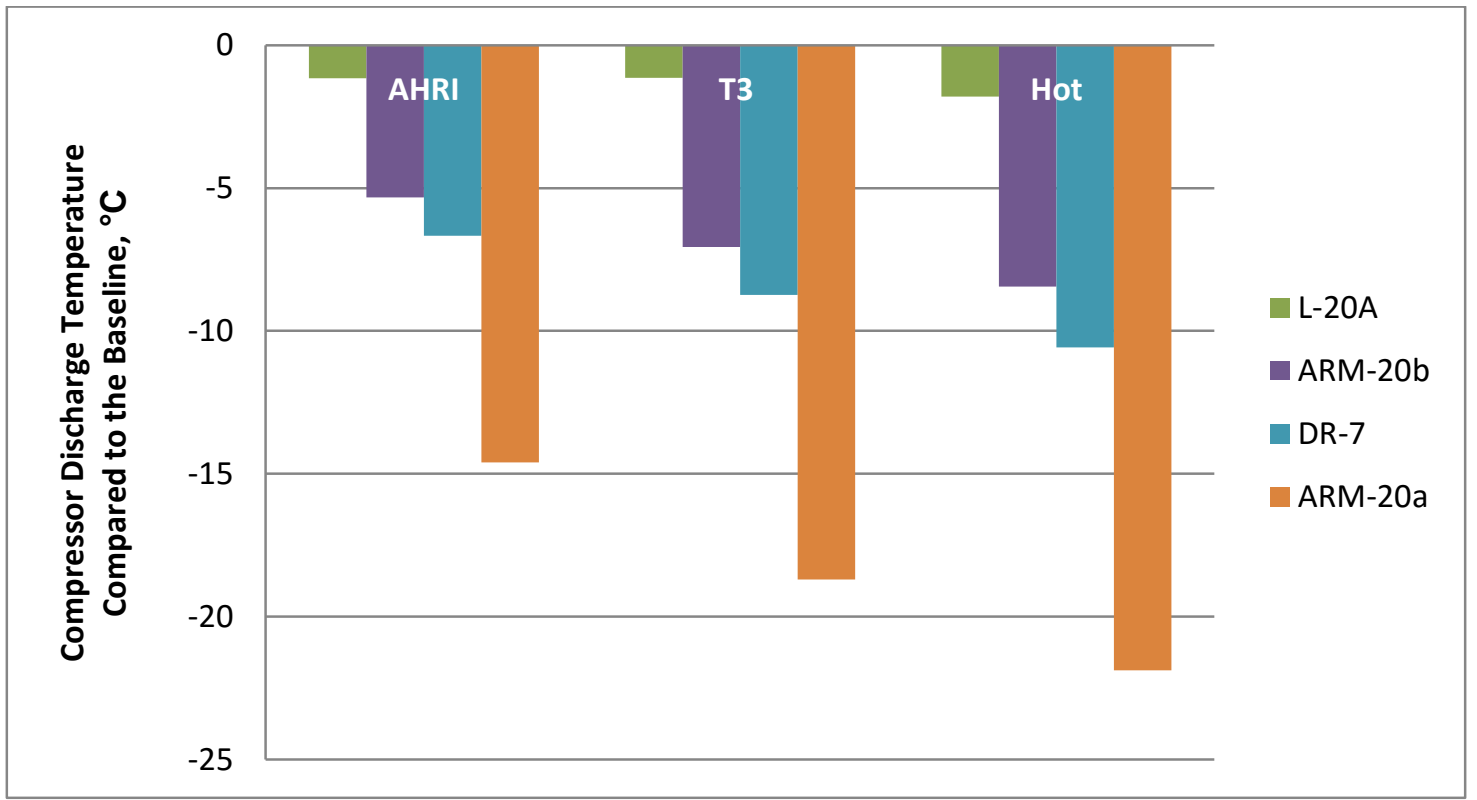

Figure 7. Compressor discharge temperature of the R-22 alternative refrigerants, with differences compared to the baseline. 


\subsubsection{Performance by Refrigerant}

Figure 8 compares the COP and capacity of the R-22 alternative refrigerants with the baseline under each of the test conditions, organized by refrigerant.

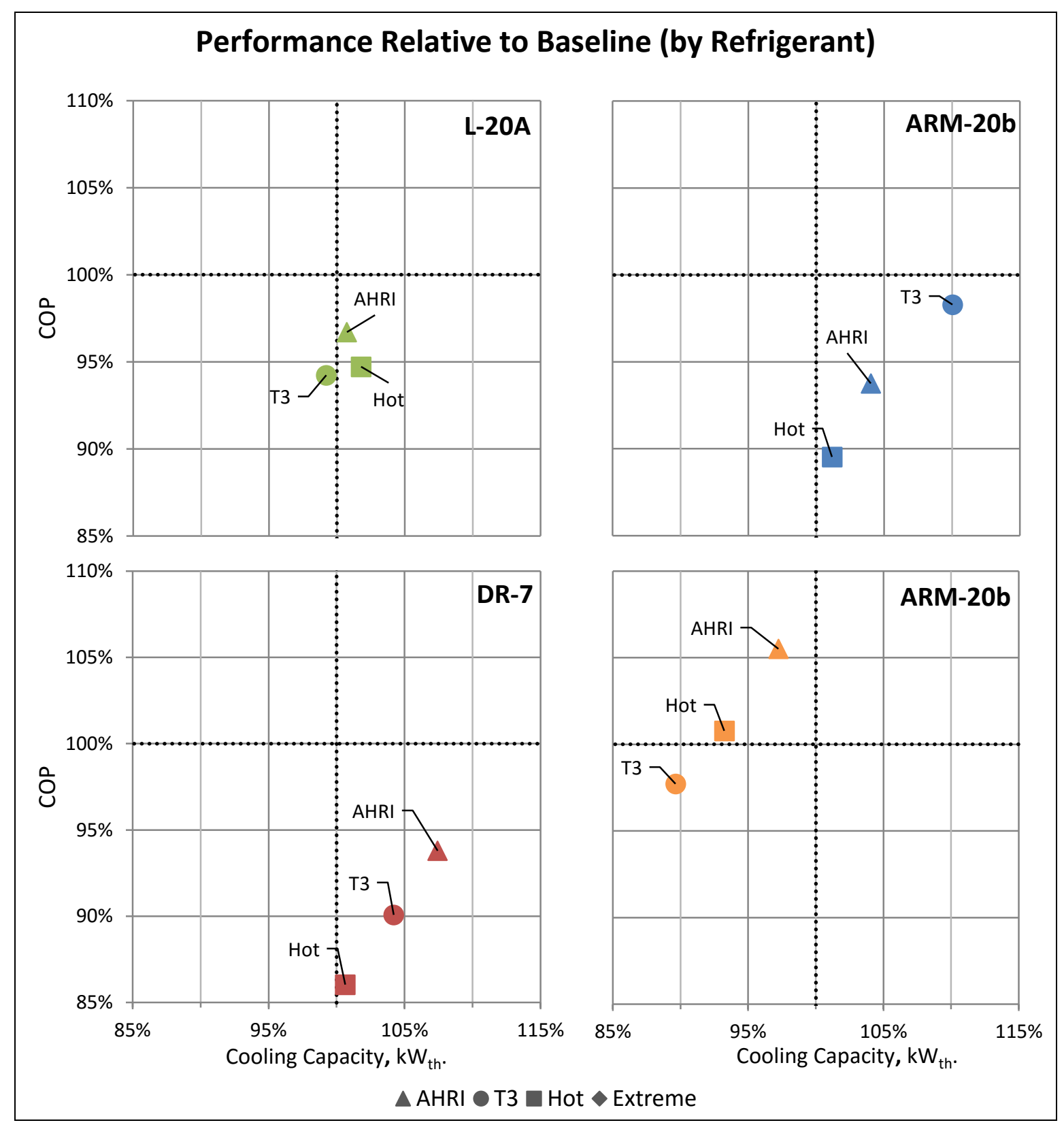

Figure 8. Performance of alternative refrigerants compared with $\mathbf{R - 2 2}$ (mineral oil) at all conditions.

The re-run of the unit with R-22 at the end of the testing (detailed results in APPENDIX D), compared with the R-22 runs at the beginning of testing showed that the unit performed within $\pm 1 \%$ for both COP and capacity. These results suggest that the extended testing with all the alternative refrigerants resulted in limited performance change and that the system reliability was not affected by the use of the alternative refrigerants. 
See APPENDIX D for comprehensive results, including detailed data tables.

\subsection{RESULTS FOR THE R-410A UNIT}

This section presents the air-side performance results for R-410A and its alternatives at all test conditions (AHRI, ISO T3, Hot, and Extreme as defined in Table 1). The four alternative refrigerants (as discussed in Section 3.2) are: DR-55 (R-452B), L41z (R-447B), ARM-71a, and R-32. All use POE oil as a lubricant.

Table 9 shows the refrigerant charge masses used in the R-410A unit after the optimization process described in Section 5.2. The charges for the alternatives range from 8\% (both L41z and ARM-71a) to $17 \%$ lower (R-32) than the baseline charge.

Table 9. Optimized refrigerant charge masses for the $\mathrm{R}-410 \mathrm{~A}$ unit

\begin{tabular}{|c|c|c|c|c|}
\hline Refrigerant & Manufacturer & $\begin{array}{c}\text { ASHRAE } \\
\text { Safety Class }\end{array}$ & $\begin{array}{c}\text { Charge Mass } \\
\text { kg (oz.) }\end{array}$ & $\begin{array}{c}\text { Charge Increase } \\
\text { vs. Baseline }\end{array}$ \\
\hline R-410A (Baseline) & - & A1 & $12.02(424)$ & N/A \\
\hline DR-55 (R-452B) & Chemours & A2L & $10.89(384)$ & $-9 \%$ \\
L41z (R-447B) & Honeywell & A2L & $11.11(392)$ & $-8 \%$ \\
ARM-71a & Arkema & A2L & $11.11(392)$ & $-8 \%$ \\
R-32 & Daikin & A2L & $9.98(352)$ & $-17 \%$ \\
\hline
\end{tabular}

Table 10 summarizes the results of testing the baseline refrigerant and alternatives in the R-410A unit at moderate ambient temperatures (AHRI and ISO T3 conditions). At these test conditions, all the alternatives performed between about -4 and $+7 \%$ of the baseline for both COP and cooling capacity.

Table 10. Test results for $R-410 A$ and its alternatives at moderate ambient temperatures (performance change from baseline in parentheses) ${ }^{a, b}$

\begin{tabular}{|c|c|c|c|c|}
\hline & \multicolumn{2}{|c|}{$\begin{array}{l}\text { AHRI Standard Rating Conditions } \\
\text { Outdoor: } 35.0^{\circ} \mathrm{C}\left(95^{\circ} \mathrm{F}\right) \\
\text { Indoor: } 26.7^{\circ} \mathrm{C}\left(80.0^{\circ} \mathrm{F}\right) \\
\end{array}$} & \multicolumn{2}{|c|}{$\begin{array}{c}\text { ISO T3 } \\
\text { Outdoor: } 46.0^{\circ} \mathrm{C}\left(114.8^{\circ} \mathrm{F}\right) \\
\text { Indoor: } 29.0^{\circ} \mathrm{C}\left(84.2^{\circ} \mathrm{F}\right)\end{array}$} \\
\hline & COP & $\begin{array}{c}\text { Cooling Capacity, } \\
\text { kW }_{\text {th. }}\end{array}$ & COP & $\begin{array}{c}\text { Cooling Capacity, } \\
\text { kW }_{\text {th. }}\end{array}$ \\
\hline R-410A (Baseline) & 3.06 & 39.37 & 2.26 & 34.32 \\
\hline DR-55 (R-452B) & $3.15(+3.0 \%)$ & $39.35(-0.1 \%)$ & $2.29(+1.4 \%)$ & $34.04(-0.8 \%)$ \\
\hline L41z (R-447B) & $3.16(+3.4 \%)$ & $37.96(-3.6 \%)$ & $2.33(+3.5 \%)$ & $33.08(-3.6 \%)$ \\
\hline ARM-71a & $3.16(+3.2 \%)$ & $38.49(-2.2 \%)$ & $2.31(+2.2 \%)$ & $33.38(-2.7 \%)$ \\
\hline R-32 & $3.12(+2.0 \%)$ & $42.12(+7.0 \%)$ & $2.23(-1.0 \%)$ & $35.64(+3.9 \%)$ \\
\hline
\end{tabular}

${ }^{a}$ Shading - green: performance improvement; blank: 0-5\% degradation; yellow: 5-10\% degradation; orange: $>10 \%$ degradation ${ }^{b} 5 \%$ losses may be nullified by optimization, while $10 \%$ losses may require additional engineering and losses greater than $10 \%$ may require complete redesign of the unit

Table 11 summarizes the results of testing the baseline refrigerant and alternatives in the R-410A unit at high ambient temperatures. At these test conditions, all the alternatives either closely matched or exceeded the performance of the baseline. 
Table 11. Test results for R-410A and its alternatives at high ambient temperatures (performance change from baseline in parentheses $)^{a, b}$

\begin{tabular}{|c|c|c|c|c|}
\hline & \multicolumn{2}{|c|}{$\begin{array}{c}\text { Hot Ambient } \\
\text { Outdoor: } 52^{\circ} \mathrm{C}\left(125.6^{\circ} \mathrm{F}\right) \\
\text { Indoor: } 29.0^{\circ} \mathrm{C}\left(84.2^{\circ} \mathrm{F}\right) \\
\end{array}$} & \multicolumn{2}{|c|}{$\begin{array}{l}\text { Extreme Ambient } \\
\text { Outdoor: } 55^{\circ} \mathrm{C}\left(131^{\circ} \mathrm{F}\right) \\
\text { Indoor: } 29.0^{\circ} \mathrm{C}\left(84.2^{\circ} \mathrm{F}\right)\end{array}$} \\
\hline & COP & $\begin{array}{c}\text { Cooling Capacity, } \\
\mathrm{kW}_{\text {th. }}\end{array}$ & COP & $\begin{array}{c}\text { Cooling Capacity, } \\
\mathrm{kW}_{\text {th. }}\end{array}$ \\
\hline R-410A (Baseline) & 1.85 & 31.01 & 1.74 & 30.37 \\
\hline DR-55 (R-452B) & $1.94(+4.9 \%)$ & $31.93(+3.0 \%)$ & $1.77(+2.1 \%)$ & $30.60(+0.8 \%)$ \\
\hline L41z (R-447B) & $2.01(+8.9 \%)$ & $31.56(+1.8 \%)$ & $1.86(+7.1 \%)$ & $30.61(+0.8 \%)$ \\
\hline ARM-71a & $1.99(+8.1 \%)$ & $31.96(+3.1 \%)$ & $1.86(+7.1 \%)$ & $31.14(+2.6 \%)$ \\
\hline $\mathrm{R}-32$ & $1.91(+3.6 \%)$ & $33.58(+8.3 \%)$ & $1.69(-2.9 \%)$ & $31.42(+3.5 \%)$ \\
\hline
\end{tabular}

${ }^{a}$ Shading - green: performance improvement; blank: 0-5\% degradation; yellow: 5-10\% degradation

${ }^{b} 5 \%$ losses may be nullified by optimization, while $10 \%$ losses may require additional engineering and losses greater than $10 \%$ may require complete redesign of the unit

Based on the uncertainty analysis described in Section 5.3.1, the air-side capacity has an uncertainty of $\pm 3.5 \%$ and the air-side COP has an uncertainty of $\pm 3.5 \%$. Considering these uncertainties and the potential for performance enhancements through system optimization, refrigerants with performance values within $5 \%$ of the baseline may be expected to match the performance of R-410A with optimization.

\subsubsection{COP and Cooling Capacity Performance}

Figure 9 shows the COP for each refrigerant at each test condition. For all refrigerants, including R-410A, the efficiency degraded with the increase in ambient temperature. The percentage of efficiency degradation associated with increasing ambient temperature was roughly consistent for both the R-410A baseline and all the alternatives; the COP degraded approximately $40 \%$ to $45 \%$ as the ambient temperature increased from AHRI to Extreme conditions. The system COP was highest using L41z at AHRI conditions ( $3.4 \%$ better than the baseline), ISO T3 conditions (3.5\% better than the baseline), and Hot conditions ( $8.9 \%$ better than the baseline). For Extreme conditions, L41z and ARM-71a both exhibited the highest COP, performing $7.1 \%$ higher than the baseline. 


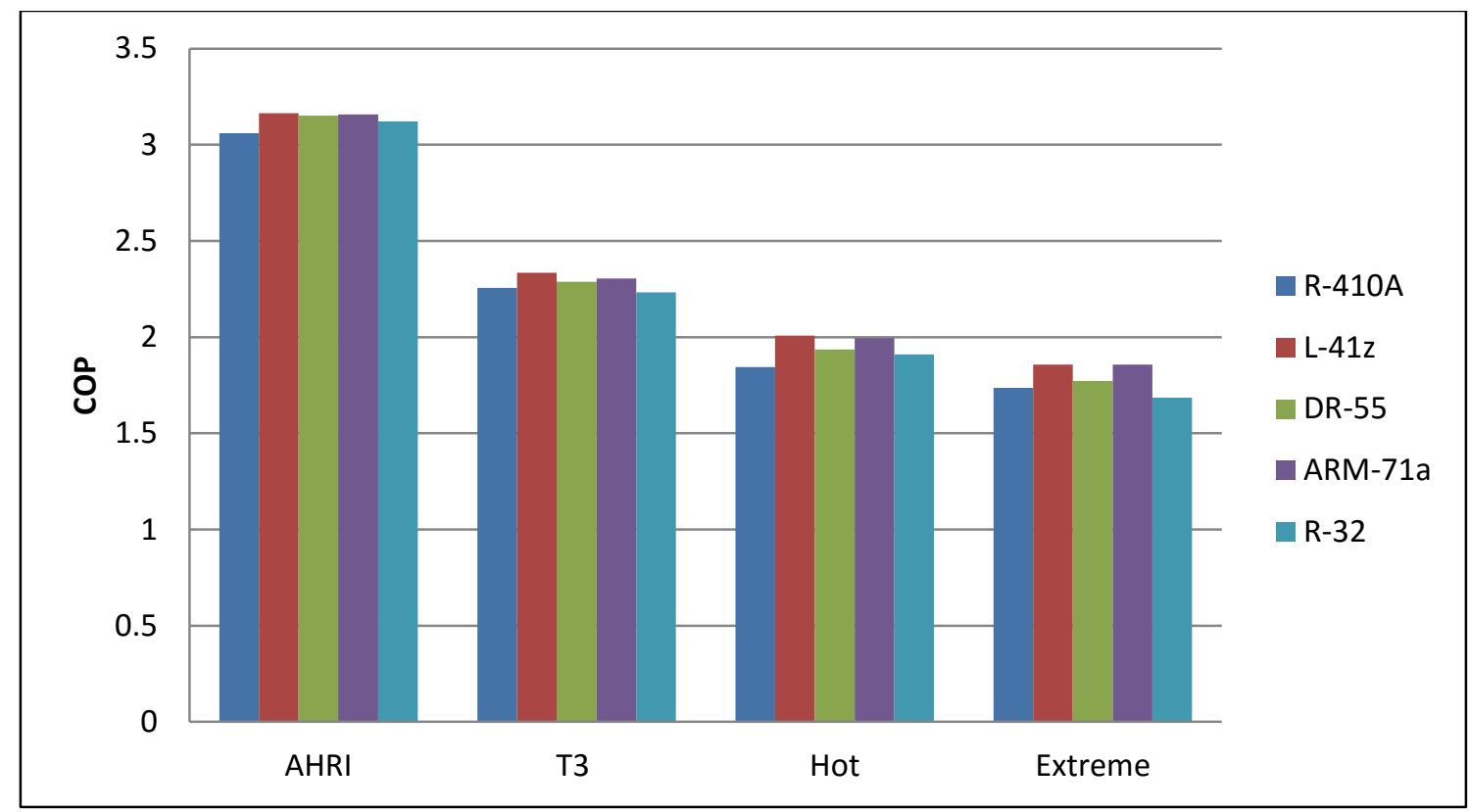

Figure 9. COP for R-410A and its alternatives at each test condition.

Figure 10 shows the cooling capacity for each refrigerant at each test condition. For all tested refrigerants, including R-410A, the cooling capacity degraded as the ambient temperature increased. The amount of capacity degradation varied by refrigerant, with ARM-71a and L41z showing the least degradation (approximately 19\%) from AHRI to Extreme conditions. The other refrigerants exhibited between 22\% (DR-55) and 25\% (R-32) degradation from AHRI to Extreme conditions. Each of the alternative refrigerants exhibited cooling capacities that closely matched or outperformed the baseline at both Hot and Extreme conditions.

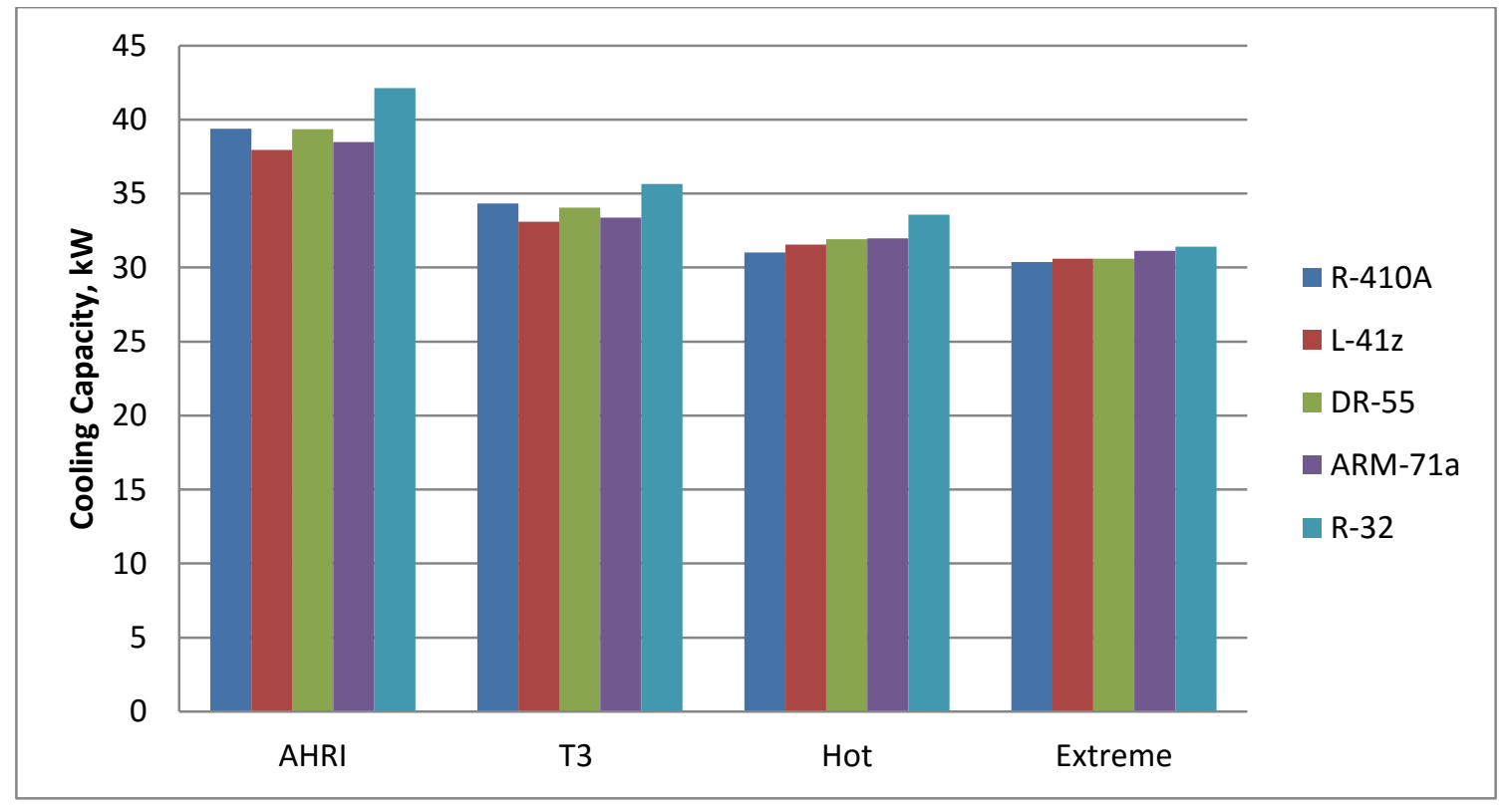

Figure 10. Cooling capacity for R-410A and its alternatives at each test condition. 


\subsubsection{Performance Relative to Baseline}

Another way to visualize the system performance using the alternative refrigerant is to normalize the COP and cooling capacity using the corresponding COP and cooling capacity of the baseline system at the same test conditions. Figure 11 compares the COP and capacity of the alternative refrigerants with the baseline under the each of the test conditions.

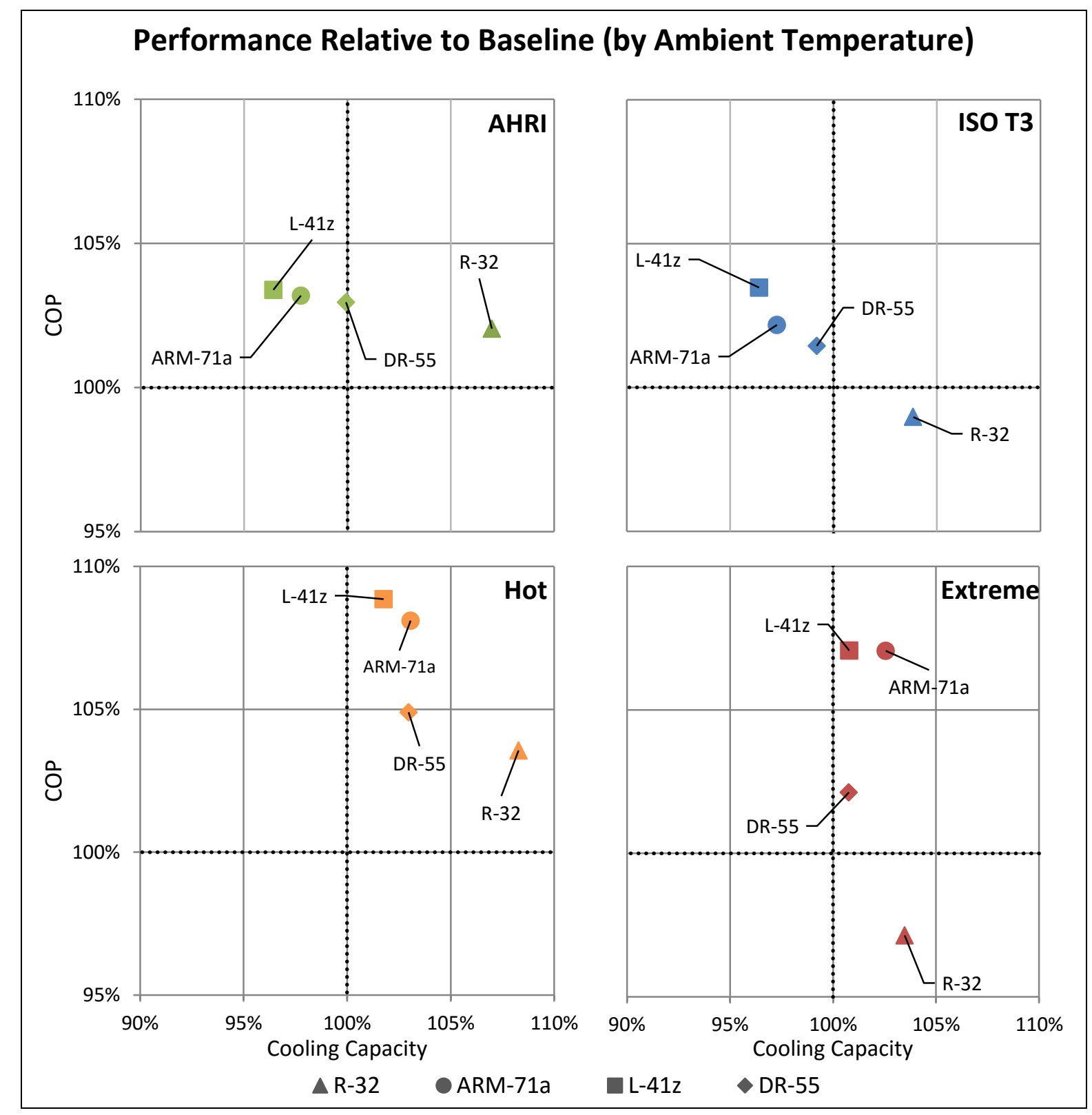

Figure 11. Performance of alternative refrigerants compared with R-410A at each test condition.

At AHRI test conditions, each of the alternative refrigerants resulted in a COP approximately $3 \%$ better than the baseline. Cooling capacity results showed varying levels of degradation (within $3.6 \%$ of the baseline) for each of the refrigerants except R-32, for which capacity increased approximately $7 \%$. 
At ISO T3 test conditions, L41z showed the highest COP, approximately $4 \%$ higher than the baseline, while ARM-71a and DR-55 experienced COPs approximately 1-2\% higher than the baseline. R-32 was the only alternative refrigerant with a COP lower than the baseline (1\% lower). The relative performance at ISO T3 (compared to the baseline) of all refrigerants except L41z decreases compared to the AHRI results for both COP and cooling capacity. The performance of L41z relative to the baseline in both COP and cooling capacity is higher at ISO T3 than at AHRI conditions.

At the Hot test conditions, the results for all the alternatives showed improvement in both COP (4-9\%) and capacity $(2-8 \%)$ relative to the baseline. The relative performance of each of the alternative refrigerants versus the baseline at Hot conditions improved compared to the ISO T3 results for both COP and cooling capacity.

At Extreme test conditions, as seen at Hot conditions, the results for ARM-71a and DR-55 show an improved COP $(7.1 \%$ and $2.1 \%$ better, respectively) and improved cooling capacity $(2.6 \%$ and $0.8 \%$ better, respectively) relative to the baseline. R-32 exceeded baseline cooling capacity by $3.5 \%$ but shows a COP approximately $3 \%$ lower than the baseline. The performance of all refrigerants at Extreme conditions relative to the baseline decreases compared to the Hot COP and cooling capacity results.

Figure 12 shows the difference between the compressor discharge temperatures of each refrigerant compared to the baseline, at each test condition. This result is to be expected from the selected alternative refrigerants because the compressor discharge temperature is largely driven by the thermophysical properties of the alternative refrigerants. In this case the selected R-410A alternatives have high heat capacities and therefore run at lower mass flow rates through the compressor compared to the baseline, which results in the same heat input from the compressor dissipating slower than would occur with R410A. The increase in compressor discharge temperatures may impact the compressor reliability and longevity.

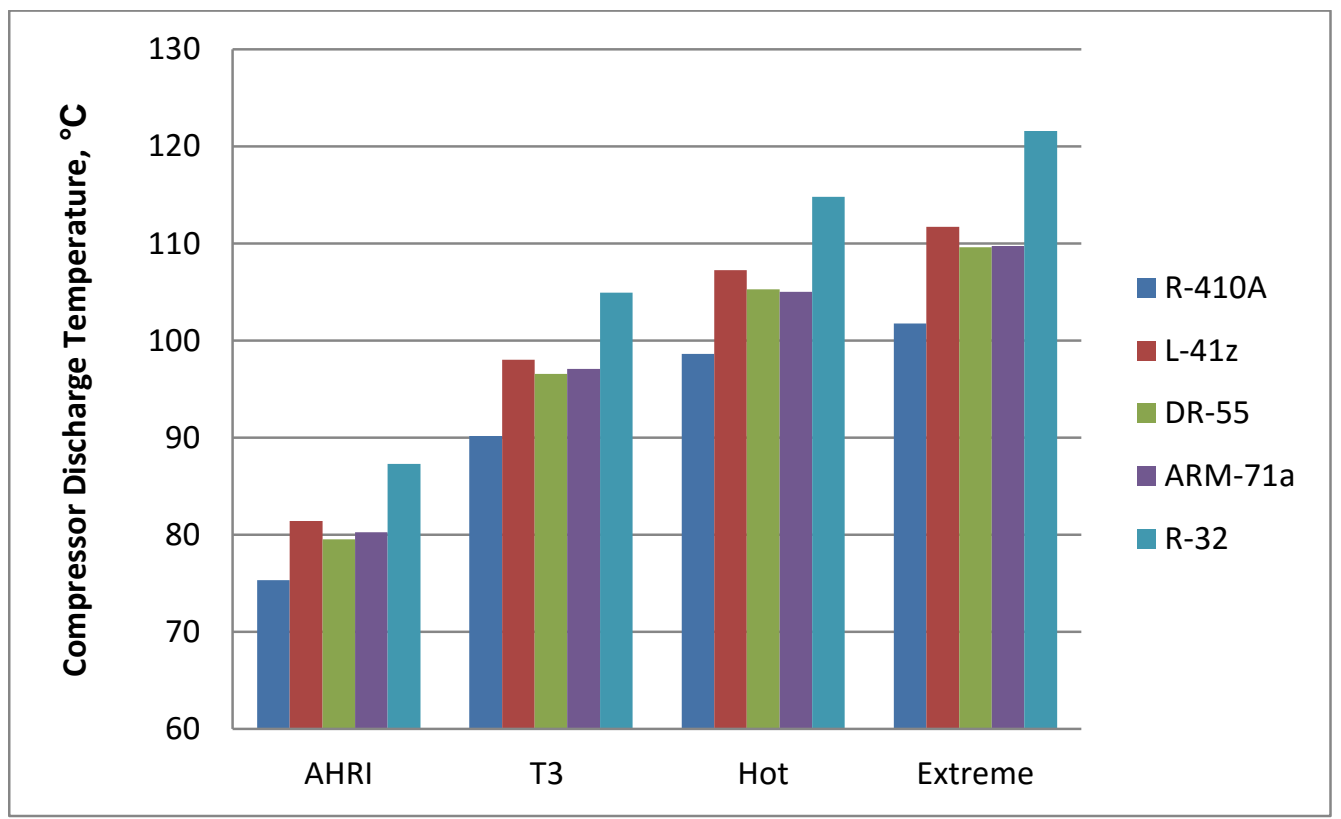

Figure 12. Compressor discharge temperature of the R-410A alternative refrigerants, with differences compared to the baseline. 


\subsubsection{Performance by Refrigerant}

Figure 13 compares the COP and capacity of the alternative refrigerants with the baseline under each of the test conditions, organized by refrigerant.

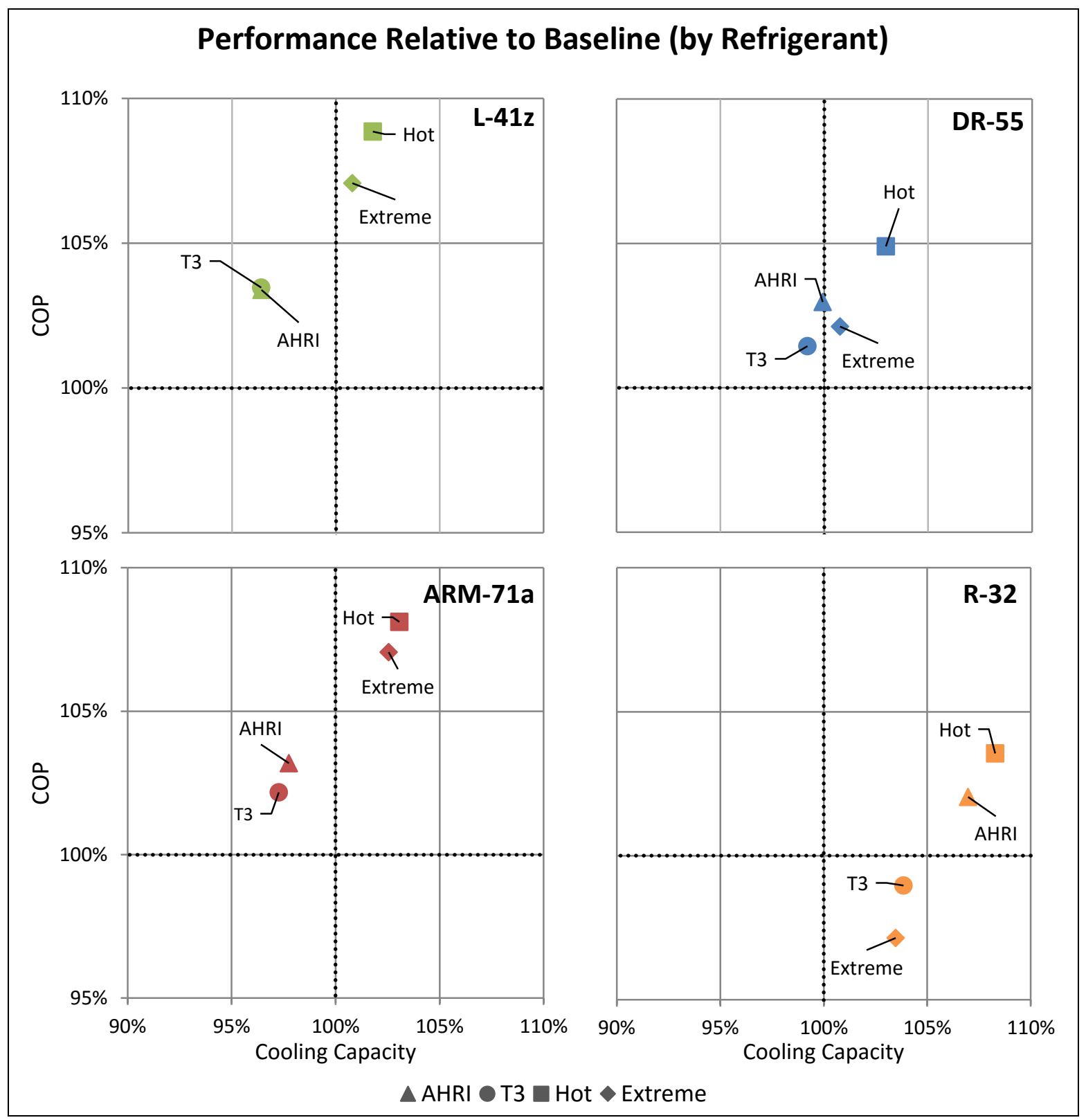

Figure 13. Performance of alternative refrigerants compared with R-22 (mineral oil) at all conditions.

The re-run of the unit with R-410A at the end of the testing (detailed results in APPENDIX E) compared with the R-410A runs at the beginning of testing showed that the unit performed within $\pm 1 \%$ for both COP and capacity. These results suggest that the extended testing with all the alternative refrigerants resulted in limited performance change and that the system reliability was not affected by the use of the alternative refrigerants.

See APPENDIX E for comprehensive results, including detailed data tables. 


\subsection{ERROR ANALYSIS}

\subsubsection{Uncertainty Analysis}

The experimental uncertainty was calculated based on the uncertainties of each of the measured variables which are propagated into the value of the calculated quantity. The method for determining this uncertainty propagation is described in NIST Technical Note 1297. [14] Assuming the individual measurements are uncorrelated and random, the uncertainty in the calculated quantity can be determined as

$$
U_{Y}=\sqrt{\sum_{i}\left(\frac{\partial Y}{\partial X_{i}}\right)^{2} U_{X_{i}}{ }^{2}}
$$

where $Y$ is the calculated quantity, $X_{i}$ is the measured variable and $U_{x i}$ is the uncertainty in the measured variable.

The uncertainty analysis, based on the instrument accuracies listed in Table C.1 and C.2, resulted in measurement uncertainty of $\pm 2.75 \%$ for both air-side capacity and COP for the R-22 unit and $\pm 3.5 \%$ for both air-side capacity and COP for the R-410A unit.

\subsubsection{Energy Balance}

ANSI/ASHRAE Standard 37* requires that the cooling capacity be evaluated both from the air side and the refrigerant side in order to establish trustworthy results by analyzing the energy balance on the system. ${ }^{\dagger}$ The investigators evaluated the airside cooling capacity using the air enthalpy method and the refrigerant side capacity was evaluated using refrigerant mass flow measurements and thermodynamic property evaluation using appropriate independent measured properties (e.g. single phase temperature and pressure). It was important to establish proper energy balance using the baseline refrigerants since for these refrigerants the thermodynamic property evaluations are established and well characterized. Table 12 shows the energy balance for both the R-22 unit and the R-410A unit at the AHRI conditions for the baseline refrigerants.

Table 12. Energy balance with baseline refrigerants

\begin{tabular}{|c|c|}
\hline Equipment & $\begin{array}{c}\text { Energy Balance at } \\
\text { AHRI Conditions }\end{array}$ \\
\hline R-22 unit with R-22 (mineral oil) & $-5.37 \%$ \\
\hline R-410A unit with R-410A (POE oil) & $4.66 \%$ \\
\hline
\end{tabular}

\section{CONCLUSIONS}

This report documents the performance evaluation of two RTUs designed to operate in high ambient environments. The first unit is designed for R-22 with a rated cooling capacity of $27.2 \mathrm{kWth}(7.7 \mathrm{TR})$ and the second unit is designed for R-410A with a rated cooling capacity of $38.7 \mathrm{kWth}(11 \mathrm{TR})$. The

\footnotetext{
* ASHRAE standards information available at: https://www.ashrae.org/standards-research--technology/standards-guidelines/titles-purposes-and-scopes

$\dagger$ The energy balance is defined as the difference between the refrigerant-side cooling capacity and the air-side cooling capacity, divided by the air-side cooling capacity.
} 
experimental facility followed the ANSI/ASHRAE Standard 37 and exhibited air-side capacity and COP measurement uncertainties of $\pm 2.75 \%$ and $\pm 2.75 \%$ for the R-22 unit, respectively, and \pm 3.5 and $\pm 3.5 \%$ for the R-410A unit, respectively. As expected, under all testing conditions, the units' performance degraded as the outdoor temperature increased.

The R-22 alternative refrigerants showed promising results; most alternatives performed within $\pm 10 \%$ of the baseline. At all test conditions, L-20A (R-444B), ARM-20b, and DR-7 (R-454A) all had cooling capacities ranging from $1 \%$ below and $10 \%$ higher than the baseline. At Hot ambient conditions, ARM20a most closely matched the COP performance of the baseline, while the other alternatives had mixed performance. All the R-22 alternative refrigerants exhibited lower compressor discharged temperatures than the baseline.

The R-410A alternative refrigerants also showed very promising results, with all refrigerants but one exhibiting COPs that exceeded the baseline at all test conditions. At high ambient temperatures (Hot and Extreme conditions), both L41z (R-447B) and ARM-71a both exceeded the COP of the baseline by more than 7\%. While R-32 experienced an improved COP relative to baseline at AHRI and Hot conditions, its ISO T3 and Extreme ambient COPs were approximately 1 to $3 \%$ lower than the baseline. Cooling capacity of all the alternatives except R-32 was within $\pm 3.6 \%$ of the baseline at all conditions. For R-32, cooling capacity was between about $3.5 \%$ and $8.3 \%$ higher than the baseline at all conditions. All the R410A alternative refrigerants exhibited higher compressor discharged temperatures than the baseline.

The efficiency and capacity of the alternative refrigerants would be expected to improve further through optimization and design modifications that manufacturers would conduct before introducing a new product to market. However, given that the scope of this study covered only drop-in testing, no detailed assessment can be made as to the extent of potential improvements through design changes. The fact that the units tested for this report did not include any optimization to account for the different performance characteristics of the alternative refrigerants likely indicates that the data presented here are conservative results that could improve through further optimization. Additional optimization, including heat transfer circuiting and proper compressor sizing and selection, would likely yield better performance results for all of the alternative refrigerants.

Losses in cooling capacity are typically easier to recover through engineering optimization compared to losses in COP. The primary practical limit to improvements in capacity is the physical size of the unit, but that is not expected to be a significant concern in this case based on the magnitude of the capacity losses exhibited in this evaluation program, where such losses were observed. Thus, the COP losses and the increase in compressor discharge temperature are particularly important results of this testing program, in that these variables will be the primary focus of future optimization efforts.

This performance evaluation shows that viable replacements exist for RTUs using either R-22 or R-410A at high-ambient temperatures. Multiple alternatives for R-22 performed well, and all R-410A alternatives closely matched or exceeded the performance of R-410A. These may be considered as prime-candidate lower-GWP refrigerants for high-ambient-temperature environments. Before commercialization, engineering optimization by manufacturers can address any performance losses, the increase in compressor discharge temperature that the R-410A alternatives exhibited, and any safety concerns associated with mildly flammable alternatives. 


\section{REFERENCES}

[1] IPCC, 2007: Climate Change 2007: The Physical Science Basis. Contribution of Working Group I to the Fourth Assessment Report of the Intergovernmental Panel on Climate Change [Solomon, S., D. Qin, M. Manning, Z. Chen, M. Marquis, K.B. Averyt, M. Tignor and H.L. Miller (eds.)]. Cambridge University Press, Cambridge, United Kingdom and New York, NY, USA; section 2.10.2: Direct Global Warming Potentials. Available: https://www.ipcc.ch/publications_and_data/ar4/wg1/en/contents.html

[2] IPCC, 2013. Myhre, G., D. Shindell, F.-M. Bréon, W. Collins, J. Fuglestvedt, J. Huang, D. Koch, J.-F. Lamarque, D. Lee, B. Mendoza, T. Nakajima, A. Robock, G. Stephens, T. Takemura and H. Zhang, 2013: Anthropogenic and Natural Radiative Forcing. In: Climate Change 2013: The Physical Science Basis. Contribution of Working Group I to the Fifth Assessment Report of the Intergovernmental Panel on Climate Change [Stocker, T.F., D. Qin, G.-K. Plattner, M. Tignor, S.K. Allen, J. Boschung, A. Nauels, Y. Xia, V. Bex and P.M. Midgley (eds.)]. Cambridge University Press, Cambridge, United Kingdom and New York, NY, USA. Available: https://www.ipcc.ch/pdf/assessmentreport/ar5/wg1/WG1AR5 Chapter08 FINAL.pdf.

[3] Xu Y., Zaelke D., Velders G. J. M., \& Ramanathan V. (2013) The role of HFCs in mitigating 21st century climate change, ATMOS. CHEM. PHYS. 13:6083-6089; see also Hare B. et al. (2012) CLOSING THE 2020 EMISSIONS GAP: ISSUES, OPTIONS AND STRATEGIES; and Ramanathan V. \& Xu Y. (2010) The Copenhagen Accord for limiting global warming: Criteria, constraints, and available avenues, PROC. NAT'L ACAD. SCI. U.S.A. 107:8055-8062

[4] UNEP \& UNIDO Presentation, EGYPRA - Testing Low-GWP Refrigerants for Air Conditioning in Egypt, June 2015.

[5] El-Talouny, A. \& Nielsen, O. (2014) Promoting Low-GWP Refrigerants for Air-Conditioning Sectors in High-Ambient Temperature Countries (PRAHA), UNEP and UNIDO, OzonAction Fact Sheet November 2014, available at http://www.unep.org/ozonaction/Portals/105/documents/events/MOP26/Fact\%20Sheet\%20Promoting \%20low-GWP\%20Refrigerants\%20for\%20Air-Conditioning\%20Sectors\%20in\%20HighAmbient\%20Temperature\%20Countries\%20(PRAHA).pdf

[6] AHRI, Participants' Handbook: AHRI Low-GWP Alternative Refrigerants Evaluation Program (LowGWP AREP), April 17, 2015; available: http://www.ahrinet.org/App_Content/ahri/files/RESEARCH/Participants_Handbook2015-04-17.pdf

[7] C. K. Rice, V. D. Baxter, S. A. Hern, T. P. McDowell, J. D. Munk, and B. Shen (2013) Development of a Residential Ground-Source Integrated Heat Pump, 2013 ASHRAE Winter Conference Paper, Dallas, TX

[8] V. D. Baxter, J. J. Tomlinson, R. W. Murphy, B. G. Ashdown, M. V. Lapsa (2005) Residential Heat Pump Water Heater (HPWH) Development Status - USA, Proceedings of 8th International Energy Agency Heat Pump Conference, Las Vegas, NV

[9] CFC project phase-out summary available: http://homer.ornl.gov/sesa/environment/ods/ornl.pdf

[10] Fischer et al. (1997) Global Warming Impacts of Ozone-Safe Refrigerants and Refrigeration, Heating, and Air-Conditioning Technologies, available: http://www.osti.gov/scitech/biblio/555370

[11] Abdelaziz et al. (2012) Development of Low Global Warming Potential Refrigerant Solutions for Commercial Refrigeration Systems using a Life Cycle Climate Performance Design Tool, available: http://docs.lib.purdue.edu/cgi/viewcontent.cgi?article=2352\&context=iracc 
[12] Sand et al. (1997) report to US DOE, Energy and Global Warming Impacts of HFC Refrigerants and Emerging Technologies, available:

http://web.ornl.gov/sci/ees/etsd/btric/eere_research_reports/electrically_driven_heat_pumps/fluids_de velopment/cfc and hcfc replacements/tewi 3/tewi 3.pdf

[13] AHRI, Participants' Handbook: AHRI Low-GWP Alternative Refrigerants Evaluation Program (Low-GWP AREP), April 17, 2015, pp24-25; available: http://www.ahrinet.org/App_Content/ahri/files/RESEARCH/Participants_Handbook2015-04-17.pdf

[14] Taylor B.N. and Kuyatt, C.E. (1994) Guidelines for Evaluating and Expressing the Uncertainty of NIST Measurement Results, National Institute of Standards and Technology Technical Note 1297. 
APPENDIX A. EXPERT PANEL - BIOGRAPHIES 



\section{APPENDIX A. EXPERT PANEL - BIOGRAPHIES}

Brief biographies of the panel members are included below.

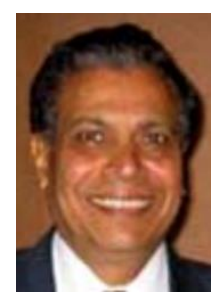

\section{Dr. Radhey Agarwal (India)}

Radhey Agarwal is a Mechanical Engineer and received his Ph.D. from the Indian Institute of Technology Delhi (India) in 1975. He specializes in refrigeration, air-conditioning, and alternative refrigerants to CFCs and HCFCs. He is a former Deputy Director (Faculty), Dean of Industrial Research \& Development and Chairman, Department of Mechanical Engineering, IIT Delhi. He was the Co-Chair, UNEP Technical Options Committee on Refrigeration, Air-conditioning and Heat Pumps (RTOC) and a member of the Technology and Economics Assessment Panel (1996-2008) of the Montreal Protocol. He has been actively contributing towards efforts to protect the ozone layer as part of the Technology and Economics Assessment Panel (UNEP TEAP) since 1989. He is the recipient of the 1998 US Environmental Protection Agency (EPA) Stratospheric Ozone Protection Award for Technical Leadership in CFC-Free Refrigeration and the 2007 US EPA Stratospheric Ozone Protection Award Best of the BEST. Dr. Agarwal was the Vice-President of IIR, Commission-B2 and member of the scientific committee of the IIR. He is a member of the American Society of Heating, Refrigerating, and Air-Conditioning Engineers (ASHRAE) and the Indian Society of Heating, Refrigerating, and Air-Conditioning Engineers (ISHRAE).

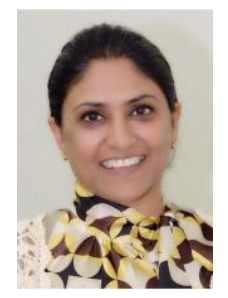

\section{Dr. Fotouh Al-Raqom (Kuwait)}

Fotouh Al-Raqom is a Manager of the Energy Efficiency Technologies Program and a research scientist at the Energy and Building Research Center (EBRC) of the Kuwait Institute for Scientific Research (KISR). She obtained her B.Sc. from Kuwait University in Mechanical engineering, M.Sc. in mechanical engineering from Northeastern University, Boston, Massachusetts, M.Sc. in aerospace engineering and $\mathrm{PhD}$ in mechanical engineering from University of Florida. She is a certified energy manager (CEM) since 2001and a Certified Sustainable Development Professional (CSDP) since 2007. She obtained several awards including the 2008 Emirates Energy Award. She is a founder of Kuwait's local chapter for the Association of Energy Engineers (AEE) and currently holding the President position. Her research interests include air-conditioning, solar fuels, hydrogen production, energy auditing, and energy efficiency. She is a member of several professional organizations including ASHRAE, ASME, AEE, and SWE. She served on Kuwait's national ozone committee from: 1998 - 2006.

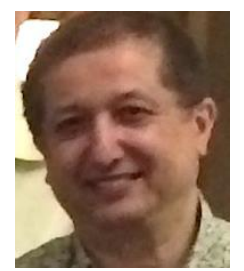

\section{Dr. Karim Amrane (USA)}

Karim Amrane is Senior Vice President of Regulatory and International Policy at the AirConditioning, Heating, and Refrigeration Institute (AHRI). He manages the industry's cooperative research program and is responsible for the development and implementation of AHRI's regulatory and international policy. He holds a Ph.D. in Mechanical Engineering from the University of Maryland at College Park (Maryland, USA) where he currently is a part-time faculty member. Dr. Amrane has over 25 years of experience in the air-conditioning and refrigeration industry. He is a member of (ASHRAE), the International Institute of Refrigeration (IIR), and the American Society of Mechanical Engineers (ASME). 


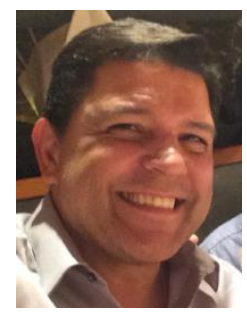

\section{Dr. Enio Bandarra (Brazil)}

Enio P. Bandarra Filho is an associate professor of mechanical engineering from the Federal University of Uberlandia (Brazil). He received his BS degree from the State University of Sao Paulo (Brazil) in 1994, and his MS and Ph.D. degrees from the University of Sao Paulo, in thermal sciences, in 1997 and 2002, respectively. In 20072008 he was a visiting professor in the heat and mass transfer laboratory at the Ecole Polytechnique Federale de Lausanne, Switzerland, working with oil-refrigerant mixtures in two-phase flow. Currently, he has 1 postdoc, 8 Ph.D., and 4 M.S. students in different areas, such as refrigeration and air-conditioning, heat transfer of nanofluids, heat exchangers, single-phase flow, control in refrigeration systems, and related topics. He published more than 260 papers in journals, book chapters, and conferences, including some awards received by the best-presented papers.

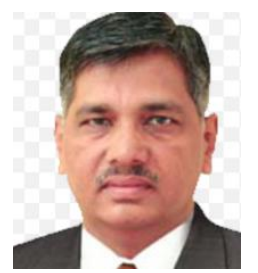

\section{Dr. Jitendra M. Bhambure (India)}

Jitendra Bhambure, who is presently the Executive Vice President - R\&D and Technology at Blue Star, received a degree in Electrical Engineering in 1979 from Bombay University (India) and a Post-Graduate degree in Management Studies from Mumbai University (India) in 1983. He joined Rallis India Ltd. in 1979 as a trainee engineer and worked there for 13 years. He was head of R\&D before he left Rallis India. He joined Blue Star in 1992, and worked in various operations, before taking charge of R\&D in 2000. He has trained in the United States, London Business School, IIM-A'bad, and at Tel Aviv University. Dr. Bhambure was the founder and President of ISHRAE Thane Sub Chapter, which over the course of 3 years has become an independent chapter. He is a member of the ISHRAE Technical Committee and an active member of the Refrigeration \& Air-Conditioning Manufacturers Association (RAMA) to represent Industry on Energy Efficiency and new refrigerants with Bureau of Energy Efficiency (BEE), Bureau of Indian Standards (BIS) and Ozone Cell under the Ministry of Environment \& Forest. He is also the Chairperson of the ozone-depleting substances committee of RAMA.

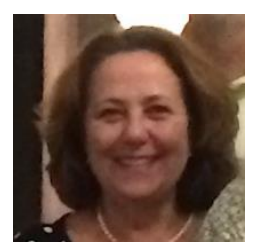

\section{Dr. Suely Machado Carvalho (co-chair; Brazil)}

Suely Carvalho is a physicist and received her Ph.D. from Purdue University (USA). She was a postdoctoral researcher at the National Superconducting Cyclotron Laboratory (NSCL), Department of Energy (DOE), at Michigan State University, East Lansing, USA (1980). As former director of the Montreal Protocol Unit and Principal Technical Adviser for Chemicals for the United Nations Development Programme in New York (2002-2013), she led the implementation of projects in over 100 developing countries to replace ozone-depleting substances in several sectors. She was the UNEP TEAP co-chair for 10 years. As the former director of Technology Transfer at the São Paulo State Environment Protection Agency, CETESB (1985-1987), she established the Climate and Ozone Protection programs at the state level. She has been involved with the Montreal Protocol nationally and internationally for 25 years. Dr. Carvalho is currently adviser to the Superintendent at the Instituto de Pesquisas Energéticas e Nucleares, IPEN-CNEN, Ministry of Science, Technology and Innovation, MCTI, São Paulo, Brazil. 


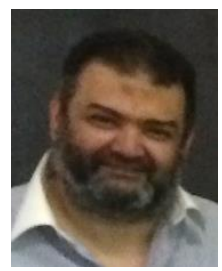

Mr. Ayman El-Talouny (UNEP)

Mr. Eltalouny holds a mechanical engineering degree from Cairo University, and specialized in the field of refrigeration and air-conditioning. Before joining the UN, he spent 10 years in the refrigeration industry and 4 years as Technical Advisor for the Egyptian Environmental Affairs Agency (EEAA) for the implementation of the Montreal Protocol. He has 20 years of experience with the Montreal Protocol at the industry, government and UN levels. Mr. Eltalouny joined UNEP in 2003 and is currently responsible for the implementation of phaseout plans of ODS in the West Asia region and is currently co-managing the UNEP-UNIDO PRAHA and EGYPRA projects for assessing low-GWP alternative refrigerants. Mr. Eltalouny is also a founding member and past president of the Bahrain ASHRAE Chapter, coordinator to the UNEP-ASHRAE and UNEP-AHRI partnerships as well as member of the drafting committees of the Arab and Egyptian Codes of refrigeration and air-conditioning.

\section{Mr. Daniel Giguère*}

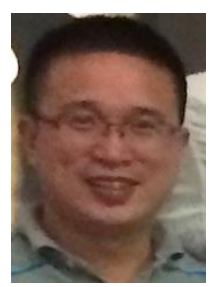

\section{Dr. Tingxun Li (China)}

Tingxun Li received his Ph.D. from SHANGHAI JIAOTONG University (China). He has been engaged in alternative refrigerant activities since 1995. As an associate professor in Sun Yat-sen University, he teaches courses in refrigeration and conducts research on airconditioning and cryogenics. He led the conversion from R-22-based to propane-based room air conditioner manufacturing at Guangdong Midea Group in a demonstration project that was funded by MLF of the Montreal Protocol. As a member of the Refrigeration and AirConditioning Technical Options Committee (RTOC) of UNEP, he is one of the authors of the 2014 RTOC report and the report of the task force. He is also a member of IEC SC61D and has been engaged in a revision of the standard IEC 60335-2-40 since 2013.

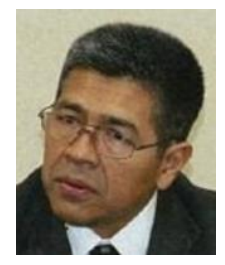

\section{Dr. Samuel Yana Motta (Peru)}

Samuel F. Yana Motta received his BS degree from the National Engineering University in his native Peru, and his Ph.D. from the Catholic University (Brazil), all in mechanical engineering. Following a guest researcher appointment at the National Institute of Standards (Thermal Machinery Group - Gaithersburg, MD, USA), he joined Honeywell as a scientist in the Buffalo Research Laboratory in 2000. At Honeywell, he participated in the development of new environment-friendly refrigerants such as HFO-1234yf and HFO-1234ze. He has also assumed positions of increasing responsibility and leadership in the development of such fluids. He now leads the Global R\&D teams responsible for developing new heat transfer fluids.

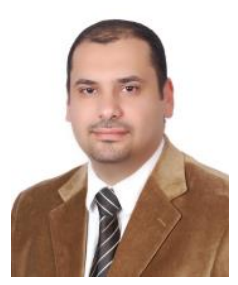

\section{Mr. Maher Mousa (Saudi Arabia)}

Maher Mousa is currently an independent consultant in HVACR industry and environmental policy; offering consultancy services both to the private and public sectors. He has been the Director of Product Development and Regulations for United Technologies BIS, Middle East/Carrier Middle East from May 2013 until June 2015. He also had the lead role in managing the laboratories and testing services at Carrier Middle

\footnotetext{
*Biography for Mr. Daniel Giguère was unavailable at the time of publishing.
} 
East with the objective of complying with international quality standards and laboratories accreditations. He is currently based in Jeddah, Saudi Arabia.

Maher Mousa started his career with Carrier Corporation in 2002. In 2011, he was working as the Product Development Manager. He led the technology transfer and development of high efficiency products with alternative refrigerants for high ambient applications in the Middle East. Prior to that, he has held several positions of increasing responsibility related to engineering and marketing.

Maher Mousa is also serving as a government advisor for energy and environmental regulations. He has contributed to the development of minimum energy efficiency regulations in Saudi Arabia and UAE. In 2013, Maher was an industry representative providing technical advisory to the regulatory authorities in KSA on Montreal Protocol implementation and impact on local HVAC industry. Currently, Maher Mousa is a member RTOC of UNEP under Montreal Protocol nominated by the Kingdom Saudi Arabia.

Maher has a Bachelor's degree and higher diploma in Mechanical Engineering from King Abdul Aziz University, Saudi Arabia, and is in the process of completing his MBA from Leicester University, UK.

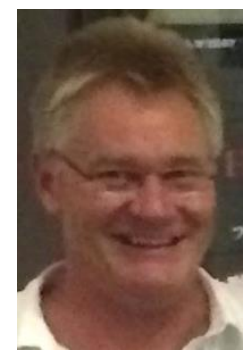

\section{Mr. Ole Nielsen (UNIDO)}

Mr. Nielsen graduated from the Technical University of Copenhagen (Denmark) in 1988 as a mechanical engineer specializing in energetics and refrigeration. He worked in the Danish refrigeration industry until 1996. Afterwards, Mr. Nielsen worked as an independent technical consultant on the Montreal Protocol project formulation and implementation until 2003. He then returned to the private sector as sales manager for refrigeration equipment. He joined the UNIDO Montreal Protocol team in 2011. Currently he is acting as Chief of the Montreal Protocol Unit. Mr. Nielsen has been involved with the Montreal Protocol since 1993 through consultancy, the private sector, and most recently through an implementing agency, with a specialty in the refrigeration and air-conditioning sectors.

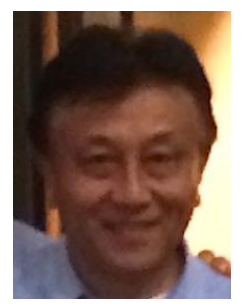

\section{Mr. Tetsuji Okada (Japan)}

Tetsuji Okada received his BS degree from the University of Tokyo (Japan) and his MS degree from the University of California, Berkeley (USA), all in mechanical engineering. He joined Mitsubishi Electric Corporation in 1980. He was engaged in the design of domestic air conditioners and the development of finned tubed-type heat exchangers until 1995. From 1995 to 1998 he researched radiation air-conditioning in the company's laboratory. He was the department manager of heat pump hot water heater development using $\mathrm{CO}_{2}$ refrigerant from 2000 to 2009 . He was transferred to the commercial air conditioners factory in Scotland as the vice president (2010-2012). Mr. Okada was the general manager of the Brussels office of Mitsubishi Electric Europe from 2012-2014 and is now the president of the Japan Refrigeration and Air Conditioner Industry Association.

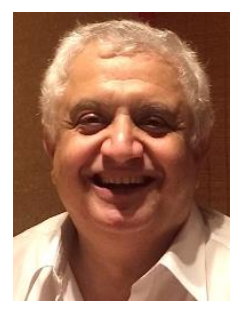

\section{Dr. Alaa Olama (Egypt)}

Alaa Olama received his M.Sc. and Ph.D. from King's College, London University (England), in mechanical engineering, specializing in refrigeration and air-conditioning. $\mathrm{He}$ is the founder, board of directors' member, and past vice chair of the first district cooling company in Egypt, GasCool. He is a member of the RTOC of UNEP. Dr. Olama is the head of the committee writing the first District Cooling code for Egypt and a 
member of the committee writing the Egyptian code of Air Conditions, Refrigeration \& Automatic Control and the Arab Refrigeration and Air-Conditioning Code. He is the past president of the Board of Directors of ASHRAE Cairo Chapter 2002-2003 and general Chair, ASHRAE, of the Second Regional Conference of Refrigeration (ARC) Region-At-Large in Cairo, September 2003. He is a member of the international reviewers' panel of the low-GWP refrigerants testing program of PRAHA and the technical advisor of EGYPRA. Dr. Olama is an independent consultant.

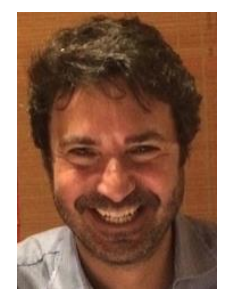

\section{Dr. Alessandro Giuliano Peru (Italy)}

Dr. Peru was a researcher at the University Consortium CUEIM, where he co-authored several research papers and technical reports for the protection of the environment. He has worked for more than 15 years in the ozone protection field. He was in charge of national plans for the phase-out of ozone-depleting and high-GWP substances from 2000 to 2010. Starting in 2006, he was in charge, as financial expert, of the mobilization of financial resources and budget of the multi-environmental agreements and member of the executive committee of the MLF for the years 2006-2007 and 2014-2015. Dr. Peru has chaired and coordinated many technical working groups at both the European and international level.

In addition, he was in charge of several bilateral and multilateral cooperation programs. In 2014, he was President of the European Union for the Montreal Protocol during the Italian Presidency of the Council of the European Union. Dr. Peru is the author of several articles and publications on environmental issues and Former Professor of Economics and Management at the Faculty of Economics at the University "La Sapienza."

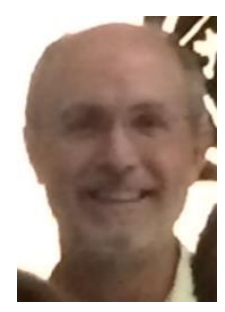

\section{Dr. Patrick Phelan (co-chair; USA)}

Patrick Phelan received his BS degree from Tulane University (New Orleans, Louisiana, USA), his MS degree from the Massachusetts Institute of Technology (USA), and his PhD from the University of California, Berkeley (USA), all in mechanical engineering. Following a 2 year postdoctoral fellowship at the Tokyo Institute of Technology (Japan), he started his academic career as an Assistant Professor at the University of Hawaii in 1992. In 1996 he moved to Arizona State University (USA), where he is a Professor of Mechanical \& Aerospace Engineering and a Senior Sustainability Scientist. While on leave from Arizona State University, he served as the Director of the National Science Foundation Thermal Transport Processes Program from 2006 to 2008, and from 2012 - 2016 as the Program Manager for Emerging Technologies in the Building Technologies Office, Energy Efficiency and Renewable Energy, US DOE. 
APPENDIX B. OTHER HIGH-AMBIENT-TEMPERATURE TESTING PROGRAMS 



\section{APPENDIX B. OTHER HIGH-AMBIENT-TEMPERATURE TESTING PROGRAMS}

\section{Comparison of high-ambient-temperature testing programs:}

Table B.1, Table B.2, and Table B.3, summarize the EGYPRA, PRAHA, and AHRI's Low-GWP AREP test programs, respectively. Low-GWP AREP includes testing of a wide range of equipment; Table B.3 covers only a subset that is directly applicable to this report.

Table B.1. EGYPRA (UNEP, UNIDO, Egypt) high-ambient-temperature testing programs

\begin{tabular}{|c|c|c|c|c|c|}
\hline Type of Test & \multicolumn{5}{|c|}{ Individual test prototypes, comparing with base units: R-22 and R-410A } \\
\hline $\begin{array}{l}\text { Number of } \\
\text { Prototypes }\end{array}$ & \multicolumn{5}{|c|}{$\begin{array}{l}36 \text { prototypes, each specific to one capacity and one refrigerant, compared with base } \\
\text { units: } R-22, \text { R-410A }\end{array}$} \\
\hline $\begin{array}{l}\text { Equipment } \\
\text { Categories (all } 50 \mathrm{~Hz} \text { ) }\end{array}$ & $\begin{array}{c}\text { Split } \\
12 \mathrm{MBH}\end{array}$ & $\begin{array}{c}\text { Split } \\
18 \mathrm{MBH}\end{array}$ & $\begin{array}{c}\text { Split } \\
24 \mathrm{MBH}\end{array}$ & $\begin{array}{l}\text { Central } \\
120 \mathrm{MBH}\end{array}$ & $\begin{array}{c}\text { Central micro } \\
\text { Channel } 120 \mathrm{MBH}\end{array}$ \\
\hline Testing Conditions & \multicolumn{5}{|c|}{ EOS 4814 and 3795 (ISO 5151), T1 conditions plus one point in T3 conditions } \\
\hline $\begin{array}{l}\text { Prototypes Supplied } \\
\& \text { Tests Performed }\end{array}$ & \multicolumn{5}{|c|}{ Prototypes built at eight OEMs, test at NREA (Local test laboratory in Egypt) } \\
\hline Refrigerants Tested & \multicolumn{5}{|c|}{$\begin{array}{l}\text { R-32, R-290, HFC/HFO blends ( } 3 \text { Types) vs. to R-22, HFC/HFO blends ( } 3 \text { Types) vs. } \\
\text { to R-410A }\end{array}$} \\
\hline $\begin{array}{l}\text { Expected Delivery } \\
\text { Dates }\end{array}$ & \multicolumn{5}{|c|}{ Fall 2016} \\
\hline Constraints & \multicolumn{5}{|c|}{$\begin{array}{l}\text { To build new prototypes with dedicated compressors for the selected refrigerants with } \\
\text { the condition to meet the same design capacities of the selected models in comparison } \\
\text { to the R-22 or R- } 410 \text { A designs }\end{array}$} \\
\hline
\end{tabular}

Table B.2. PRAHA (UNEP, UNIDO, high-ambient-temperature countries)

\begin{tabular}{|c|c|c|c|c|}
\hline Type of Test & \multicolumn{4}{|c|}{$\begin{array}{l}\text { Individual test prototypes, comparing } \\
\text { with base units: R-22 and R-410A }\end{array}$} \\
\hline $\begin{array}{l}\text { Number of } \\
\text { Prototypes }\end{array}$ & \multicolumn{4}{|c|}{$\begin{array}{l}14 \text { prototypes each specific to one capacity and one refrigerant, compared with } 9 \\
\text { additional base units using R-22 or R- } 410 \text { A }\end{array}$} \\
\hline $\begin{array}{l}\text { Equipment } \\
\text { Categories }\end{array}$ & $\begin{array}{l}\text { Window } \\
18 \mathrm{MBH}(60 \mathrm{~Hz})\end{array}$ & $\begin{array}{l}\text { Decorative Split } \\
24 \mathrm{MBH}(60 \mathrm{~Hz})\end{array}$ & $\begin{array}{l}\text { Ducted } \\
36 \mathrm{MBH}(50 \mathrm{~Hz})\end{array}$ & $\begin{array}{l}\text { Packaged } \\
90 \mathrm{MBH}(50 \mathrm{~Hz})\end{array}$ \\
\hline Testing Conditions & \multicolumn{4}{|c|}{ ISO 5151 at $\mathrm{T} 1, \mathrm{~T} 3$ and $\mathrm{T} 3+\left(50^{\circ} \mathrm{C}\right)$ and a continuity test for $2 \mathrm{hr}$ at $52^{\circ} \mathrm{C}$} \\
\hline $\begin{array}{l}\text { Prototypes Supplied } \\
\text { \& Tests Performed }\end{array}$ & \multicolumn{4}{|c|}{ Prototypes built at 6 OEMs; test at Intertek } \\
\hline Refrigerants Tested & \multicolumn{4}{|c|}{$\begin{array}{l}\text { Comparison to R-22: R-290, R-444B (L-20), DR-3 } \\
\text { Comparison to R-410A: R-32, R-447A (L-41) }\end{array}$} \\
\hline $\begin{array}{l}\text { Expected Delivery } \\
\text { Dates }\end{array}$ & \multicolumn{4}{|c|}{ Report published April 2016} \\
\hline Constraints & \multicolumn{4}{|c|}{$\begin{array}{l}\text { To build new prototypes with dedicated compressors for the selected refrigerants with the } \\
\text { condition to meet the same design capacities of the selected models in comparison to the } \\
\text { R- } 22 \text { or R- } 410 \text { A designs }\end{array}$} \\
\hline Other Components & \multicolumn{4}{|c|}{$\begin{array}{l}\text { The project includes other non-testing elements to assess relevant issues of EE standards, } \\
\text { technology transfer and economics in addition to special reporting on the potential of } \\
\text { District Cooling to reduce the use of high-GWP alternatives. }\end{array}$} \\
\hline
\end{tabular}


Table B.3. Low-GWP AREP (AHRI $)^{a}$

\begin{tabular}{|c|c|}
\hline Type of Test & Soft-optimization and drop-in tests. Baseline units vary by application. \\
\hline $\begin{array}{l}\text { Number of } \\
\text { Prototypes }\end{array}$ & $\begin{array}{l}\text { Data for } 17 \text { prototypes has been published so far; } 18 \text { reports with high-ambient- } \\
\text { temperature tests are expected in total. }\end{array}$ \\
\hline $\begin{array}{l}\text { Equipment } \\
\text { Categories (all } 60 \mathrm{~Hz})\end{array}$ & $\begin{array}{l}\text { - 056: System Soft-optimization Tests of Refrigerant R-32, DR-5A, and DR-55 in a R- } \\
\text { 410A 4-ton Unitary Rooftop Heat Pump (Cooling Mode) } \\
\text { - 055: System Soft-optimization Tests of Refrigerant R-32 in a 6-ton RTU } \\
\text { - 053: System Drop-In Test of Refrigerant Blend DR-55 in a Five-Ton R-410A RTU } \\
\text { - 047: System Drop-in Test of R-32 and Refrigerant Blends ARM-71a, HPR2A, L-41-2 } \\
\text { and DR-5A in a Five-Ton R 410A RTU } \\
\text { - 057: System Soft-optimization Tests of Refrigerant R-32 in a } 2.5 \text { ton Rooftop Heat } \\
\text { Pump }\end{array}$ \\
\hline Testing Conditions & $\begin{array}{l}\text { Varies by test report; see reports for details at: } \\
\text { http://www.ahrinet.org/Resources/Research/AHRI-Low-GWP-Alternative-Refrigerants- } \\
\text { Evaluation-Program/Reports-by-Category.aspx\#Ambient }\end{array}$ \\
\hline $\begin{array}{l}\text { Prototypes Supplied } \\
\& \text { Tests Performed }\end{array}$ & Units were manufactured or obtained by each party and tested at each party's facilities \\
\hline Refrigerants Tested & $\begin{array}{l}\text { For rooftop air-conditioning applications, the refrigerants included: DR-55, R-32, DR-5A, } \\
\text { ARM-71a, HPR2A, L-41-2. }\end{array}$ \\
\hline $\begin{array}{l}\text { Expected Delivery } \\
\text { Dates }\end{array}$ & $\begin{array}{l}\text { Phase I results have already been published; Phase II results are currently being published } \\
\text { on a rolling basis }\end{array}$ \\
\hline Constraints & $\begin{array}{l}\text { To conduct drop-in system tests and soft-optimized tests with any modifications clearly } \\
\text { indicated in the test reports }\end{array}$ \\
\hline Other Components & Compressor calorimeter tests are also performed \\
\hline
\end{tabular}

${ }^{a}$ Only includes test results that are directly related to this report. 


\section{APPENDIX C. EXPERIMENTAL TEST SETUP}





\section{APPENDIX C. EXPERIMENTAL TEST SETUP}

The code testers used for the airside flow measurement and the outdoor unit setup are shown in Figure C. 1 for the R-22 unit and Figure C.2 for the R-410A unit.
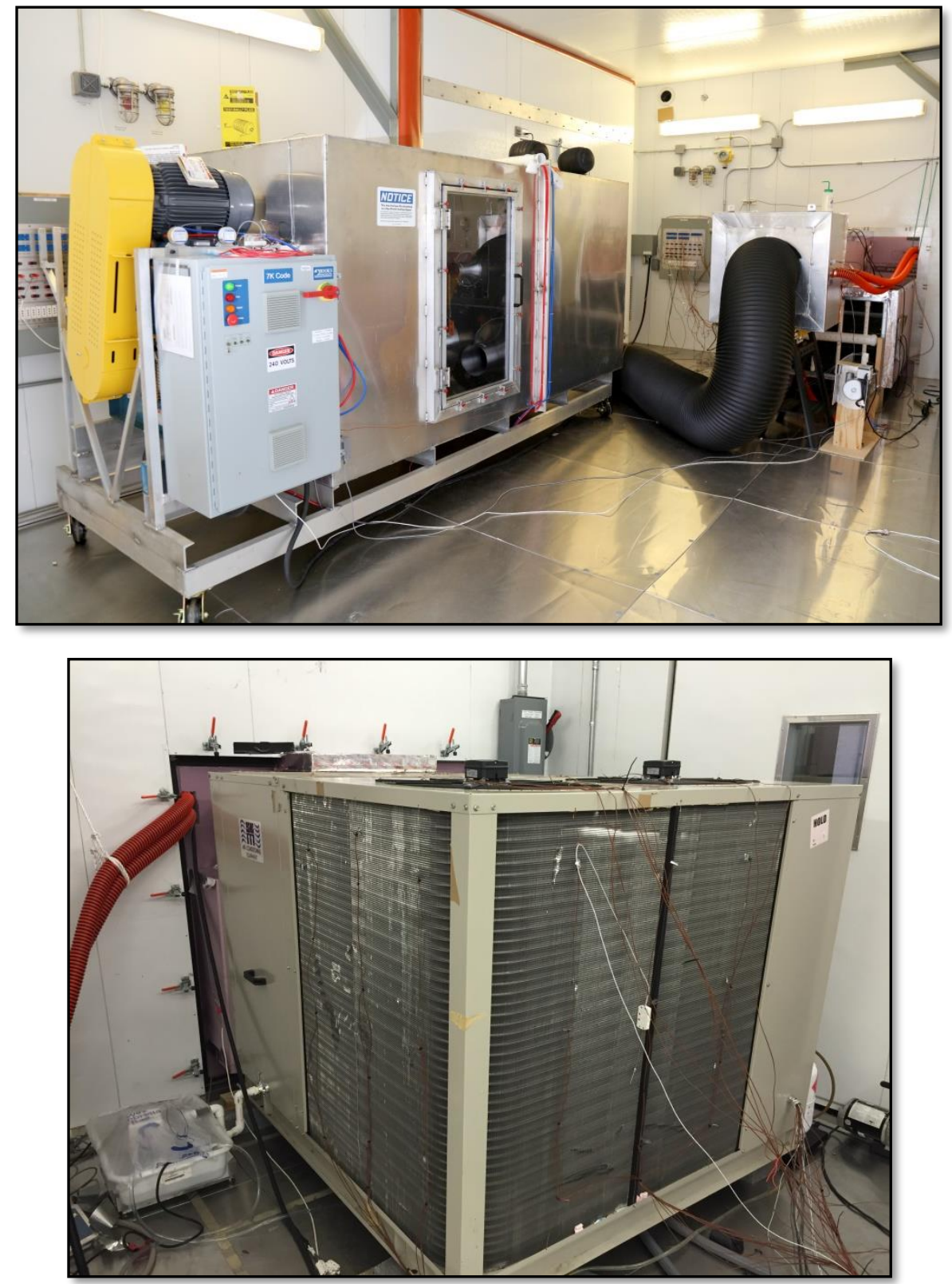

Figure C.1. As installed R-22 indoor unit. 

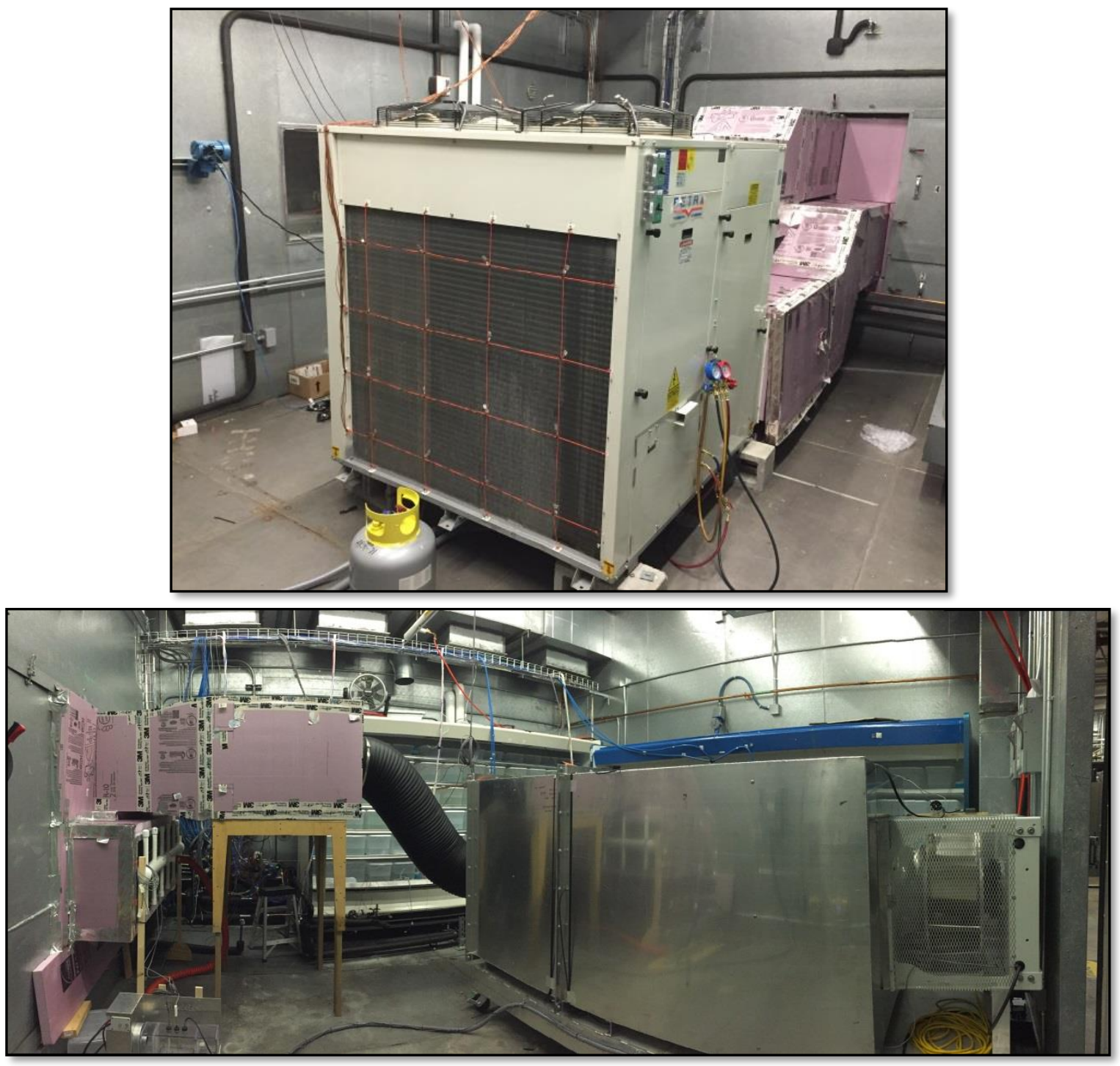

Figure C.2. As installed R-410A unit.

Table C. 1 provides a summary of the instrumentation used for testing of the R-22 unit and Table C.2 provides a summary of the instrumentation used for testing of the R-410A unit. 
Table C.1. R-22 unit experimental setup instrumentation

\begin{tabular}{|c|c|c|c|}
\hline Data & Instrument & Range and Accuracy & Comments \\
\hline $\begin{array}{l}\text { Indoor unit air } \\
\text { inlet temperature }\end{array}$ & Class-A RTD & $\begin{array}{l}-200 \text { to } 500^{\circ} \mathrm{C} \\
\pm 0.15 \pm 0.002 \times \text { t }^{\circ} \mathrm{C}\end{array}$ & \multirow{2}{*}{$\begin{array}{l}\text { Using aspirated } \\
\text { sampling } \\
\text { temperature tree }\end{array}$} \\
\hline $\begin{array}{l}\text { Indoor unit air } \\
\text { inlet wet bulb } \\
\text { temperature }\end{array}$ & $\begin{array}{l}\text { Wetted hygrometer with Class-A } \\
\text { RTD }\end{array}$ & $\begin{array}{l}-200 \text { to } 500^{\circ} \mathrm{C} \\
\pm 0.15 \pm 0.002 \times \text { t }^{\circ} \mathrm{C}\end{array}$ & \\
\hline $\begin{array}{l}\text { Indoor unit air } \\
\text { outlet temperature }\end{array}$ & Class-A RTD & $\begin{array}{l}-200 \text { to } 500^{\circ} \mathrm{C} \\
\pm 0.15 \pm 0.002 \times \text { t }^{\circ} \mathrm{C}\end{array}$ & \multirow{2}{*}{$\begin{array}{l}\text { Using aspirated } \\
\text { sampling } \\
\text { temperature tree }\end{array}$} \\
\hline $\begin{array}{l}\text { Indoor unit air } \\
\text { outlet wet bulb } \\
\text { temperature }\end{array}$ & Class-A RTD & $\begin{array}{l}-200 \text { to } 500^{\circ} \mathrm{C} \\
\pm 0.15 \pm 0.002 \times \text { t }^{\circ} \mathrm{C}\end{array}$ & \\
\hline Condensate rate & Sartorius Midrics electronic scale & $\begin{array}{l}0 \text { to } 30 \mathrm{~kg}, \\
2 \mathrm{~g} \text { readability }\end{array}$ & \\
\hline Airflow rate & $\begin{array}{l}\text { Code tester with two } 203.2 \mathrm{~mm} \\
\text { nozzles and one } 25.4 \mathrm{~mm} \text { nozzle }\end{array}$ & & \multirow{4}{*}{$\begin{array}{l}\text { Air mass flow rate } \\
\text { measurement }\end{array}$} \\
\hline $\begin{array}{l}\text { Barometric } \\
\text { pressure upstream } \\
\text { of the nozzle }\end{array}$ & $\begin{array}{l}\text { Setra model } 278 \text { barometric } \\
\text { pressure sensor }\end{array}$ & $\begin{array}{l}800 \text { to } 1100 \mathrm{hPa} / \mathrm{mb} \\
\pm 0.6 \mathrm{hPa} / \mathrm{mb}\end{array}$ & \\
\hline $\begin{array}{l}\text { Temperature } \\
\text { upstream of the } \\
\text { nozzle }\end{array}$ & T-type thermocouple & 1.7 to $79.4^{\circ} \mathrm{C}, \pm 0.28^{\circ} \mathrm{C}$ & \\
\hline $\begin{array}{l}\text { Pressure drop } \\
\text { across the nozzle }\end{array}$ & $\begin{array}{l}\text { Setra Model } 239 \text { differential } \\
\text { pressure sensor }\end{array}$ & $\begin{array}{l}0 \text { to } 2.5 \text { in. } \mathrm{H}_{2} \mathrm{O} \\
\pm 0.073 \% \text { FS }\end{array}$ & \\
\hline $\begin{array}{l}\text { External static } \\
\text { pressure }\end{array}$ & Setra 239 & $\begin{array}{l}0 \text { to } 1 \text { in. } \mathrm{H} 2 \mathrm{O} \\
\pm 0.073 \% \mathrm{FS}\end{array}$ & \\
\hline $\begin{array}{l}\text { Liquid line } \\
\text { pressure }\end{array}$ & $\begin{array}{l}\text { Omega Pressure Transducer } \\
\text { PX409 absolute pressure sensor }\end{array}$ & $\begin{array}{l}0-750 \mathrm{psia} \\
\pm 0.05 \% \mathrm{BSL}\end{array}$ & \multirow{2}{*}{$\begin{array}{l}\text { Used to evaluate } \\
\text { evaporator inlet } \\
\text { enthalpy }\end{array}$} \\
\hline \multirow[t]{2}{*}{$\begin{array}{l}\text { Liquid line } \\
\text { temperature }\end{array}$} & In-stream Class-A RTD & $\begin{array}{l}-200 \text { to } 500^{\circ} \mathrm{C} \\
\pm 0.15 \pm 0.002 \times \mathrm{t}^{\circ} \mathrm{C}\end{array}$ & \\
\hline & & $\begin{array}{l}-200 \text { to } 500^{\circ} \mathrm{C} \\
\pm 0.15 \pm 0.002 \times t^{\circ} \mathrm{C}\end{array}$ & \\
\hline $\begin{array}{l}\text { Evaporator outlet } \\
\text { pressure }\end{array}$ & $\begin{array}{l}\text { Omega Pressure Transducer } \\
\text { PX409 absolute pressure sensor }\end{array}$ & $\begin{array}{l}0 \text { to } 250 \mathrm{psiA} \\
\pm 0.05 \% \mathrm{BSL}\end{array}$ & \multirow{2}{*}{$\begin{array}{l}\text { Used to evaluate } \\
\text { evaporator outlet } \\
\text { enthalpy }\end{array}$} \\
\hline $\begin{array}{l}\text { Evaporator outlet } \\
\text { temperature }\end{array}$ & In-stream Class-A RTD & $\begin{array}{l}-200 \text { to } 500^{\circ} \mathrm{C} \\
\pm 0.15 \pm 0.002 \times t^{\circ} \mathrm{C}\end{array}$ & \\
\hline $\begin{array}{l}\text { Refrigerant mass } \\
\text { flow rate }\end{array}$ & $\begin{array}{l}\text { Micro Motion Elite CMF025 } \\
\text { Coriolis mass flow meter }\end{array}$ & $\begin{array}{l}0 \text { to } 0.19 \mathrm{~kg} / \mathrm{s} \\
\pm 0.1 \% \text { of rate }\end{array}$ & \\
\hline Total power & Power meter & $\begin{array}{l}0 \text { to } 20 \mathrm{~kW}, \pm 0.2 \% \\
\text { reading }\end{array}$ & \\
\hline
\end{tabular}




\begin{tabular}{|l|l|l|l|}
\hline Data & Instrument & Range and Accuracy & Comments \\
\hline Compressor power & Power meter & $\begin{array}{l}0-15 \mathrm{~kW}, \pm 0.2 \% \\
\text { reading }\end{array}$ & \\
\hline Outdoor fan power & Power meter & $0-4 \mathrm{~kW}, \pm 0.2 \%$ reading & \\
\hline Indoor unit power & Power meter & $0-4 \mathrm{~kW}, \pm 0.2 \%$ reading & \\
\hline
\end{tabular}

Table C.2. R-410A unit experimental setup instrumentation

\begin{tabular}{|c|c|c|c|}
\hline Data & Instrument & Range and Accuracy & Comments \\
\hline $\begin{array}{l}\text { Indoor unit air inlet } \\
\text { temperature }\end{array}$ & Class-A RTD & $\begin{array}{l}-200 \text { to } 500^{\circ} \mathrm{C} \\
\pm 0.15 \pm 0.002 \times \text { t }^{\circ} \mathrm{C}\end{array}$ & \multirow{4}{*}{$\begin{array}{l}\text { Using aspirated } \\
\text { sampling } \\
\text { temperature tree }\end{array}$} \\
\hline $\begin{array}{l}\text { Indoor unit air inlet } \\
\text { wet bulb } \\
\text { temperature }\end{array}$ & $\begin{array}{l}\text { Wetted hygrometer with Class-A } \\
\text { RTD }\end{array}$ & $\begin{array}{l}-200 \text { to } 500^{\circ} \mathrm{C} \\
\pm 0.15 \pm 0.002 \times \text { t }^{\circ} \mathrm{C}\end{array}$ & \\
\hline $\begin{array}{l}\text { Indoor unit air } \\
\text { outlet temperature }\end{array}$ & Class-A RTD & $\begin{array}{l}-200 \text { to } 500^{\circ} \mathrm{C} \\
\pm 0.15 \pm 0.002 \times \text { t }^{\circ} \mathrm{C}\end{array}$ & \\
\hline $\begin{array}{l}\text { Indoor unit air } \\
\text { outlet wet bulb } \\
\text { temperature }\end{array}$ & $\begin{array}{l}\text { Wetted hygrometer with Class-A } \\
\text { RTD }\end{array}$ & $\begin{array}{l}-200 \text { to } 500^{\circ} \mathrm{C} \\
\pm 0.15 \pm 0.002 \times \text { t }^{\circ} \mathrm{C}\end{array}$ & \\
\hline Condensate rate & Sartorius Midrics electronic scale & $\begin{array}{l}0 \text { to } 30 \mathrm{~kg}, \\
2 \text { g readability }\end{array}$ & \\
\hline Airflow rate & $\begin{array}{l}\text { Code tester with three } 203.2 \mathrm{~mm} \\
\text { nozzles }\end{array}$ & & \multirow{4}{*}{$\begin{array}{l}\text { Air mass flow rate } \\
\text { measurement }\end{array}$} \\
\hline $\begin{array}{l}\text { Barometric } \\
\text { pressure upstream } \\
\text { of the nozzle }\end{array}$ & $\begin{array}{l}\text { Setra model } 278 \text { barometric } \\
\text { pressure sensor }\end{array}$ & $\begin{array}{l}800 \text { to } 1100 \mathrm{hPa} / \mathrm{mb} \\
\pm 0.6 \mathrm{hPa} / \mathrm{mb}\end{array}$ & \\
\hline $\begin{array}{l}\text { Temperature } \\
\text { upstream of the } \\
\text { nozzle }\end{array}$ & T-type thermocouple & $\begin{array}{l}-200 \text { to } 500^{\circ} \mathrm{C} \\
\pm 0.15 \pm 0.002 \times \text { t }^{\circ} \mathrm{C}\end{array}$ & \\
\hline $\begin{array}{l}\text { Pressure drop } \\
\text { across the nozzle }\end{array}$ & $\begin{array}{l}\text { Setra Model } 239 \text { differential } \\
\text { pressure sensor }\end{array}$ & $\begin{array}{l}0 \text { to } 2.5 \text { in. } \mathrm{H}_{2} \mathrm{O} \\
\pm 0.073 \% \text { FS }\end{array}$ & \\
\hline $\begin{array}{l}\text { External static } \\
\text { pressure }\end{array}$ & Setra 239 & $\begin{array}{l}0 \text { to } 1 \text { in. } \mathrm{H} 2 \mathrm{O} \\
\pm 0.073 \% \mathrm{FS}\end{array}$ & \\
\hline $\begin{array}{l}\text { Liquid line } \\
\text { pressure }\end{array}$ & $\begin{array}{l}\text { Omega Pressure Transducer } \\
\text { PX409 absolute pressure sensor }\end{array}$ & $\begin{array}{l}0-750 \mathrm{psiA} \\
\pm 0.05 \% \mathrm{BSL} \\
\end{array}$ & \multirow{2}{*}{$\begin{array}{l}\text { Used to evaluate } \\
\text { evaporator inlet } \\
\text { enthalpy }\end{array}$} \\
\hline $\begin{array}{l}\text { Liquid line } \\
\text { temperature }\end{array}$ & In-stream Class-A RTD & $\begin{array}{l}-200 \text { to } 500^{\circ} \mathrm{C} \\
\pm 0.15 \pm 0.002 \times t^{\circ} \mathrm{C}\end{array}$ & \\
\hline $\begin{array}{l}\text { Evaporator inlet } \\
\text { temperature }\end{array}$ & In-stream Class-A RTD & $\begin{array}{l}-200 \text { to } 500^{\circ} \mathrm{C} \\
\pm 0.15 \pm 0.002 \times \mathrm{t}^{\circ} \mathrm{C}\end{array}$ & \\
\hline $\begin{array}{l}\text { Evaporator outlet } \\
\text { pressure }\end{array}$ & $\begin{array}{l}\text { Omega Pressure Transducer } \\
\text { PX409 absolute pressure sensor }\end{array}$ & $\begin{array}{l}0 \text { to } 250 \mathrm{psiA} \\
\pm 0.05 \% \mathrm{BSL}\end{array}$ & \\
\hline
\end{tabular}




\begin{tabular}{|l|l|l|l|}
\hline \multicolumn{1}{|c|}{ Data } & \multicolumn{1}{|c|}{ Instrument } & \multicolumn{1}{c|}{ Range and Accuracy } & \multicolumn{1}{c|}{ Comments } \\
\hline $\begin{array}{l}\text { Evaporator outlet } \\
\text { temperature }\end{array}$ & In-stream Class-A RTD & $\begin{array}{l}-200 \text { to } 500^{\circ} \mathrm{C} \\
\pm 0.15 \pm 0.002 \times \mathrm{t}^{\circ} \mathrm{C}\end{array}$ & $\begin{array}{l}\text { Used to evaluate } \\
\text { evaporator outlet } \\
\text { enthalpy }\end{array}$ \\
\hline $\begin{array}{l}\text { Refrigerant mass } \\
\text { flow rate }\end{array}$ & $\begin{array}{l}\text { Micro Motion Elite CMF50 } \\
\text { Coriolis mass flow meter }\end{array}$ & $\begin{array}{l}0 \text { to } 0.4158 \mathrm{~kg} / \mathrm{s}, \\
\pm 0.1 \% \text { of rate }\end{array}$ & \\
\hline Total power & Power meter & $\begin{array}{l}0 \text { to } 10 \mathrm{~kW}, \pm 0.2 \% \\
\text { reading }\end{array}$ & \\
\hline Compressor power & Power meter & $\begin{array}{l}0 \text { to } 10 \mathrm{~kW}, \pm 0.2 \% \\
\text { reading }\end{array}$ & \\
\hline Outdoor fan power & Power meter & $\begin{array}{l}0 \text { to } 800 \mathrm{~W}, \pm 0.2 \% \\
\text { reading }\end{array}$ & \\
\hline Indoor unit power & Power meter & $\begin{array}{l}0 \text { to } 2 \mathrm{~kW}, \pm 0.2 \% \\
\text { reading }\end{array}$ & \\
\hline
\end{tabular}


APPENDIX D. DETAILED R-22 TEST DATA 



\section{APPENDIX D. DETAILED R-22 TEST DATA}

This appendix provides additional details of the testing documented in Section 5.1. ORNL conducted three sets of tests with R-22, one with mineral oil (the baseline), and one with POE oil, both before any other refrigerants were tested, and one with POE oil after all alternative refrigerants had been tested. By comparing the results before and after testing the alternative refrigerants, it is possible to establish the performance reliability using the alternative refrigerants. The results for the first R-22 (POE) run and the R-22 with POE oil re-run agree within 3.8\% in terms of COP and within 3.1\% in terms of cooling capacity for all test conditions. At Hot conditions, results agreed within $1.9 \%$ and $1.6 \%$ for cooling capacity and COP, respectively.

Table D.1 shows additional test data, including

- Air-side cooling capacity

- Air-side COP

- Condenser subcooling

- Evaporator superheat

- Compressor discharge temperature

- Liquid line temperature

- Liquid line pressure

- Evaporator inlet temperature

- Evaporator outlet temperature

- Airflow

- External static pressure

- Compressor suction temperature

- Liquid line saturation temperature

- Evaporator outlet saturation temperature

- Compressor discharge saturation temperature

- Refrigerant Mass flow rate

- Energy Balance

- Refrigerant charge 
Table D.1. Complete test data for the R-22 unit

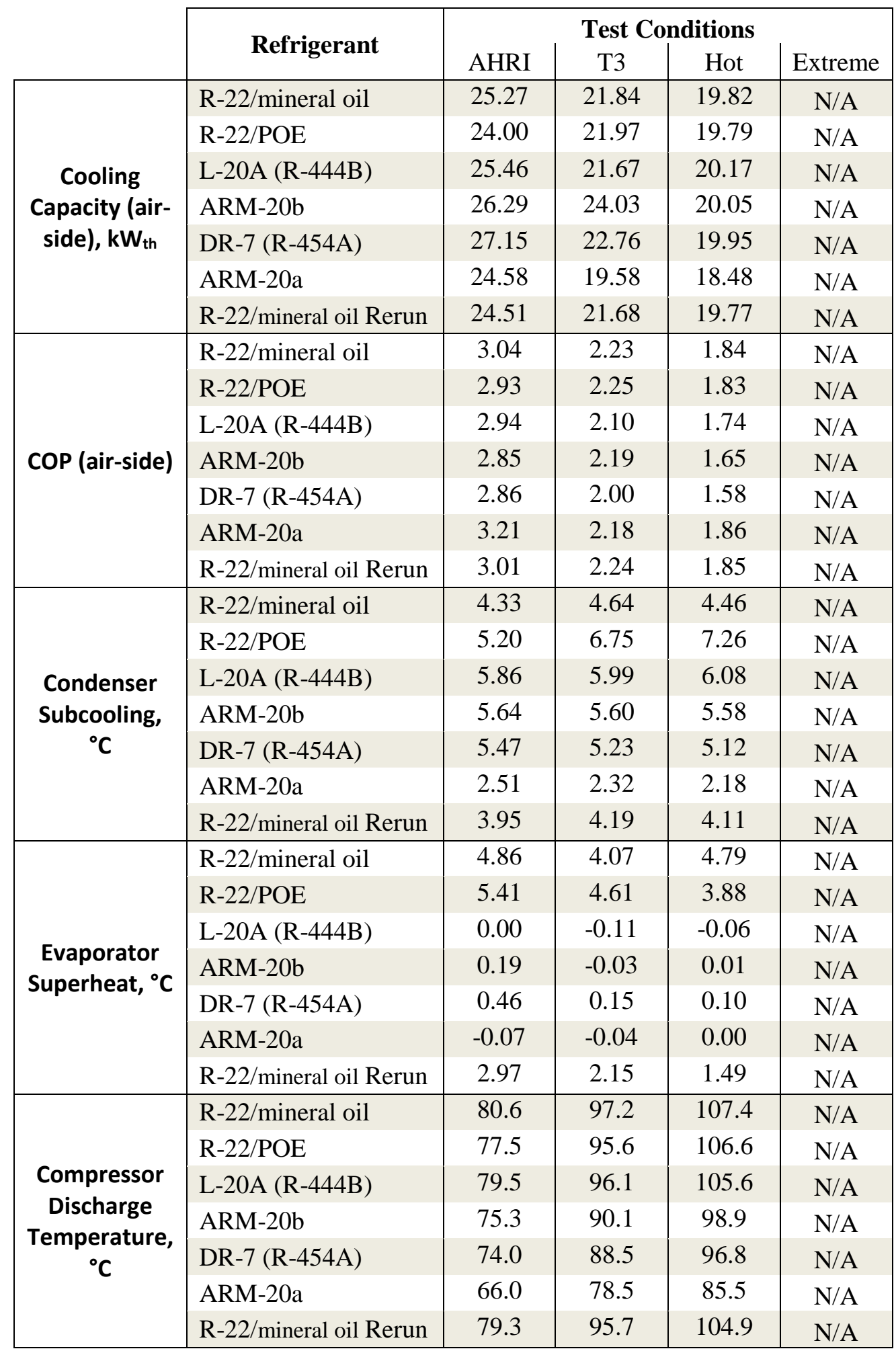


Table D.1. (continued)

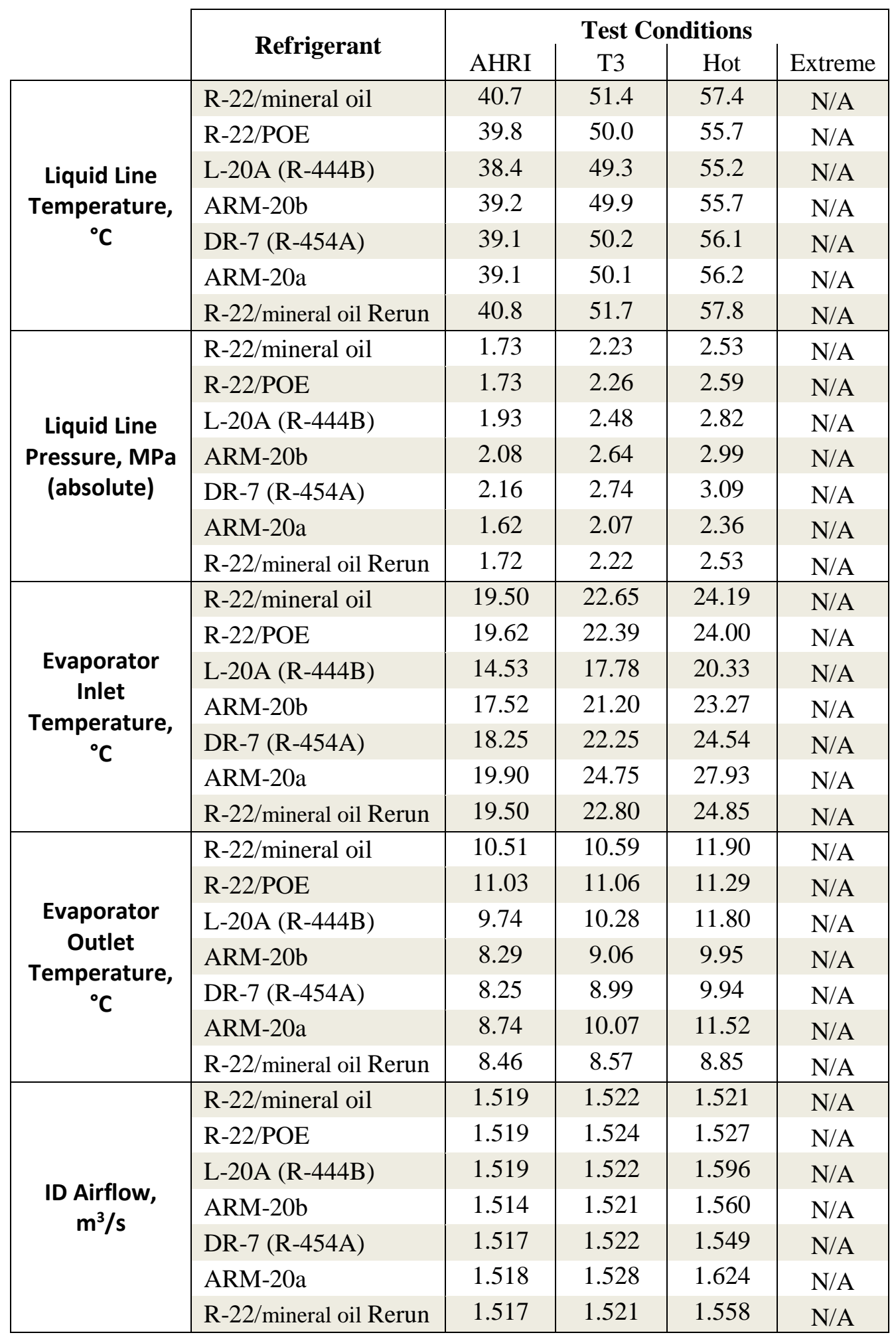

D-5 
Table D.1. (continued)

\begin{tabular}{|c|c|c|c|c|c|}
\hline & \multirow{2}{*}{ Refrigerant } & \multicolumn{4}{|c|}{ Test Conditions } \\
\hline & & AHRI & T3 & Hot & Extreme \\
\hline \multirow{7}{*}{$\begin{array}{c}\text { External } \\
\text { Static } \\
\text { Pressure, mm }\end{array}$} & $\mathrm{R}-22 /$ mineral oil & 6.37 & 6.82 & 7.25 & N/A \\
\hline & $\mathrm{R}-22 / \mathrm{POE}$ & 6.28 & 6.84 & 7.36 & N/A \\
\hline & L-20A (R-444B) & 6.05 & 6.83 & 6.48 & N/A \\
\hline & ARM-20b & 5.93 & 6.71 & 6.32 & N/A \\
\hline & DR-7 (R-454A) & 6.02 & 6.60 & 6.58 & N/A \\
\hline & ARM-20a & 6.43 & 7.58 & 6.32 & N/A \\
\hline & $\mathrm{R}-22 /$ mineral oil Rerun & 6.04 & 6.60 & 6.25 & N/A \\
\hline \multirow{7}{*}{$\begin{array}{l}\text { Compressor } \\
\text { Suction } \\
\text { Temperature, } \\
{ }^{\circ} \mathrm{C}\end{array}$} & R-22/mineral oil & 12.09 & 12.88 & 14.21 & N/A \\
\hline & $\mathrm{R}-22 / \mathrm{POE}$ & 12.16 & 13.08 & 14.04 & N/A \\
\hline & L-20A (R-444B) & 12.87 & 13.46 & 14.93 & N/A \\
\hline & ARM-20b & 12.31 & 13.27 & 14.22 & $\mathrm{~N} / \mathrm{A}$ \\
\hline & DR-7 (R-454A) & 11.96 & 13.14 & 14.19 & N/A \\
\hline & ARM-20a & 12.62 & 14.13 & 15.44 & N/A \\
\hline & R-22/mineral oil Rerun & 12.23 & 13.19 & 13.99 & N/A \\
\hline \multirow{7}{*}{$\begin{array}{c}\text { Saturation } \\
\text { Temperature, } \\
\text { Liquid Line, } \\
{ }^{\circ} \mathrm{C}\end{array}$} & R-22/mineral oil & 45.0 & 56.0 & 61.9 & N/A \\
\hline & $\mathrm{R}-22 / \mathrm{POE}$ & 45.0 & 56.7 & 62.9 & N/A \\
\hline & L-20A (R-444B) & 44.3 & 55.3 & 61.3 & $\mathrm{~N} / \mathrm{A}$ \\
\hline & ARM-20b & 44.8 & 55.5 & 61.3 & $\mathrm{~N} / \mathrm{A}$ \\
\hline & DR-7 (R-454A) & 44.6 & 55.5 & 61.2 & N/A \\
\hline & ARM-20a & 41.6 & 52.4 & 58.4 & N/A \\
\hline & R-22/mineral oil Rerun & 44.7 & 55.9 & 61.9 & N/A \\
\hline \multirow{7}{*}{$\begin{array}{c}\text { Saturation } \\
\text { Temperature, } \\
\text { Evaporator } \\
\text { Outlet, }{ }^{\circ} \mathrm{C}\end{array}$} & R-22/mineral oil & 5.65 & 6.52 & 7.11 & N/A \\
\hline & $\mathrm{R}-22 / \mathrm{POE}$ & 5.62 & 6.45 & 7.32 & N/A \\
\hline & L-20A (R-444B) & 9.74 & 10.38 & 11.87 & N/A \\
\hline & ARM-20b & 8.11 & 9.08 & 9.94 & N/A \\
\hline & DR-7 (R-454A) & 7.80 & 8.84 & 9.84 & N/A \\
\hline & ARM-20a & 8.81 & 10.10 & 11.53 & N/A \\
\hline & R-22/mineral oil Rerun & 5.49 & 6.41 & 7.36 & N/A \\
\hline \multirow{7}{*}{$\begin{array}{c}\text { Saturation } \\
\text { Temperature, } \\
\text { Compressor } \\
\text { Discharge, }{ }^{\circ} \mathrm{C}\end{array}$} & R-22/mineral oil & 47.8 & 58.1 & 63.5 & N/A \\
\hline & $\mathrm{R}-22 / \mathrm{POE}$ & 48.0 & 58.7 & 64.6 & N/A \\
\hline & L-20A (R-444B) & 53.3 & 63.2 & 68.6 & N/A \\
\hline & ARM-20b & 52.2 & 61.8 & 67.0 & N/A \\
\hline & DR-7 (R-454A) & 52.3 & 61.9 & 66.9 & N/A \\
\hline & ARM-20a & 50.4 & 60.1 & 65.6 & N/A \\
\hline & R-22/mineral oil Rerun & 47.6 & 58.0 & 63.6 & N/A \\
\hline
\end{tabular}


Table D.1. (continued)

\begin{tabular}{|c|c|c|c|c|c|}
\hline & \multirow{2}{*}{ Refrigerant } & \multicolumn{4}{|c|}{ Test Conditions } \\
\hline & & AHRI & T3 & Hot & Extreme \\
\hline \multirow{7}{*}{$\begin{array}{l}\text { Mass Flow } \\
\text { Rate, kg/min }\end{array}$} & $\mathrm{R}-22 /$ mineral oil & 9.73 & 9.71 & 9.63 & N/A \\
\hline & $\mathrm{R}-22 / \mathrm{POE}$ & 9.90 & 9.78 & N/A & N/A \\
\hline & L-20A (R-444B) & 8.13 & 8.04 & 8.20 & N/A \\
\hline & ARM-20b & 9.87 & 9.88 & 9.91 & N/A \\
\hline & DR-7 (R-454A) & 10.88 & 10.93 & 11.03 & N/A \\
\hline & ARM-20a & 9.47 & 9.70 & 10.02 & N/A \\
\hline & R-22/mineral oil Rerun & 9.73 & 9.74 & 9.84 & N/A \\
\hline \multirow{7}{*}{$\begin{array}{c}\text { Energy } \\
\text { Balance, \% }\end{array}$} & R-22/mineral oil & -5.37 & -4.67 & -3.90 & N/A \\
\hline & $\mathrm{R}-22 / \mathrm{POE}$ & 2.53 & -2.69 & -1.18 & N/A \\
\hline & L-20A (R-444B) & N/A & N/A & N/A & N/A \\
\hline & ARM-20b & N/A & N/A & N/A & N/A \\
\hline & DR-7 (R-454A) & N/A & N/A & N/A & N/A \\
\hline & ARM-20a & N/A & N/A & N/A & N/A \\
\hline & R-22/mineral oil Rerun & -3.49 & -5.11 & -3.72 & N/A \\
\hline \multirow{7}{*}{$\begin{array}{l}\text { Refrigerant } \\
\text { Charge, kg }\end{array}$} & $\mathrm{R}-22 /$ mineral oil & \multicolumn{4}{|c|}{8.335} \\
\hline & $\mathrm{R}-22 / \mathrm{POE}$ & \multicolumn{4}{|c|}{8.335} \\
\hline & L-20A (R-444B) & \multicolumn{4}{|c|}{8.618} \\
\hline & ARM-20b & \multicolumn{4}{|c|}{8.448} \\
\hline & DR-7 (R-454A) & \multicolumn{4}{|c|}{8.703} \\
\hline & ARM-20a & \multicolumn{4}{|c|}{8.420} \\
\hline & R-22/mineral oil Rerun & \multicolumn{4}{|c|}{8.335} \\
\hline
\end{tabular}


Table D.2. Data for additional tests on R-22 unit (See Table 5 for Test ID)

\begin{tabular}{|c|c|c|c|c|c|}
\hline & \multirow{2}{*}{$\begin{array}{l}\text { Test } \\
\text { ID }\end{array}$} & \multirow{2}{*}{ Refrigerant } & \multicolumn{3}{|c|}{ Test Conditions } \\
\hline & & & AHRI & T3 & Hot \\
\hline \multirow{6}{*}{$\begin{array}{c}\text { Cooling } \\
\text { Capacity (air- } \\
\text { side), kW th }\end{array}$} & $\mathrm{T} 1$ & $\mathrm{R}-22 / \mathrm{POE}$ & 24.50 & 21.94 & 19.96 \\
\hline & $\mathrm{T} 2$ & L-20A (R-444B) & 25.03 & 21.16 & 19.28 \\
\hline & $\mathrm{T} 3$ & ARM-20b & 26.04 & Not tested & Not tested \\
\hline & $\mathrm{T} 4$ & DR-7 (R-454A) & 25.70 & Not tested & Not tested \\
\hline & T5 & ARM-20a & 22.47 & Not tested & Not tested \\
\hline & T6 & ARM-20a & 20.74 & Not tested & Not tested \\
\hline \multirow{6}{*}{ COP (air-side) } & $\mathrm{T} 1$ & $\mathrm{R}-22 / \mathrm{POE}$ & 3.04 & 2.28 & 1.86 \\
\hline & $\mathrm{T} 2$ & L-20A (R-444B) & 2.96 & 2.10 & 1.71 \\
\hline & T3 & ARM-20b & 2.86 & Not tested & Not tested \\
\hline & $\mathrm{T} 4$ & DR-7 (R-454A) & 2.74 & Not tested & Not tested \\
\hline & T5 & ARM-20a & 2.98 & Not tested & Not tested \\
\hline & T6 & ARM-20a & 2.74 & Not tested & Not tested \\
\hline \multirow{6}{*}{$\begin{array}{l}\text { Condenser } \\
\text { Subcooling, } \\
{ }^{\circ} \mathrm{C}\end{array}$} & $\mathrm{T} 1$ & $\mathrm{R}-22 / \mathrm{POE}$ & 5.89 & 7.39 & 7.73 \\
\hline & $\mathrm{T} 2$ & L-20A (R-444B) & 5.92 & 5.47 & 5.40 \\
\hline & $\mathrm{T} 3$ & ARM-20b & 5.99 & Not tested & Not tested \\
\hline & $\mathrm{T} 4$ & DR-7 (R-454A) & 5.23 & Not tested & Not tested \\
\hline & T5 & ARM-20a & 3.27 & Not tested & Not tested \\
\hline & T6 & ARM-20a & 3.11 & Not tested & Not tested \\
\hline \multirow{6}{*}{$\begin{array}{c}\text { Evaporator } \\
\text { Superheat, }{ }^{\circ} \mathrm{C}\end{array}$} & $\mathrm{T} 1$ & $\mathrm{R}-22 / \mathrm{POE}$ & 4.25 & 3.32 & 2.37 \\
\hline & $\mathrm{T} 2$ & L-20A (R-444B) & 4.15 & 1.86 & 1.08 \\
\hline & T3 & ARM-20b & 3.57 & Not tested & Not tested \\
\hline & $\mathrm{T} 4$ & DR-7 (R-454A) & 3.49 & Not tested & Not tested \\
\hline & T5 & ARM-20a & 4.14 & Not tested & Not tested \\
\hline & T6 & ARM-20a & 4.05 & Not tested & Not tested \\
\hline \multirow{6}{*}{$\begin{array}{c}\text { Compressor } \\
\text { Discharge } \\
\text { Temperature, } \\
{ }^{\circ} \mathrm{C}\end{array}$} & $\mathrm{T} 1$ & $\mathrm{R}-22 / \mathrm{POE}$ & 77.57 & 96.39 & 106.59 \\
\hline & $\mathrm{T} 2$ & L-20A (R-444B) & 82.21 & 98.75 & 108.13 \\
\hline & T3 & ARM-20b & 77.77 & Not tested & Not tested \\
\hline & $\mathrm{T} 4$ & DR-7 (R-454A) & 76.13 & Not tested & Not tested \\
\hline & T5 & ARM-20a & 68.15 & Not tested & Not tested \\
\hline & T6 & ARM-20a & 68.52 & Not tested & Not tested \\
\hline
\end{tabular}


Table D.2 (continued)

\begin{tabular}{|c|c|c|c|c|c|}
\hline & \multirow{2}{*}{$\begin{array}{c}\text { Test } \\
\text { ID }\end{array}$} & \multirow{2}{*}{ Refrigerant } & \multicolumn{3}{|c|}{ Test Conditions } \\
\hline & & & AHRI & T3 & Hot \\
\hline \multirow{6}{*}{$\begin{array}{l}\text { Liquid Line } \\
\text { Temperature, } \\
{ }^{\circ} \mathrm{C}\end{array}$} & $\mathrm{T} 1$ & R-22/POE & 39.19 & 49.55 & 55.37 \\
\hline & $\mathrm{T} 2$ & $\mathrm{~L}-20 \mathrm{~A}(\mathrm{R}-444 \mathrm{~B})$ & 37.82 & 49.23 & 55.29 \\
\hline & $\mathrm{T} 3$ & ARM-20b & 38.83 & Not tested & Not tested \\
\hline & $\mathrm{T} 4$ & DR-7 (R-454A) & 39.28 & Not tested & Not tested \\
\hline & T5 & ARM-20a & 38.13 & Not tested & Not tested \\
\hline & T6 & ARM-20a & 38.75 & Not tested & Not tested \\
\hline \multirow{6}{*}{$\begin{array}{l}\text { Liquid Line } \\
\text { Pressure, } \\
\text { MPa } \\
\text { (absolute) }\end{array}$} & $\mathrm{T} 1$ & $\mathrm{R}-22 / \mathrm{POE}$ & 1.73 & 2.27 & 2.59 \\
\hline & $\mathrm{T} 2$ & $\mathrm{~L}-20 \mathrm{~A}(\mathrm{R}-444 \mathrm{~B})$ & 1.91 & 2.45 & 2.79 \\
\hline & $\mathrm{T} 3$ & ARM-20b & 2.08 & Not tested & Not tested \\
\hline & $\mathrm{T} 4$ & DR-7 (R-454A) & 2.16 & Not tested & Not tested \\
\hline & $\mathrm{T} 5$ & ARM-20a & 1.61 & Not tested & Not tested \\
\hline & T6 & ARM-20a & 1.63 & Not tested & Not tested \\
\hline \multirow{6}{*}{$\begin{array}{c}\text { Evaporator } \\
\text { Inlet } \\
\text { Temperature, } \\
{ }^{\circ} \mathrm{C}\end{array}$} & $\mathrm{T} 1$ & $\mathrm{R}-22 / \mathrm{POE}$ & 19.47 & 22.18 & 24.11 \\
\hline & $\mathrm{T} 2$ & $\mathrm{~L}-20 \mathrm{~A}(\mathrm{R}-444 \mathrm{~B})$ & 13.77 & 17.31 & 19.65 \\
\hline & $\mathrm{T} 3$ & ARM-20b & 16.98 & Not tested & Not tested \\
\hline & $\mathrm{T} 4$ & DR-7 (R-454A) & 17.81 & Not tested & Not tested \\
\hline & T5 & ARM-20a & 19.05 & Not tested & Not tested \\
\hline & T6 & ARM-20a & 19.44 & Not tested & Not tested \\
\hline \multirow{6}{*}{$\begin{array}{c}\text { Evaporator } \\
\text { Outlet } \\
\text { Temperature, } \\
{ }^{\circ} \mathrm{C}\end{array}$} & $\mathrm{T} 1$ & $\mathrm{R}-22 / \mathrm{POE}$ & 9.88 & 9.66 & 9.67 \\
\hline & $\mathrm{T} 2$ & L-20A (R-444B) & 13.37 & 11.88 & 12.41 \\
\hline & T3 & ARM-20b & 11.42 & Not tested & Not tested \\
\hline & $\mathrm{T} 4$ & DR-7 (R-454A) & 10.91 & Not tested & Not tested \\
\hline & T5 & ARM-20a & 12.57 & Not tested & Not tested \\
\hline & T6 & ARM-20a & 12.54 & Not tested & Not tested \\
\hline \multirow{6}{*}{$\begin{array}{c}\text { ID Airflow, } \\
\mathrm{m}^{3} / \mathrm{s}\end{array}$} & $\mathrm{T} 1$ & $\mathrm{R}-22 / \mathrm{POE}$ & 1.521 & 1.524 & 1.559 \\
\hline & $\mathrm{T} 2$ & $\mathrm{~L}-20 \mathrm{~A}(\mathrm{R}-444 \mathrm{~B})$ & 1.517 & 1.520 & 1.582 \\
\hline & T3 & ARM-20b & 1.515 & Not tested & Not tested \\
\hline & $\mathrm{T} 4$ & DR-7 (R-454A) & 1.521 & Not tested & Not tested \\
\hline & T5 & ARM-20a & 1.518 & Not tested & Not tested \\
\hline & T6 & ARM-20a & 1.521 & Not tested & Not tested \\
\hline
\end{tabular}

D-9 
Table D.2 (continued)

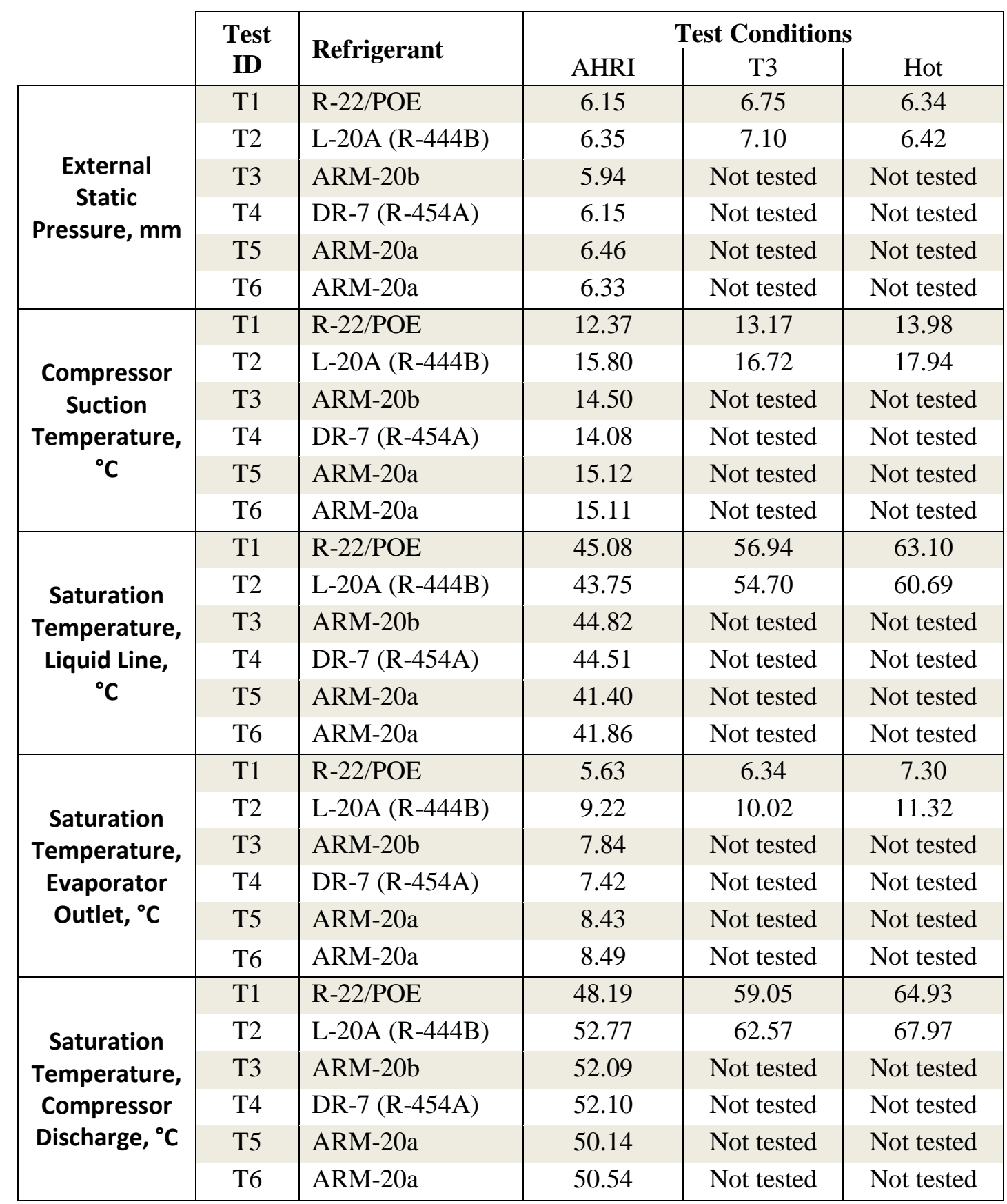


Table D.2 (continued)

\begin{tabular}{|c|c|c|c|c|c|}
\hline & \multirow{2}{*}{$\begin{array}{l}\text { Test } \\
\text { ID }\end{array}$} & \multirow{2}{*}{ Refrigerant } & \multicolumn{3}{|c|}{ Test Conditions } \\
\hline & & & AHRI & T3 & Hot \\
\hline \multirow{6}{*}{$\begin{array}{c}\text { Mass Flow } \\
\text { Rate, kg/min }\end{array}$} & $\mathrm{T} 1$ & $\mathrm{R}-22 / \mathrm{POE}$ & 9.91 & 9.73 & 9.79 \\
\hline & $\mathrm{T} 2$ & $\mathrm{~L}-20 \mathrm{~A}(\mathrm{R}-444 \mathrm{~B})$ & 7.87 & 7.84 & 7.94 \\
\hline & $\mathrm{T} 3$ & ARM-20b & 9.65 & Not tested & Not tested \\
\hline & $\mathrm{T} 4$ & DR-7 (R-454A) & 10.62 & Not tested & Not tested \\
\hline & $\mathrm{T} 5$ & ARM-20a & 9.24 & Not tested & Not tested \\
\hline & T6 & ARM-20a & 9.26 & Not tested & Not tested \\
\hline \multirow{6}{*}{$\begin{array}{c}\text { Energy } \\
\text { Balance, \% }\end{array}$} & $\mathrm{T} 1$ & $\mathrm{R}-22 / \mathrm{POE}$ & $-0.49 \%$ & $-4.41 \%$ & $-2.91 \%$ \\
\hline & $\mathrm{T} 2$ & L-20A (R-444B) & $-7.10 \%$ & $-6.98 \%$ & $-6.18 \%$ \\
\hline & T3 & ARM-20b & $-4.82 \%$ & Not tested & Not tested \\
\hline & $\mathrm{T} 4$ & DR-7 (R-454A) & $-5.77 \%$ & Not tested & Not tested \\
\hline & T5 & ARM-20a & $-5.36 \%$ & Not tested & Not tested \\
\hline & T6 & ARM-20a & $7.48 \%$ & Not tested & Not tested \\
\hline \multirow{6}{*}{$\begin{array}{l}\text { Refrigerant } \\
\text { Charge, kg }\end{array}$} & T1 & $\mathrm{R}-22 / \mathrm{POE}$ & 10.15 & 10.15 & 10.15 \\
\hline & $\mathrm{T} 2$ & $\mathrm{~L}-20 \mathrm{~A}(\mathrm{R}-444 \mathrm{~B})$ & 8.33 & 8.33 & 8.33 \\
\hline & $\mathrm{T} 3$ & ARM-20b & 8.45 & Not tested & Not tested \\
\hline & $\mathrm{T} 4$ & DR-7 (R-454A) & 8.70 & Not tested & Not tested \\
\hline & T5 & ARM-20a & 8.42 & Not tested & Not tested \\
\hline & T6 & ARM-20a & 8.62 & Not tested & Not tested \\
\hline
\end{tabular}


APPENDIX E. DETAILED R-410A TEST DATA 



\section{APPENDIX E. DETAILED R-410A TEST DATA}

This appendix provides additional details of the testing documented in Section 5.2. ORNL conducted two sets of tests with R-410A: one set used as the baseline test result, and a set of "rerun" tests conducted after the alternatives had been tested in the unit. By comparing the results with before and after testing the alternative refrigerants, it is possible to establish the performance reliability using the alternative refrigerants. The maximum discrepancy between the first R-410A run and the rerun was approximately $2.5 \%$ both for COP and cooling capacity; this result is within the experimental uncertainty.

Table E.1 shows additional test data, including

- Air-side cooling capacity,

- Air-side COP,

- Condenser subcooling

- Evaporator superheat

- Compressor discharge temperature

- Liquid line temperature

- Liquid line pressure

- Evaporator inlet temperature

- Evaporator outlet temperature

- Airflow

- External static pressure

- Compressor suction temperature

- Liquid line saturation temperature

- Evaporator outlet saturation temperature

- Compressor discharge saturation temperature

- Refrigerant Mass flow rate

- Energy Balance

- Refrigerant charge 
Table E.1. Complete test data for the R-410A unit

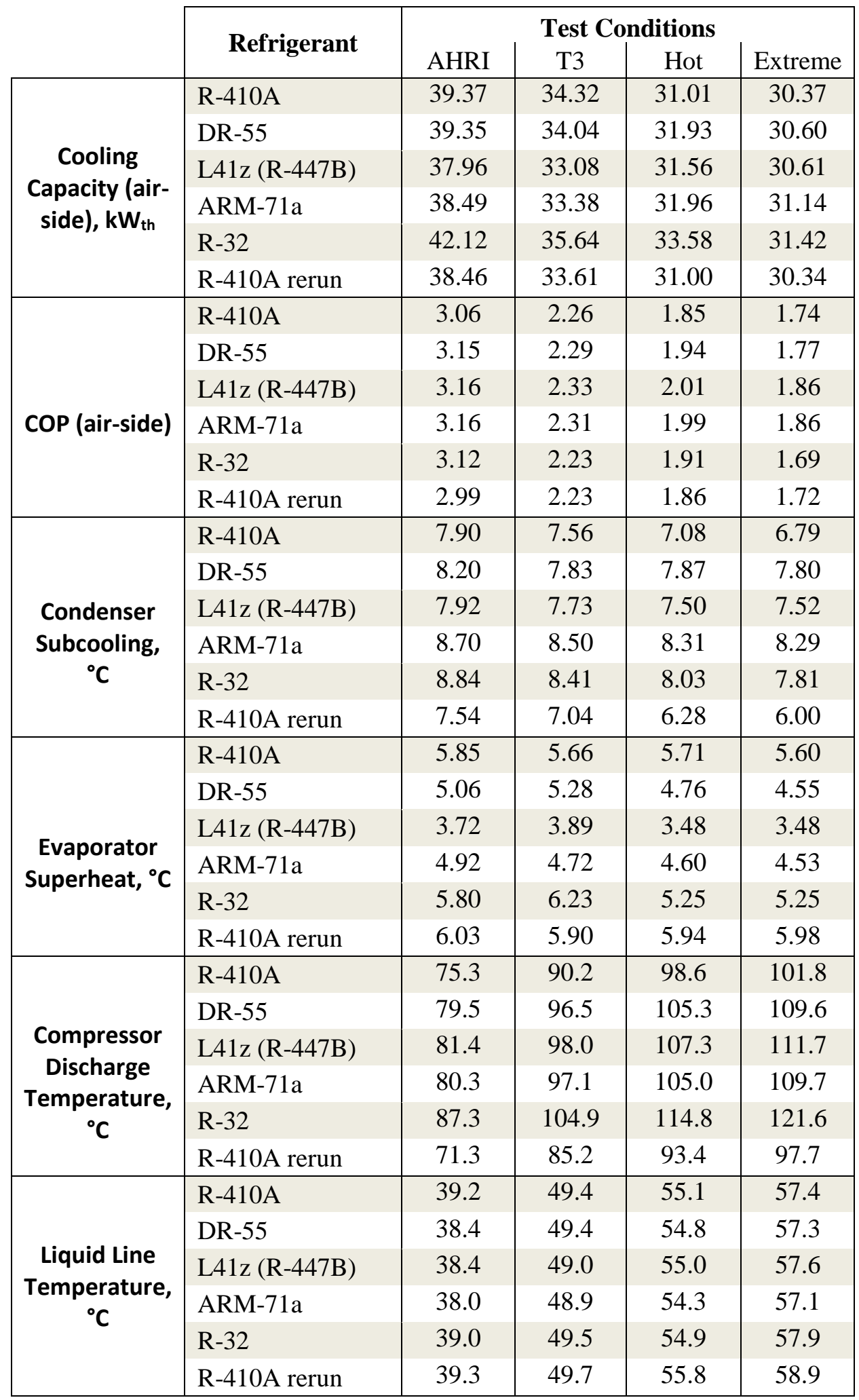

E-4 
Table E.1. (continued)

\begin{tabular}{|c|c|c|c|c|c|}
\hline & \multirow{3}{*}{ Refrigerant } & \multirow{2}{*}{\multicolumn{4}{|c|}{ Test Conditions }} \\
\hline & & & & & \\
\hline & & AHRI & $\mathrm{T} 3$ & Hot & Extreme \\
\hline \multirow{6}{*}{$\begin{array}{l}\text { Liquid Line } \\
\text { Pressure, } \\
\text { MPa } \\
\text { (absolute) }\end{array}$} & $\mathrm{R}-410 \mathrm{~A}$ & 2.87 & 3.60 & 4.03 & 4.21 \\
\hline & DR-55 & 2.73 & 3.47 & 3.91 & 4.11 \\
\hline & L41z (R-447B) & 2.59 & 3.28 & 3.71 & 3.91 \\
\hline & ARM-71a & 2.66 & 3.38 & 3.79 & 4.01 \\
\hline & $\mathrm{R}-32$ & 2.99 & 3.76 & 4.19 & 4.45 \\
\hline & $\mathrm{R}-410 \mathrm{~A}$ rerun & 2.85 & 3.57 & 4.02 & 4.27 \\
\hline \multirow{6}{*}{$\begin{array}{l}\text { Evaporator } \\
\text { Inlet } \\
\text { Temperature, } \\
{ }^{\circ} \mathrm{C}\end{array}$} & $\mathrm{R}-410 \mathrm{~A}$ & 16.1 & 18.6 & 20.3 & 21.0 \\
\hline & DR-55 & 14.5 & 16.8 & 18.9 & 19.5 \\
\hline & L41z (R-447B) & 13.5 & 15.9 & 18.0 & 18.8 \\
\hline & ARM-71a & 14.0 & 16.4 & 18.7 & 19.4 \\
\hline & $\mathrm{R}-32$ & 13.2 & 15.0 & 16.2 & 16.6 \\
\hline & $\mathrm{R}-410 \mathrm{~A}$ rerun & 16.0 & 18.6 & 20.4 & 21.6 \\
\hline \multirow{6}{*}{$\begin{array}{c}\text { Evaporator } \\
\text { Outlet } \\
\text { Temperature, } \\
{ }^{\circ} \mathrm{C}\end{array}$} & $\mathrm{R}-410 \mathrm{~A}$ & 15.0 & 15.9 & 17.0 & 17.6 \\
\hline & DR-55 & 15.3 & 16.4 & 17.3 & 17.6 \\
\hline & L41z (R-447B) & 16.2 & 17.4 & 18.4 & 19.0 \\
\hline & ARM-71a & 15.8 & 16.6 & 18.2 & 18.6 \\
\hline & $\mathrm{R}-32$ & 14.8 & 16.1 & 16.0 & 16.4 \\
\hline & $\mathrm{R}-410 \mathrm{~A}$ rerun & 15.2 & 16.1 & 17.4 & 18.3 \\
\hline \multirow{6}{*}{$\begin{array}{l}\text { Compressor } \\
\text { Suction } \\
\text { Temperature, } \\
{ }^{\circ} \mathrm{C}\end{array}$} & $\mathrm{R}-410 \mathrm{~A}$ & 15.6 & 16.5 & 17.6 & 18.1 \\
\hline & DR-55 & 15.9 & 16.9 & 18.0 & 18.3 \\
\hline & L41z (R-447B) & 16.8 & 17.9 & 19.1 & 19.7 \\
\hline & ARM-71a & 16.5 & 17.2 & 18.9 & 19.3 \\
\hline & $\mathrm{R}-32$ & 15.1 & 16.3 & 16.6 & 16.9 \\
\hline & $\mathrm{R}-410 \mathrm{~A}$ rerun & 15.7 & 16.5 & 17.8 & 18.7 \\
\hline \multirow{6}{*}{$\begin{array}{c}\text { Saturation } \\
\text { Temperature, } \\
\text { Liquid Line, } \\
{ }^{\circ} \mathrm{C}\end{array}$} & $\mathrm{R}-410 \mathrm{~A}$ & 47.1 & 57.0 & 62.2 & 64.2 \\
\hline & DR-55 & 46.6 & 57.2 & 62.7 & 65.1 \\
\hline & L41z (R-447B) & 46.3 & 56.8 & 62.6 & 65.1 \\
\hline & ARM-71a & 46.7 & 57.4 & 62.6 & 65.3 \\
\hline & $\mathrm{R}-32$ & 47.8 & 58.0 & 63.0 & 65.7 \\
\hline & $\mathrm{R}-410 \mathrm{~A}$ rerun & 46.8 & 56.7 & 62.1 & 64.9 \\
\hline \multirow{6}{*}{$\begin{array}{l}\text { Saturation } \\
\text { Temperature, } \\
\text { Evaporator } \\
\text { Outlet, }{ }^{\circ} \mathrm{C}\end{array}$} & $\mathrm{R}-410 \mathrm{~A}$ & 9.2 & 10.3 & 11.3 & 12.0 \\
\hline & DR-55 & 10.2 & 11.1 & 12.6 & 13.1 \\
\hline & L41z (R-447B) & 12.4 & 13.5 & 15.0 & 15.6 \\
\hline & ARM-71a & 10.9 & 11.8 & 13.6 & 14.1 \\
\hline & $\mathrm{R}-32$ & 9.0 & 9.9 & 10.8 & 11.2 \\
\hline & $\mathrm{R}-410 \mathrm{~A}$ rerun & 9.2 & 10.2 & 11.5 & 12.3 \\
\hline
\end{tabular}

E-5 
Table E.1. (continued)

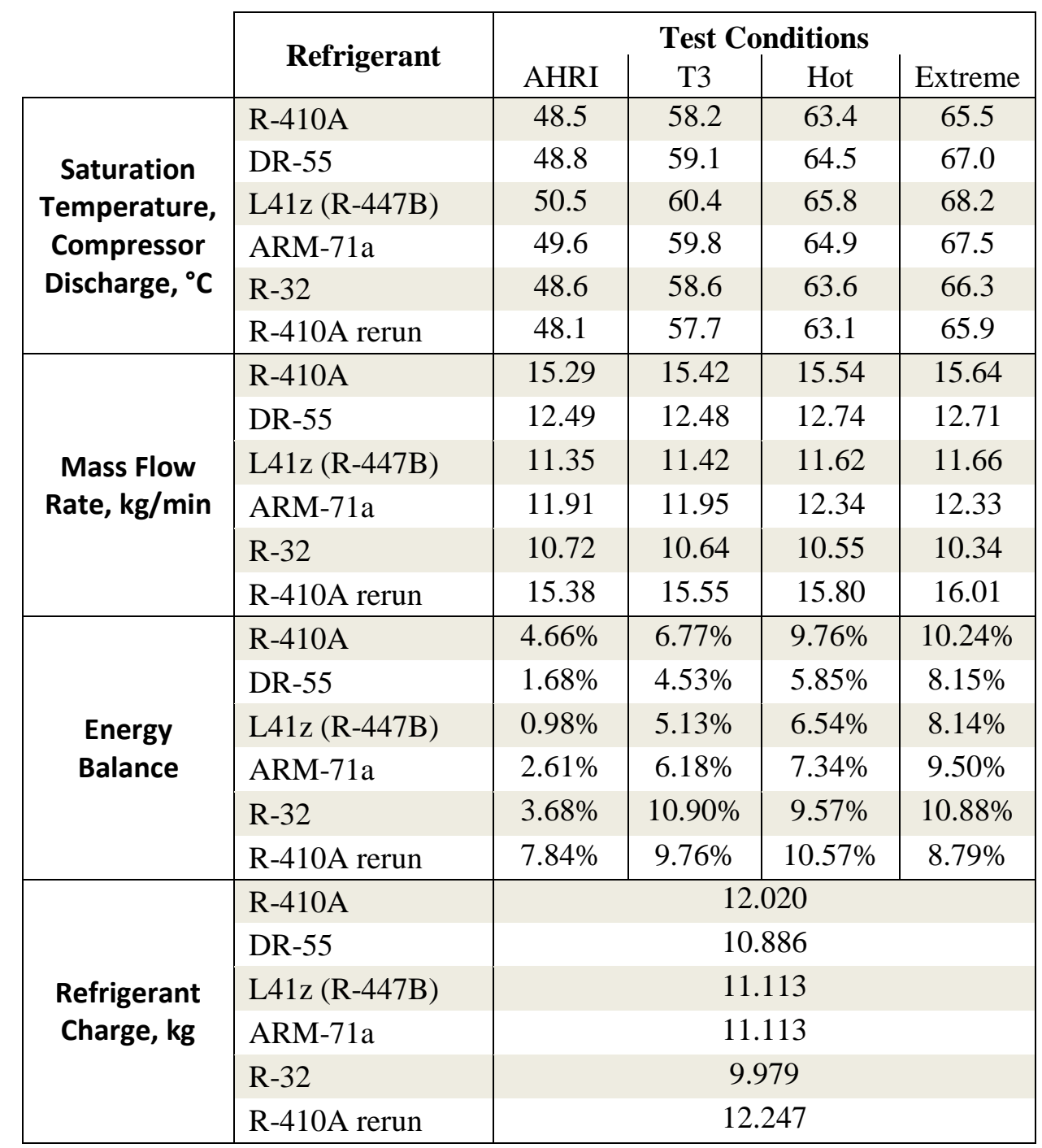





\section{APPENDIX F. DATA REDUCTION METHODOLOGY}

The measured data obtained using the instrumentation listed in APPENDIX $\mathrm{C}$ were recorded using a National Instrument Data Acquisition system. Data were recorded continually at 5-second intervals. LabView ${ }^{\circledR}$ code was developed to allow for real-time data visualization and performance monitoring, as shown in Figure F.1 and Figure F.2. REFPROP property calculations were included in the code, as shown in Figure F.3, in order to facilitate the real-time evaluation of the refrigerant side properties, e.g., saturation properties and capacity. The airflow, air-side capacity, refrigerant-side capacity, and refrigerant subcooling and superheat calculations are presented in the following sections. Table F.1 shows the symbols, and Table F.2 shows the subscripts used in the calculations.

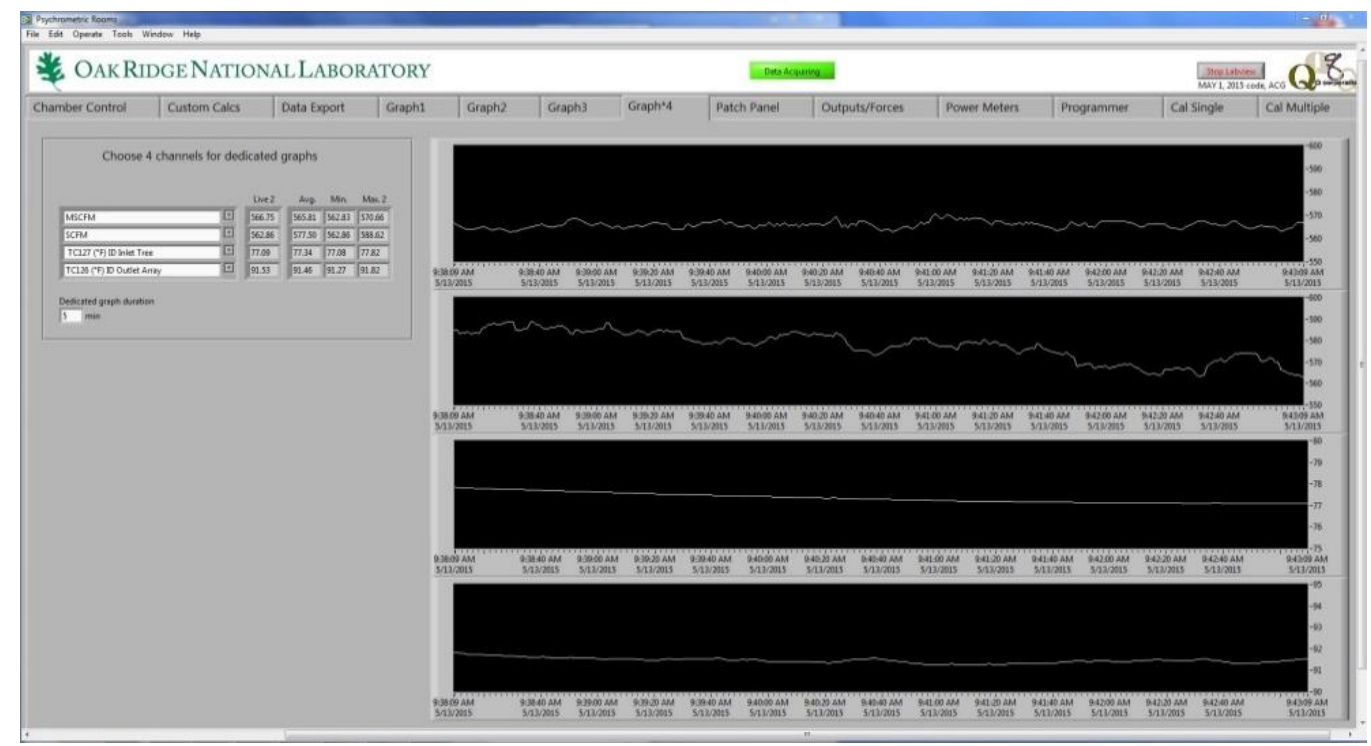

Figure F.1. LabView ${ }^{\circledR}$ display of room temperature and fan flow rate.

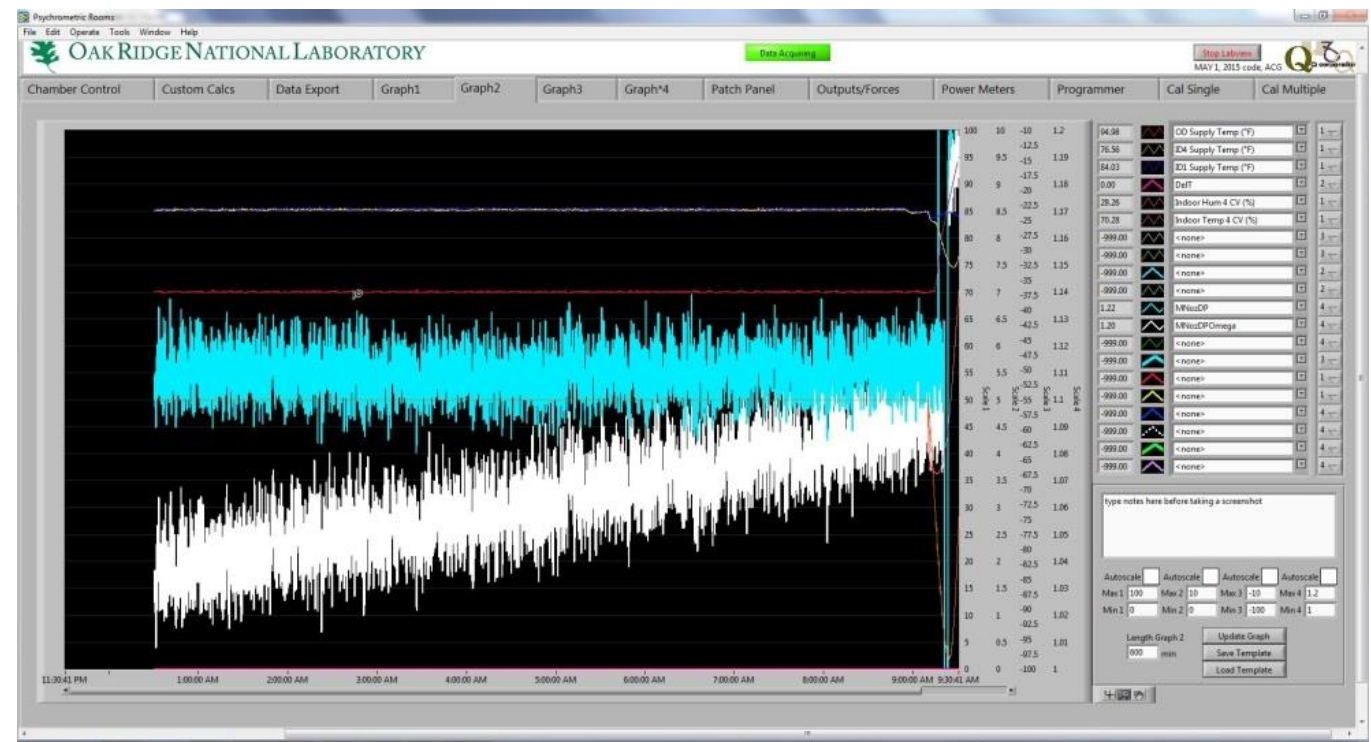

Figure F.2. LabView $®$ display of various monitored parameters. 


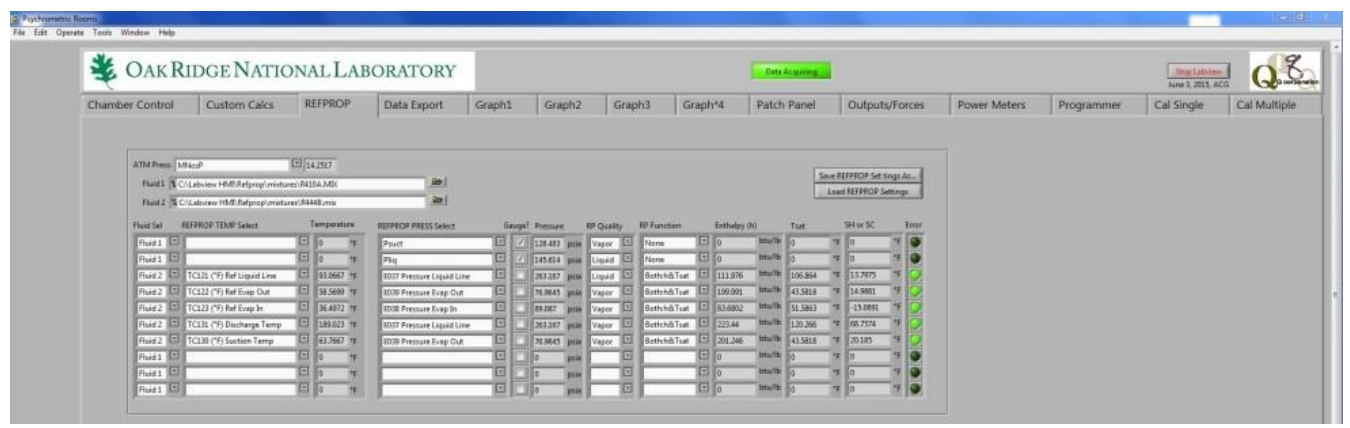

Figure F.3. LabView ${ }^{\circledR}$ display of built-in REFPROP calculation.

Table F.1. Data reduction methodology symbols

\begin{tabular}{|l|l|c|}
\hline Symbol & \multicolumn{1}{|c|}{ Description } & Unit \\
\hline$A_{\text {nozzle }}$ & Area of cross section at the nozzle throat & $\mathrm{ft}^{2}$ \\
$C_{\text {nozzle }}$ & Nozzle discharge coefficient & - \\
$C_{p}$ & Specific heat & $\mathrm{Btu} / \mathrm{lbm} \cdot{ }^{\circ} \mathrm{F}$ \\
$D$ & Diameter & $\mathrm{In}$ \\
$h$ & Enthalpy & $\mathrm{Btu} / \mathrm{lbm}$ \\
$L$ & Side & in \\
$\dot{m}$ & Flow rate & $\mathrm{lbm} / \mathrm{h}$ \\
$P$ & Absolute pressure & $\mathrm{inH}_{2} \mathrm{O}$ \\
$q$ & Heat capacity & $\mathrm{Btu}^{\circ} \mathrm{h}$ \\
$Q$ & Airflow rate & $\mathrm{cfm}$ \\
$Q_{S}$ & Standard airflow rate & $\mathrm{scfm}$ \\
$R e$ & Reynolds number & - \\
$T$ & Dry bulb temperature & ${ }^{\circ} \mathrm{F}$ \\
$Y$ & Expansion Factor & - \\
$W$ & Electric Power & $\mathrm{Watt}$ \\
$\alpha$ & Ratio of the absolute pressure at exit from the & - \\
$\beta$ & nozzle to the absolute pressure entering the nozzle & - \\
$\Delta$ & Ratio of nozzle throat diameter to duct diameter & $\mathrm{inH}_{2} \mathrm{O},{ }^{\circ} \mathrm{F}$ \\
$\mu$ & Differential & $\mathrm{lb} \mathrm{H}_{2} 0 / \mathrm{lb}$ air \\
$\rho$ & Moist air humidity ratio & $1 \mathrm{bm} / \mathrm{ft}^{3}$ \\
\hline
\end{tabular}


Table F.2. Data reduction methodology subscripts

\begin{tabular}{|l|l|}
\hline \multicolumn{1}{|c|}{ Subscript } & \multicolumn{1}{c|}{ Description } \\
\hline air & Air side \\
compressor & Compressor \\
condenser fan & Condensate collected from the evaporator \\
duct & Condenser fan \\
evaporator fan & Related to the duct \\
evap, in & Evaporator fan \\
evap, out & Evaporator inlet conditions \\
exit & Evaporator outlet conditions \\
latent & Exiting the nozzle \\
nozzle & Latent capacity \\
ref & Nozzle condition \\
coil & Refrigerant side \\
return & At the coil \\
sat & Return air to the indoor unit \\
subcooling & Saturated conditions at the equilibrium \\
superheat & Degrees of subcooling \\
sensible & Degrees of superheat \\
supply & Sensible capacity \\
total & Supply air exiting the indoor unit \\
tree & Total capacity \\
upstream & From sampling tree \\
\hline
\end{tabular}

\section{Airflow Rate Calculation:}

The airflow rate calculations were performed according to ASHRAE Standard 41.2-87 (RA92). The airflow rate is calculated as shown in equation (1). Equations (2) and (5) are used to calculate the expansion factor, $Y$, and the nozzle discharge coefficient, $C_{\text {nozzle }}$, respectively; both of them are inputs to Equation (1). The expansion factor is in turn a function of two parameters: $\alpha$, the ratio of absolute pressures at the exit and the inlet of the nozzle, and $\beta$, the ratio of nozzle throat diameter to duct diameter. $\alpha$ and $\beta$ are calculated as shown in Equations (3) and (4), respectively. The nozzle discharge coefficient, $C_{n o z z l e}$, is calculated based on $R e$, which can be approximately calculated using Equation (6) since the airflow velocity is not known. Finally, in order to evaluate the standard airflow rate, we use Equation (7) to normalize using the standard dry air density at $70^{\circ} \mathrm{F}$ and $14.696 \mathrm{psia}$ of $0.075 \mathrm{lbm} / \mathrm{ft}^{3}$.

$$
\begin{aligned}
Q & =1096 \times Y \times \sqrt{\Delta P_{\text {nozzle }} / \rho_{\text {nozzle }}} \times C_{\text {nozzle }} \times A_{\text {nozzle }} \\
Y & =1-\left(0.548+0.71 \times \beta^{4}\right)(1-\alpha) \\
\alpha & =\frac{P_{\text {nozzle, exit }}}{P_{\text {nozzle, upstream }}}
\end{aligned}
$$




$$
\begin{aligned}
& \beta=\frac{D_{\text {nozzle }}}{D_{\text {duct }}}=\left(\frac{D_{\text {nozzle }}}{\sqrt{\frac{4}{\pi} \times L_{\text {duct }}^{2}}}\right)=\left(\frac{5}{\sqrt{\frac{4}{\pi} \times 20^{2}}}\right)=0.22155673 \\
& C_{\text {nozzle }}=0.9986-\left(\frac{7.006}{\sqrt{R e}}\right)+\left(\frac{134.6}{R e}\right) \\
& R e=1,363,000 \times D_{\text {nozzle }} \times \sqrt{\frac{\Delta P \times \rho_{\text {nozzle }}}{1-\beta^{4}}} \\
& Q_{S}=\frac{Q \times \rho_{\text {nozzle }}}{\left(1+\mu_{\text {nozzle }}\right)} / 0.075
\end{aligned}
$$

In the above calculations, $\rho_{\text {nozzle }}$ is calculated based on barometric pressure, temperature, and dew-point measurement upstream of the nozzle using equations from the ASHRAE Handbook of Fundamentals, 2009, Chapter 1 (Equations 23 and 28). The $P_{\text {nozzle, upstream }}$ is measured using a barometric pressure sensor and the $P_{\text {nozzle, exit }}$ is calculated using the $P_{\text {nozzle }}$, upstream and the differential pressure drop across the nozzle, which is measured using a differential pressure sensor and can be calculated as shown in Equation (8) below.

$P_{\text {nozzle, exit }}=P_{\text {nozzle, upstream }}-\Delta P_{\text {nozzle }}$

\section{Air-Side Capacity Calculations:}

Air-side capacity is calculated according to ANSI/ASHRAE Standard 37-2009 Air Enthalpy Method. The total air-side capacity can be calculated as shown in Equation (9); the supply and return enthalpies used in Equation (9) are calculated using Equations (10) and (11). The factor of 60 is used to convert the airflow rate from $\mathrm{cfm}$ to $\mathrm{ft}^{3} / \mathrm{h}$.

$$
\begin{aligned}
& q_{\text {total }}=Q_{s} \times 0.075 \times 60 \times\left(h_{\text {return }}-h_{\text {supply }}\right) \\
& h_{\text {return }}=0.24 \times T_{\text {return, } \text { tree }}+\mu_{\text {return, tree }} \times\left(1061+0.444 \times T_{\text {return, tree }}\right) \\
& h_{\text {supply }}=0.24 \times T_{\text {supply, tree }}+\mu_{\text {supply, tree }} \times\left(1061+0.444 \times T_{\text {supply, tree }}\right)
\end{aligned}
$$

The air-side sensible and latent capacities can be calculated as shown in Equations (12) and (15). Also, when the dew-point temperature difference is low, it would be more accurate to use the condensate measurement for latent capacity measurement, as shown in Equation (16).

$$
\begin{aligned}
& q_{\text {sensible }}=Q_{s} \times 0.075 \times 60 \times\left((C p T)_{\text {return }}-(C p T)_{\text {supply }}\right) \\
& (C p T)_{\text {return }}=0.24 \times T_{\text {return, tree }}+\mu_{\text {return, tree }} \times 0.444 \times T_{\text {return, tree }} \\
& (C p T)_{\text {supply }}=0.24 \times T_{\text {supply, tree }}+\mu_{\text {supply, tree }} \times 0.444 \times T_{\text {supply, tree }} \\
& q_{\text {latent }}=Q_{s} \times 0.075 \times 60 \times 1061 \times\left(\mu_{\text {return, tree }}-\mu_{\text {supply, tree }}\right) \\
& q_{\text {latent, condensate }}=\dot{m}_{\text {condensate }} \times 1061
\end{aligned}
$$

\section{Refrigerant-Side Capacity Calculations:}


The refrigerant-side capacity is calculated according to ANSI/ASHRAE Standard 37-2009 Refrigerant Enthalpy Method with refrigerant mass flow measurement. It can be calculated as shown in Equation (17) below.

$q_{\text {ref, coil }}=\dot{m}_{\text {ref }} \times\left(h_{\text {evap, out }}-h_{\text {evap, in }}\right)$

In this equation, the refrigerant flow rate, $\dot{m}_{r e f}$, was measured using a Coriolis mass flow meter, and the refrigerant enthalpies were calculated using NIST REFPROP based on pressure and temperature measurements at the evaporator outlet and the condenser liquid line for $h_{\text {evap, out }}$ and $h_{\text {evap, in }}$, respectively. To compare both the air-side and the refrigerant-side capacities, the fan power dissipated into the airstream has to be considered: $W_{\text {evaporator fan }}$.

\section{Efficiency Calculations:}

The EER can be calculated based on the air-side or the refrigerant-side measurements by using Equations (18) or (19), respectively. The COP can be obtained from the EER through a unit conversion, as shown in Equations (20) and (21) for the air side and the refrigerant side, respectively.

$$
\begin{aligned}
& E E R_{\text {air }}=\frac{q_{\text {total }}}{W_{\text {compressor }}+W_{\text {condenser fan }}+W_{\text {evaporator fan }}} \\
& E E R_{\text {ref }}=\frac{q_{\text {ref }, \text { coil }}-W_{\text {evaporator fan }}}{W_{\text {compressor }}+W_{\text {condenser fan }}+W_{\text {evaporator fan }}} \\
& C O P_{\text {air }}=\frac{E E R_{\text {air }}}{3.4121} \\
& C O P_{\text {ref }}=\frac{E E R_{\text {ref }}}{3.4121}
\end{aligned}
$$

\section{Subcooling:}

The liquid line subcooling was calculated based on the equation below, in which the saturation temperature, $T_{\text {sat }}$, was calculated using NIST REFPROP based on pressure measurements at the liquid line. The temperature, $T$, was directly measured using an in-stream thermocouple or RTD.

$$
\Delta T_{\text {subcooling }}=T_{\text {sat }}-T
$$

\section{Superheat:}

The evaporator outlet and compressor inlet superheat were calculated based on the equation below, in which the saturation temperature, $T_{\text {sat }}$, was calculated using NIST REFPROP based on the pressure at the evaporator outlet. The temperature, $T$, was directly measured at both locations using in-stream thermocouples or RTDs.

$$
\Delta T_{\text {superheat }}=T-T_{\text {sat }}
$$





\section{APPENDIX G. DISCLOSURES OF INTEREST}

The disclosures of interest of the panel members are included in this appendix. 


\title{
Disclosure of Interest Declaration \\ International Expert Panel for the High-Ambient Testing Program
}

\author{
Radhey S. Agarwal \\ Sector Phase-out Plan Unit, Ozone Cell \\ India
}

I, Radhey S. Agarwal, residing in New-Delhi, India, as a member of the International Expert Panel for the High Ambient Testing Program, declare as follows:

1) That my responsibilities related to ODS, HFCs, or their alternatives include: I work as a Technical Consultant for implementation of ODS phase-out projects. I am the former Professor of Mechanical Engineering and Dean Industrial Research and Development, Indian Institute of Technology Delhi. I was teaching and guiding $\mathrm{Ph}$. D. research students in the field of refrigeration and Air-Conditioning As an expert of Refrigeration and Air-Conditioning. I provide advise on implementation ODS phase-out projects to various entities. These include organizations dealing with refrigeration and air conditioning issues, and organizations dealing with Montreal Protocol and UNFCCC related climate issues. Neither I, nor my spouse or my children own stock or have proprietary interest in companies producing HFCs or their alternatives or substitutes.

2) My interests and those of my spouse or children related to ODS, HFCs, or their alternatives include the following:

a. Proprietary interests related to ODS, HFCs, or their alternatives: [None]

b. Financial interests related to ODS, HFCs, or their alternatives: [None]

c. Employment, consultancy, directorship, or other positions related to ODS, HFCs, or their alternatives: [ Technacal Consultant, for implementation of ODS phase-out projects]

d. Government advice and other policy development related to ODS, HFCs, or their alternatives: [ Technical and policy advise on ODS phase-out to Ozone Cell, India]

e. Paid rescarch activities, fellowships, or grants related to ODS, HFCs, or their alternatives: [ None]

f. Other interests related to ODS, HFCs, or their alternatives: [None]

3) I undertake to disclose any material change to any of the above information, within 30 days of any such change.

4) I undertake to make further declarations of interest needed for so long as I remain a member of this Panel.

5) I understand that this Disclosure of Interest will expire no later than one year after I have signed it.

Printed Name: Radhey S. Agarwal

\section{Signature: Signature on File}




\section{Disclosure of Interest Declaration}

International Expert Panel for the High-A mbient Testing Program

Fotouh Al-Raq̣om

Kuwait Institute for Scientific Researeh

Kuwait

If Fotouh Al-Ragom, residing in Surra, Kuwait, as a member of the International Expert Panel for the High-Ambient Testing Program, declare as follows:

1) That my responsibilities related to $\mathrm{ODS}, \mathrm{HFCs}$, or their alternatives include:

- Mànager; Energy Effieieney Technologies Prograim, where I conduet research in areas of energy efficiency, hydrogen production and air conditioning.

- Neither', nor my spouse or my ehildren own stock or have proprictary interest in companies producing HFCs or their alternatives or substitutes.

2). My interests and those of my spouse or children related to ODS, HFCs, or their alternatives include the following:

- Research in areas of energy efficiency, hydrogen production and air conditioning none for my children

- Proprietary finterests related to ODS, HFCs, or their altematives: None

- Financial interests related to:ODS, HFC, or their altematives: None:

- Employment, consultaney, directorship, or other positions related to ODS, HFCs. or their alternatives: None.

- Government advice and other poliey development related to ODS, HFCs, or their alternatives: Currently none, but I previously served as a member of Kuwait National Ozone Unit $1998-2006$.

- Paid rescarch activities, fellowships, or grants related to ODS, HFCs, or their altematives: Currently leading a project on Effect of R-410A on the performance of air conditioning units in high ambient temperatures

- Other interests related to ODS, $\mathrm{HFC}_{-}$or their alternatives. None currently

3) I undertake to diselose any material change to any of the above information, within 30 days of any such chainge.

4). I undertaké to mäke further declarations of interest needed for so long às I remain a member of this Panel.

5) Iunderstand that this Disclosure of Interest will expire no later than i year after I have signed it.

Printed Name: Fotouih Al-Ragiom.

Date: August 26, 2016

Signature: Signature on File 


\section{Disclosure of Interest Declaration}

\section{International Expert Panel for the High-Ambient Testing Program}

Karim Amrane

Air-Conditioning, Heating, and Refrigeration Institute

USA

I, Karim Amrane, residing in Bethesda, Maryland, USA, as a member of the International Expert Panel for the High Ambient Testing Program, declare as follows:

1) That my responsibilities related to ODS, HFCs, or their altematives include:

- Managing the industry cooperative research program, where I oversee research activities on HVAC technologies including alternative refrigerants to HFCs.

- Developing and implementing AHRI's regulatory and international policy on issues affecting refrigerants including HFCs and their altematives.

- Neither I, nor my spouse or my children own stock or have proprietary interest in companies producing $\mathrm{HFCs}$ or their alternatives or substitutes.

2) My interests and those of my spouse or children related to ODS, HFCs, or their alternatives include the following:

a. Proprietary interests related to ODS, HFCs, or their alternatives: None

b. Financial interests related to ODS, HFCs, or their altematives: None

c. Employment, consultancy, directorship, or other positions related to ODS, HFCs, or their altematives: See above

d. Government advice and other policy development related to ODS, HFCs, or their altematives: None

e. Paid research activities, fellowships, or grants related to ODS, HFCs, or their altematives: None

f. Other interests related to ODS, HFCs, or their altematives: None

3) I undertake to disclose any material change to any of the above information, within 30 days of any such change.

4) I undertake to make further declarations of interest needed for so long as I remain a member of this Panel.

5) I understand that this Disclosure of Interest will expire no later than one year after I have signed it.

Printed Name: Karim Amrane

Date: September 6, 2015

Signature: Signature on File 


\title{
Disclosure of Interest Declaration International Expert Panel for the High-Ambient Testing Program
}

\author{
ENIO PEDONE BANDARRA FILHO \\ FEDERAL UNIVERSITY OF UBERLANDIA \\ BRAZIL
}

I, Enio Pedone Bandarra Filho, residing in Uberlandia - Brazil, as a member of the International Expert Panel for the High Ambient Testing Program, declare as follows:

1) That my responsibilities related to ODS, HFCs, or their alternatives include: I work as an associate Professor of Mechanical Engineering, teaching courses and doing research in the fields of thermal sciences and refrigeration and air conditioning, at Federal University of Uberlandia, in Uberlandia, Minas Gerais, Brazil. As an expert of my institution, I consult for various entities. These include organizations dealing with refrigeration and air conditioning issues, and organizations dealing with Montreal Protocol and UNFCCC related climate issues. All consultancies are conducted on a short-term assignment basis. Neither I, nor my spouse or my children own stock or have proprietary interest in companies producing HFCs or their alternatives or substitutes.

2) My interests and those of my spouse or children related to ODS, HFCs, or their alternatives include are related to research in the academy, mainly associated to developments in refrigeration and air conditioning areas with $\mathrm{PhD}$ and Masters students.

3) I undertake to disclose any material change to any of the above information, within 30 days of any such change.

4) I undertake to make further declarations of interest needed for so long as I remain a member of this Panel.

5) I understand that this Disclosure of Interest will expire no later than one year after I have signed it.

\section{Printed Name: ENIO PEDONE BANDARRA FILHO}

Signature: Signature on File

Date : MÁY, 20th, 2015 


\section{Disclosure of Interest Declaration International Expert Panel for the High-Ambient Testing Program}

Jitendra M. Bhambure

Blue Star Limited 2nd Pokhran Road, Majiwada

Thane, Maharashtra, INDIA

1. Jitendra M. Bhambure, residing in Thane, Maharashtra, INDIA as a member of the International Expert Panel for the High Ambient Testing Program, declare as follows:

1) That my responsibilities related to ODS, HFCs, or their altematives include:

- Understanding of various refrigerants and developing refrigeration and airconditioning products, as Head of R\&D, for Blue Star Limited, INDIA.

- Neither I, nor my spouse or my children own stock or have proprietary interest in companies producing HFCs or their alternatives or substitutes.

2) My interests and those of my spouse or children related to ODS, HFCs, or their alternatives include the following:

- Research and teaching in the areas of heat transfer and sustainable energy: None

- Proprietary interests related to ODS, HFCs, or their alternatives: None

- Financial interests related to ODS, HFCs, or their alternatives: None

- Employment, consultancy, directorship, or other positions related to ODS, HFCs, or their alternatives: None, except for holding shares of Blue Star Limited, India

- Government advice and other policy development related to ODS, HFCs, or their alternatives: Participate in workshops and as ODS Sub-Committee Head of Refrigeration and Air-Conditioning Manufacturers Association of India (RAMA)

- Paid research activities, fellowships, or grants related to ODS, HFCs, or their alternatives: None

- Other interests related to ODS, HFCs, or their alternatives: None

3) I undertake to disclose any material change to any of the above information, within 30 days of any such change.

4) I undertake to -make further declarations of interest needed for so long as I remain a member of this Panel.

5) I understand that this Disclosure of Interest will expire no later than one year after I have signed it.

Printed Name: Jitendra M. Bhambure

\section{Signature: Signature on File}


Disclosure of Interest Declaration

International Expert Panel for the High-Ambient Testing Program

Carvalho, Suely M. Machado

I, Suely M. Machado Carvalho, residing in São Paulo, SP, Brazil, as a member (co-chair) of the International Expert Panel for the High Ambient Testing Program, declare as follows:

1) That my responsibilities related to ODS, HFCs, or their alternatives include:

- Senior expert UNEP Technology and Economics Assessment Panel, TEAP, in the field of policy, technology and energy efficiency, nominated by Brazil.

- Participant expert of the Energy Efficiency Partnership programme with the Instituto de Pesquisas Energéticas e Nucleares (IPEN) and the Instituto de Energia e Ambiente, (IEE) of the University of São Paulo. As such, I liaise with organizations dealing with Montreal Protocol and UNFCCC related climate issues, manufacturers of equipment and alternatives to HFCs, NGOs and industry associations.

- Invited author, LAC Regional Assessment of Short Lived Climate Pollutants (SLCPs), UNEP ROLAC and Climate and Clean Air Coalition to Reduce Short Lived Climate Pollutants, CCAC.

2) My interests and those of my spouse or children related to ODS, HFCs, or their alternatives include the following: Research on energy efficiency improvements, chemicals and policy options to mitigate climate change. None for my spouse and children.

Proprietary interests related to ODS, HFCs, or their alternatives: None for me nor for spouse and children

Financial interests related to COS, HFCs, or their alternatives: None

Employment, consultancy, directorship, or other positions related to ODS, HFCs, or their alternatives: Short-term consultant for the World Bank (OORG), Institute for Governance and Sustainable Development and UNDP; Co-chair of the International Expert Panel for the High-Ambient Testing Program (pro-bono)

Government advice and other policy development related to ODS, HFCs, or their alternatives: eventual and upon request.

Paid research activities, fellowships, or grants related to ODS, HFCs, or their alternatives: None currently.

Other interests related to ODS, HFCs, or their alternatives: Providing expert advice and leadership to facilitate decision making processes that can help mitigate climate change and protect the ozone layer, and symergies among international agreements.

3) I undertake to disclose any material change to any of the above information, within 30 days of any such change.

4) I undertake to make further declarations of interest needed for so long as I remain a member of this Panel.

5) I understand that this Disclosure of Interest will expire no later than one year after I have signed it.

Printed Name and signature:

Suely Maria Machado Carvalho

Date: 12 September 2016

Signature: Signature on File 


\title{
Disclosure of Interest Declaration \\ International Expert Panel for the High-Ambient Testing Program
}

\author{
Ayman El-Talouny \\ Programme Officer \\ United Nations Environment Programme, UNEP \\ Regional office for West Asia, ROWA \\ Bahrain
}

I, Ayman El-Talouny, residing in Manama- Bahrain, as a member of the International Expert Panel for the High Ambient Testing Program, managed by US Departgement of Energy, declare as follows:

1) That my responsibilities related to ODS, HFCs, or their alternatives include:

- Manage HCFC phase-out programs and projects, in developing countries, within my job responsibilities as UNEP Staff Memebr

- Coordinate international partnership and projects between UNEP and several international HVAC\&R associations and orgnizations

- Neither I, nor my spouse or my children own stock or have proprietary interest in companies producing, trading or servicing any type of refrigerants including HFCs and their substititues.

2) My interests and those of my spouse or children related to ODS, HFCs, or their alternatives include the following:

- My interest is within my job description, as UNEP staff member, by advising governments and supporting industry/private sectors, in developing countries, to impimente projects and manage initiatives to phase-out HCFCs and minmize the use of high-GWP alterantives.

- Proprietary interests related to ODS, HFCs, or their aiternatives: None

- Financial interests related to ODS, HFCs, or their alternatives: None

- Pesonally received funds or grants for relevant reserach: None

- Niether my spouse nor my children has interests in any research, commercial or policy related topic to ODS, HFCs or alterantives.

3) I undertake to disclose any material change to any of the above information, within 30 days of any such change and till the end of the project.

4) I undertake to make further declarations of interest needed for so long as I remain a member of this Panel.

5) I understand that this Disclosure of Interest will expire no later than one year after I have signed it.

Printed Name: Ayman T El-Talouny

Date: September 19, 2015

Signature: Signature on File 


\section{Daniel Giguère*}

*Disclosure of Interest for Mr. Daniel Giguère was unavailable at the time of publishing. G-11 


\section{Disclosure of Interest Declaration}

\section{International Expert Panel for the High-Ambient Testing Program}

\section{Tingxun Li}

Sun Yat Sen University

China

I, Tingxun Li, residing in GUANGZHOU, China, as a member of the International Expert Panel for the High Ambient Testing Program, declare as follows:

1) That my responsibilities related to ODS, HFCs, or their alternatives include: I work as an associate Professor, teaching courses and doing research in the fields of thermal sciences and refrigeration and air conditioning, at Sun Yat Sen University, a comprehensive University in Guangzhou, Guangdong, China. As an expert of China national HPMP of RAC, I consult for various entities. These include organizations dealing with refrigeration and air conditioning issues, and organizations dealing with Montreal Protocol and UNFCCC related climate issues. All consultancies are conducted on a short-term assignment basis. Neither I, nor my spouse or my children own stock or have proprietary interest in companies producing HFCs or their alternatives or substitutes.

2) My interests and those of my spouse or children related to ODS, HFCs, or their alternatives include the following:

a. Proprietary interests related to ODS, HFCs, or their alternatives: $\llbracket \mathrm{No}$

b. Financial interests related to $\mathrm{ODS}, \mathrm{HFCs}$, or their alternatives: [No]

c. Employment, consultancy, directorship, or other positions related to ODS, HFCs, or their alternatives: [No]

d. Government advice and other policy development related to ODS, HFCs, or their alternatives: [No]

e. Paid research activities, fellowships, or grants related to ODS, HFCs, or their alternatives: [No]

f. Other interests related to ODS, HFCs, or their alternatives: [No]

3) I undertake to disclose any material change to any of the above information, within 30 days of any such change.

4) I undertake to make further declarations of interest needed for so long as I remain a member of this Panel

5) I understand that this Disclosure of Interest will expire no later than one year after I have signed it.

\section{Printed Name: Tingxun Li}

Signature: Signature on File 


\section{Disclosure of Interest Declaration}

International Expert Panel for the High-Ambient Testing Program

Samuel F Yana Motta

Honeywell International Inc.

USA

I, Samuel F Yana Motta, residing in Buffalo NY, USA, as a member of the International Expert Panel for the High Ambient Testing Program, declare as follows:

1) That my responsibilities related to ODS, HFCs, or their alternatives include:

- Director of Technology (refrigerants) for Honeywell International, where I direct $R \& D$ activities.

2) My interests related to ODS, HFCs, or their alternatives include the following:

- Research in the areas of heat transfer and development of heat transfer for HVAC applications.

- Proprietary interests related to ODS, HFCs, or their alternatives: None

- Financial interests related to ODS, HFCs, or their alternatives: None

- Other interests related to ODS, HFCs, or their altematives: None currently

3) I undertake to disclose any material change to any of the above information, within 30 days of any such change.

4) 1 undertake to make further declarations of interest needed for so long as I remain a member of this Panel.

5) I understand that this Disclosure of Interest will expire no later than one year after I have signed it.

Printed Name: Samuel F Yana Motta

Date: September 22, 2015

Signature: Signature on File 
Disclosure of Interest Declaration

International Expert Panel for the High-Ambient Testing Program

Maher H. Mousa

Consultant, HVACR Industry and Environmental Policy

The Consultancy Office of Maher H. Mousa

Jeddah, Saudi Arabia

I, Maher H. Mousa, located in Jeddah, Saudi Arabia, as a member of the Intemational Expert Panel for the High Ambient Testing Program, declare as follows:

1) That my responsibilities related to $\mathrm{ODS}, \mathrm{HFCs}$, or their alternatives include:

- Consultancy, HVAC Product development, program management, testing laboratories, technology transfer and energy and environmental regulations, under my private consultancy office located in Jeddah, Saudi Arabia.

- Neither I, nor my spouse or my children own stock or have proprietary interest in companies producing $\mathrm{HFC}$ s or their alternatives or substitutes.

2) My interests and those of my spouse or children related to ODS, HFCs, or their alternatives include the following:

- Consultancy, to private and public sectors on short tasks bases.

- Business research for my MBA degree at University of Leicester, UK.

- Proprietary interests related to ODS, HFCs, or their altematives: None

- Financial interests related to ODS, HFCs, or their alternatives: None

- Employment, directorship, or other positions related to ODS, HFCs, or their alternatives: None

- Government advice and other policy development related to ODS, HFCs, or their altematives: technical advisory in my capacity as a consultant, on short tasks bases

- Paid research activities, fellowships, or grants related to ODS, HFCs, or their alternatives: None currently

- Other interests related to ODS, HFCs, or their alternatives: None currently

3) I undertake to disclose any material change to any of the above information, within 30 days of any such change.

4) I undertake to make further declarations of interest needed for so long as I remain a member of this Panel.

5) I understand that this Disclosure of Interest will expire no later than one year after I have signed it.

\section{Printed Name: Maher $\mathrm{H}^{\text {Mousa }}$}

Signature: Signature on File 


\section{Disclosure of Interest Declaration International Expert Panel for the High-Ambient Testing Program}

Ole Reinholdt Nielsen

United Nations Industrial Development Organization, UNIDO

Austria

I, Ole Reinholdt Nielsen, residing in Vienna, Austria, as a member of the International Expert Panel for the High Ambient Testing Program, declare as follows:

1) That my responsibilities related to ODS, HFCs, or their alternatives include: I work as Chief of the Montreal Protocol Unit within the Environmental Branch of UNIDO. The overall objective of the work is to assist developing countries - at their request - in meeting their obligations within the framework of the Montreal Protocol on Substances that Deplete the Ozone Layer. The assistance comprise: a) Support in drafting a country strategy to phase-out ODS as per Montreal Protocol schedule; including necessary policy requirements; institutional activities and investment components; b) Ensure funding for the before-mentioned strategy from the Multilateral Fund of the Montreal Protocol; and c) implement the before-mentioned strategy in accordance with the agreed schedule of activities. All advices given are based on Montreal Protocol eligibility and modus operandi; and are fully neutral towards specific substances, processes and equipment.

2) My interests and those of my spouse or children related to ODS, HFCs, or their alternatives include the following:

a. Proprietary interests related to ODS, HFCs, or their alternatives: Neither I, nor my spouse or my children have proprietary interests related to ODS, HFCs or their alternatives.

b. Financial interests related to ODS, HFCs, or their alternatives: Neither I, nor my spouse or my children have financial interests related to ODS, HFCs or their alternatives.

c. Employment, consultancy, directorship, or other positions related to ODS, HFCs, or their alternatives: In addition to what has been specified under paragraph 1) above; neither I, nor my spouse or my children have employment, consultancy, directorship, or other positions related to ODS, HFCs or their alternatives.

d. Government advice and other policy development related to ODS, HFCs, or their alternatives: In addition to what has been specified under paragraph 1) above; neither I, nor my spouse or my children provide government advices and other policy development activities related to ODS, HFCs or their alternatives.

e. Paid research activities, fellowships, or grants related to ODS, HFCs, or their alternatives: Neither I, nor my spouse or my children have paid research activities, fellowships, or grants related to ODS, HFCs or their alternatives.

f. Other interests related to ODS, HFCs, or their alternatives: Neither I, nor my spouse or my children have other interests related to ODS, HFCs or their alternatives. 
3) I undertake to disclose any material change to any of the above information, within 30 days of any such change.

4) I undertake to make further declarations of interest needed for so long as I remain a member of this Panel.

5) I understand that this Disclosure of Interest will expire no later than one year after I have signed it.

\section{Printed Name: Ole Reinholdt Nielsen}

Signature: Signature on File 


\section{Disclosure of Interest Declaration \\ International Expert Panel for the High-Ambient Testing Program}

\section{Tetsuji Okada}

Japan Refrigeration and Air conditioning Industry Association

Japan

I, Tetsuji Okada, residing in Tokyo, Japan, as a member of the International Expert Panel for the High Ambient Testing Program, declare as follows:

1) That my responsibilities related to ODS, HFCs, or their alternatives include: I work as the president of JRAIA, managing the development or research of the equipment or refrigerants. I have been a member of the UNEP RTOC from 2013. I have engaged in the research and development of the air conditioners and the hot water systems by $\mathrm{CO} 2$ (Eco cute). I am also familiar with the heat exchangers used in the air conditioners and the refrigerant circuits of the heat pump systems. Neither I, nor my spouse or my children own stock or have proprietary interest in companies producing HFCs or their alternatives or substitutes.

2) My interests and those of my spouse or children related to ODS, HFCs, or their alternatives include the following:

a. Proprietary interests related to ODS, HFCs, or their alternatives: [None]

b. Financial interests related to ODS, HFCs, or their alternatives: [None]

c. Employment, consultancy, directorship, or other positions related to ODS, HFCs, or their alternatives: [described in number 1 above]

d. Government advice and other policy development related to ODS, HFCs, or their alternatives: [None]

e. Paid research activities, fellowships, or grants related to ODS, HFCs, or their alternatives: [None]

f. Other interests related to ODS, HFCs, or their alternatives: [None]

3) I undertake to disclose any material change to any of the above information, within 30 days of any such change.

4) I undertake to make further declarations of interest needed for so long as I remain a member of this Panel.

5) I understand that this Disclosure of Interest will expire no later than one year after I have signed it.

\section{Printed Name:}

Tetsuji Okada

Signature: Signature on File 
Disclosure of Interest Declaration

International Expert Panel for the High-Ambient Testing Program

Dr M. Alaa Olama

Independent consultant

Egypt.

I, Dr Olama, residing in Cairto, Egypt, as a member of the International Expert Panel for the High Ambient Testing Program, declare as follows:

1) That my responsibilities related to ODS, HFCs, or their alternatives include:

2) I work as an independent Refrigeration and Air Conditioning Consultant, providing consultancy services in the fields of refrigeration and air conditioning and thermal sciences. As an expert I consult for various entities. These include organizations dealing with refrigeration and air conditioning issues, and organizations dealing with Montreal Protocol and UNFCCC related climate issues. All consultancies are conducted on a shortterm assignment basis. Neither I, nor my spouse or my children own stock or have proprietary interest in companies producing HFCs or their alternatives or substitutes.

3) My interests and those of my spouse or children related to ODS, HFCs, or their alternatives include the following:

None.

4) I undertake to disclose any material change to any of the above information, within 30 days of any such change.

5) I undertake to make further declarations of interest needed for so long as I remain a member of this Panel.

6) I understand that this Disclosure of Interest will expire no later than one year after I have signed it.

\section{Printed Name: Dr M. Alaa A. Olama}

Signature: Signature on File 


\title{
Disclosure of Interest Declaration
}

\section{International Expert Panel for the High-Ambient Testing Program}

\author{
Alessandro Giuliano Peru \\ Department of Environment \\ CUEIM (University Consortium for Industrial Economy and Management) \\ Rome \\ ITALY
}

I, Alessandro Giuliano Peru, residing in Rome, ITALY, as a member of the International Expert Panel for the High Ambient Testing Program, declare as follows:

1) That my responsibilities related to ODS, HFCs, or their alternatives include:

- Programme manager for several pubblications and papers in relation to the managment of chemical substances, including those who harm the climate change and deplete the ozone layer. Past President of the EU Italian Presidency of the International Ozone group and Senior Environemntal Expert for the Italian Ministry of the Environment, Land and the Sea.

- Member of the European Association for the refrigeration and air conditioning (AREA)

- Neither I, nor my spouse or my children own stock or have proprietary interest in companies producing HFCs or their alternatives or substitutes.

2) My interests and those of my spouse or children related to ODS, HFCs, or their alternatives include the following:

- Proprietary interests related to ODS, HFCs, or their alternatives: None

- Financial interests related to ODS, HFCs, or their alternatives: None

- Employment, consultancy, directorship, or other positions related to ODS, HFCs, or their altematives: None

- Government advice and other policy development related to ODS, HFCs, or their alternatives: yes

- Paid research activities, fellowships, or grants related to ODS, HFCs, or their alternatives: None currently

- Other interests related to ODS, HFCs, or their altematives: None currently

3) I undertake to disclose any material change to any of the above information, within 30 days of any such change.

4) I undertake to make further declarations of interest needed for so long as I remain a member of this Panel.

5) I understand that this Disclosure of Interest will expire no later than one year after I have signed it.

Printed Name: Alessandro Giuliano Peru

Date: May 16, 2015

Signature: Signature on File 


\section{Disclosure of Interest Declaration \\ International Expert Panel for the High-Ambient Testing Program}

Patrick E. Phelan

Arizona State University, School for Engineering of Matter, Transport \& Energy

USA

I, Patrick E. Phelan, residing in Scottsdale, Arizona, USA, as a member (co-chair) of the International Expert Panel (co-chair) for the High-Ambient Testing Program, declare as follows:

1) That my responsibilities related to ODS, HFCs, or their alternatives include:

- Professor of Mechanical \& Aerospace Engineering, and Senior Sustainability Scientist, Arizona State University, where I conduct research and teach in areas of heat transfer and sustainable energy

- Neither I, nor my spouse or my children own stock or have proprietary interest in companies producing HFCs or their alternatives or substitutes.

2) My interests and those of my spouse or children related to ODS, HFCs, or their alternatives include the following:

- Research and teaching in the areas of heat transfer and sustainable energy; my spouse has research interests in urban heat island and its impacts on economics and public health; none for my children

- Proprietary interests related to ODS, HFCs, or their alternatives: None

- Financial interests related to ODS, HFCs, or their alternatives: None

- Employment, consultancy, directorship, or other positions related to ODS, HFCs, or their alternatives: None

- Government advice and other policy development related to ODS, HFCs, or their alternatives: Currently none, but I previously served as the Emerging Technologies Manager for the US Department of Energy, Building Technologies Office

- Paid research activities, fellowships, or grants related to ODS, HFCs, or their alternatives: None currently

- Other interests related to ODS, HFCs, or their alternatives: None currently

3) I undertake to disclose any material change to any of the above information, within 30 days of any such change.

4) I undertake to make further declarations of interest needed for so long as I remain a member of this Panel.

5) I understand that this Disclosure of Interest will expire no later than 1 year after I have signed it.

Printed Name: Patrick E. Phelan

Date: August 10, 2016

Signature: Signature on File 